\title{
EDUCATING FOR COMPLEXITIES: USING FUTURE FOCUS EDUCATION TO APPROACH THE WICKED PROBLEM OF CLIMATE CHANGE
}

By

Lisa McLaren

Thesis

ENVIRONMENTAL STUDIES 593

2013

A 90 point thesis submitted to Victoria University of Wellington, as partial fulfilment of requirements for the degree of Master of Environmental Studies

School of Geography, Environment and Earth Sciences

Victoria University of Wellington

June, 2013 


\title{
EDUCATING FOR COMPLEXITIES: USING FUTURE FOCUS EDUCATION TO APPROACH THE WICKED PROBLEM OF CLIMATE CHANGE
}

\author{
Lisa McLaren
}

\begin{abstract}
Climate change is a wicked problem. It is one that, among other things, is caused by those trying to solve it, is a symptom of deeper problems, and is complicated and full of uncertainties. Future focus education approaches are designed to enable learners to work within those complexities. This thesis looked at the 2012 NZ/Pacific Power Shift conference as an example of a future focus education approach to climate change education. Thematic analysis of semi-structured interviews and Power Shift participant questionnaires allowed for the development of five theoretical constructs; Complexity, Connections, Collaboration, Confidence, and Commitment. Wicked problem literature showed that framing climate change as 'wicked' enables learners to deal with the underlying issues associated with the complexities of climate change. Power Shift as an example of a future focus education approach to climate change education created engaged thinkers and participants. It embraced complexities and did not let them get in the way of creating positive and ambitious solutions to climate change issues. Learners benefited from Power Shifts future focus approach to climate change education in four interconnected ways. Firstly, it provided educational processes that could lead to the development of more capable learners. Learners were able to approach the wicked problem of climate change at localised levels. Secondly, it provided solutions-based approaches to working towards climate change actions. Thirdly, it increased self-confidence within some participants. And lastly, it created connections between participants that developed into a climate change action community.
\end{abstract}




\section{Acknowledgments}

I would like to thank each and every person who contributed in some way to my thesis. It was a big challenge and I wouldn't have made it without such fantastic, unwavering support.

A huge thank you to my supervisor, Dr Jessica Hutchings, who gave great advice and guidance. Your input was instrumental in the creation of this thesis. The topic may have changed several times, but your flexibility and willingness to embrace change made this process so much easier.

I would also like to thank Associate Professor Ralph Chapman for his guidance in the initial development stages of this thesis.

Thank you to the various people I consulted with while researching my thesis topic, especially my lovely classmates. It was a hard choice to make but all your advice contributed greatly and for that, I am truly thankful.

To my wonderful family and friends, thank you all for the endless support and encouragement. The laughs when it all seemed too hard were most appreciated. To my good friend Ashleigh MacLeod- you are a star for all the hours you put into helping me create my thesis diagrams, and for generally being a constant supporter. To Richard Rooney- thank you for the love and support, and for finally remembering what my thesis topic is!

A big thank you to my family for proofreading my work and taking my endless phone calls. Thanks to my sister, Bridget, for her constant IT advice. To my Mum, who helped me bounce ideas around when my head was too full. And to my Dad, who helped me financially when my pockets were too empty. 


\section{Table of Contents}

$\overline{\text { Abstract..........................................................................ii }}$

$\overline{\text { Acknowledgements...................................................iii }}$

$\overline{\text { List of Figures.........................................................ix }}$

Chapter 1: Introduction............................................1

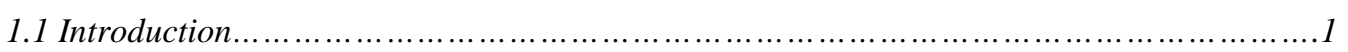

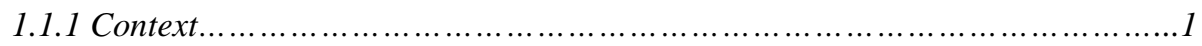

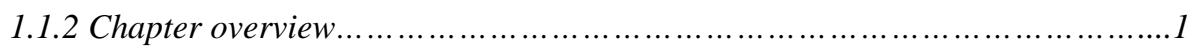

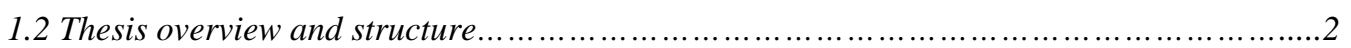

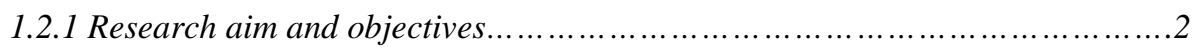

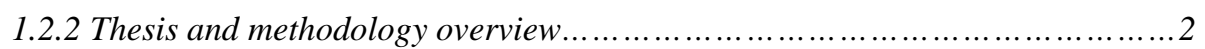

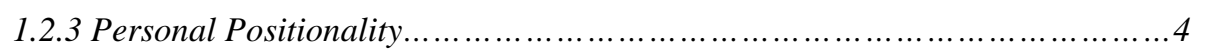

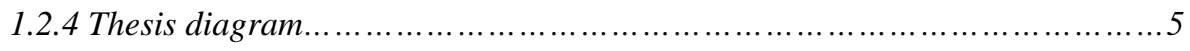

1.2.5 Synthesis and overview of Thesis Structure .......................................

Chapter 2: Background...............................................7

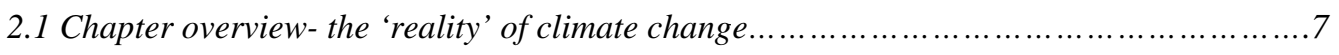

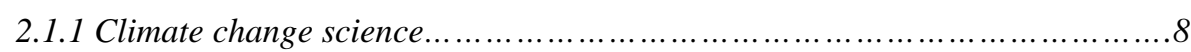

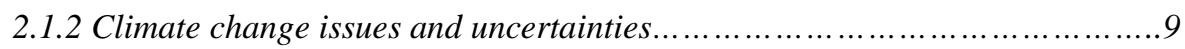

2.1.3 Social costs, risk management and economic implications......................10

2.2 Climate Change in Aotearoa/New Zealand....................................................12

2.2.1 Aotearoa/New Zealand Government climate change action.......................12

2.2.2 Community levels responses to climate change....................................13

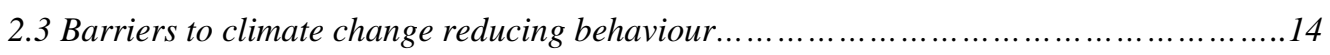

2.3.1 Climate change knowledge deficit theory..........................................15

2.3.2 Future focus education as a solution to climate change knowledge deficit...17

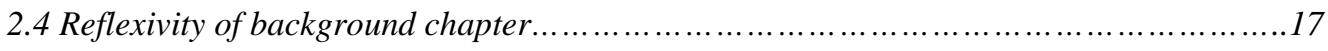

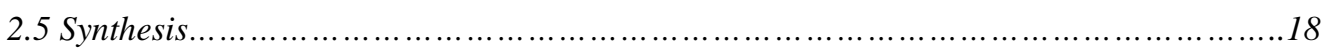

Chapter 3: Methods................................................19

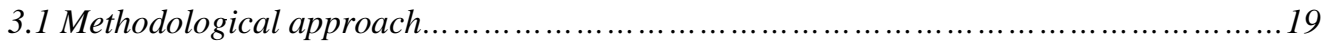

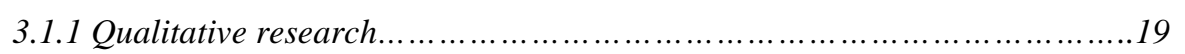

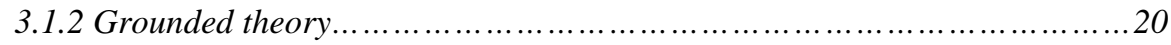

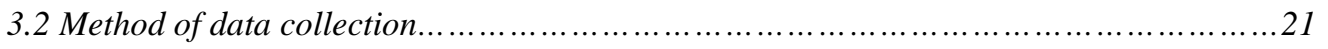




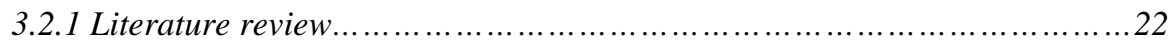

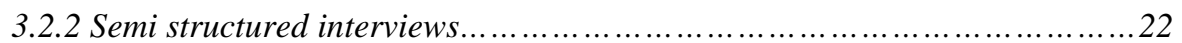

3.2.3 Questionnaire...........................................................22

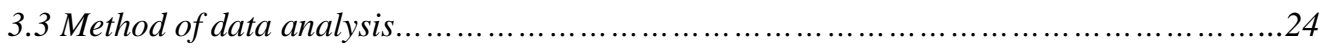

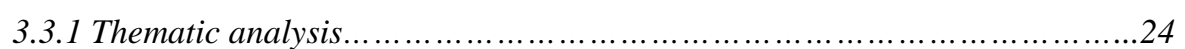

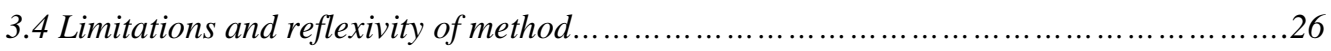

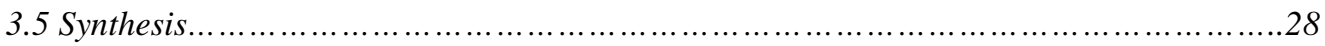

Chapter 4: Literature Review Presentation...........................29

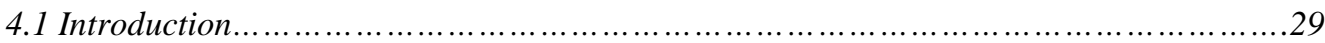

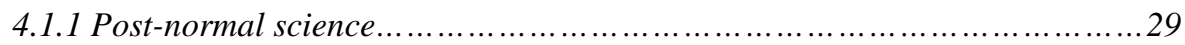

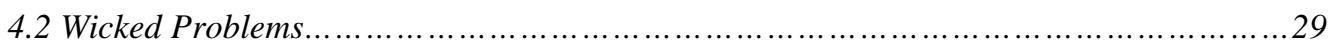

4.3 Part one- Key Features of Wicked Problems.............................................30

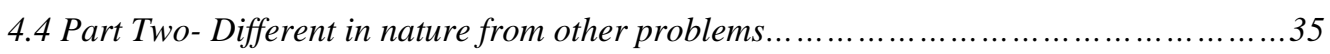

4.4.1 Wicked problem difference...............................................

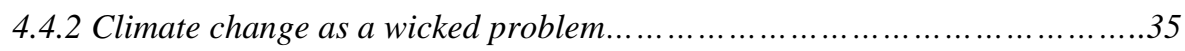

4.5 Part Three- Addressing Wicked Problems....................................................38

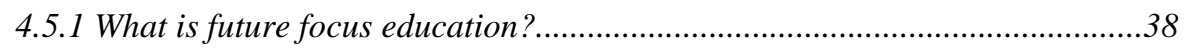

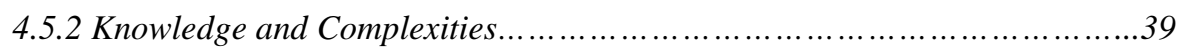

4.5.3 Learning within complex systems........................................42

4.5.4 List of summarised future focus education and complexity within learning

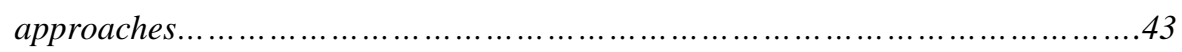

4.5.5 Use future focus education as a way to address the wicked problem of

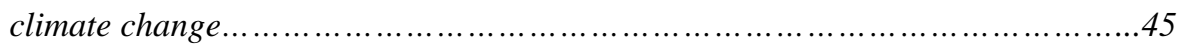

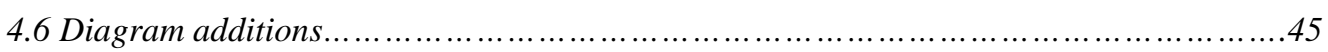

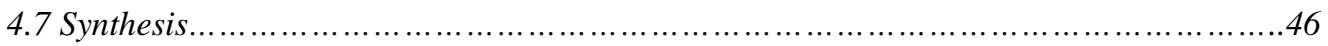

Chapter 5: Data Presentation and Analysis......................47

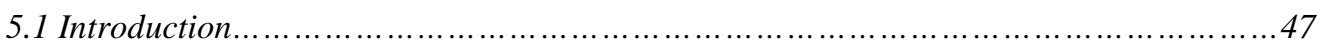

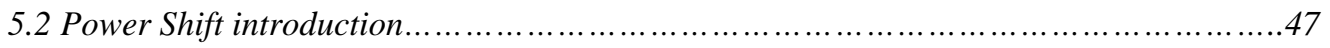

5.2.1 Power Shift as an example of future focus education in New Zealand.........49

5.2.2 Power Shift as an example of working within complex learning systems......50

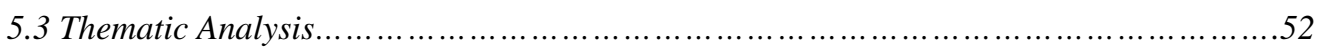

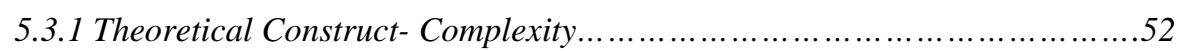

5.3.1.1 Theme- climate change is complicated and full of uncertainties...53

5.3.1.2 Theme- climate change is a symptom of deeper problems...........58

5.3.1.3 Theme- those trying to solve the problem of climate change are also creating it. .60

5.3.1.4 Theme- the central authority needed to address climate change 
is weak or non-existent. .61

5.3.1.5 Power Shift climate change word diagram........................62

5.3.1.6 Summary diagram for theoretical construct of Complexity..........62

5.3.2 Theoretical Construct- Connection..........................................63

5.3.2.1 Theme- a sense of connection to other people who are involved in climate change issues. .64

5.3.2.2 Theme- a connection to the environment that learning about climate change creates or strengthens. .

5.3.2.3 Theme- a connection to the issue and problems resulting from climate change, and the solutions to those problems.

5.3.2.4 Theme- a connection to space/place aids the learning process when learning about climate change issues...............................70

5.3.2.5 Summary diagram for theoretical construct of Connections.........71

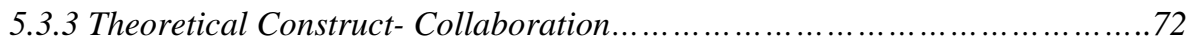

5.3.3.1 Theme- a diverse range of people needed to approach the climate change issue- including different backgrounds, knowledge sets, and ages.

5.3.3.2 Theme- a diverse range of learning styles needs to be catered to when educating on climate change issues. . .76

5.3.3.3 Theme- need to create pathways for climate change action using common goals. .78

5.3.3.4 Open space topics............................................ 80

5.3.3.5 Summary diagram for theoretical construct of Collaboration.......81

5.3.4 Theoretical Construct- Confidence..... . .82

5.3.4.1 Theme- the participants gaining confidence in themselves from the learning process and the feeling of empowerment they take from it.....82 5.3.4.2 Theme- having confidence in the science and knowledge surrounding climate change.

5.3.4.3 Theme- is arming learners with the right skills and tools to use while approaching climate change issues................................86

5.3.4.4 Summary diagram for theoretical construct of Confidence..........88

5.3.5 Theoretical Construct- Commitment. .89

5.3.5.1 Theme- a personal commitment to addressing the issues of climate change.

5.3.5.2 Theme- commitment within our communities towards action on climate change issues.

5.3.5.3 Theme- a commitment to change at the government level in regards to climate change.............................................93

5.3.5.4 Summary diagram for theoretical construct of Commitment........95 
5.4.1 Aaron Packard interview..................................................96

5.5 Diagram of theoretical constructs/themes..........................................97

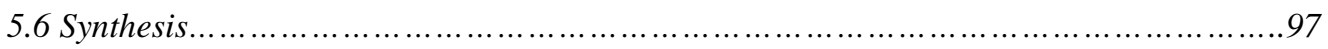

Chapter 6: Discussion........................................... 98

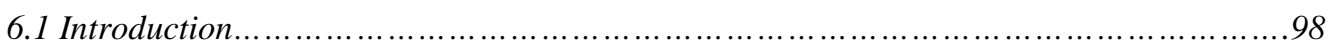

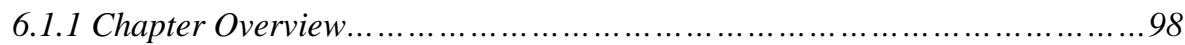

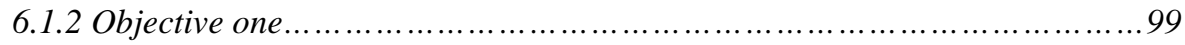

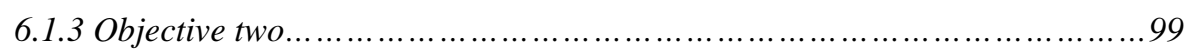

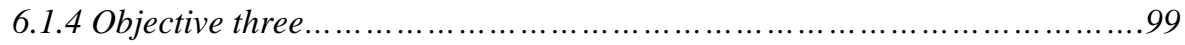

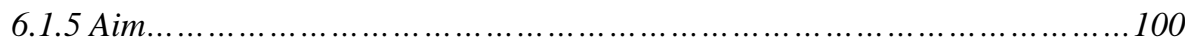

6.2 Objective one- climate change as wicked problem.......................................100

6.2.1 Wicked problem framing of climate change.................................100

6.2.2 Complex aspects of educating learners about climate change issues..........102

6.2.3 Why is wicked problem theory a good way to frame climate change

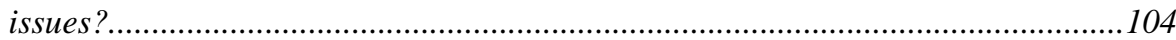

6.3 Objective two- Power Shift good example of future focus approach to climate change

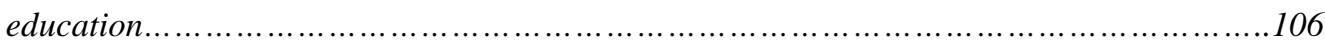

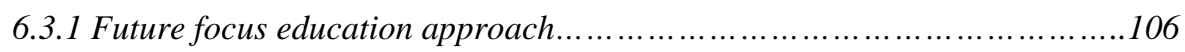

6.3.2 Why is Power Shift is a good example of a future focus education

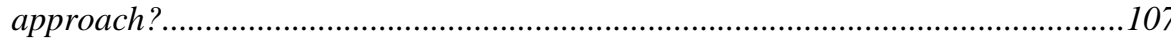

6.4 Objective three-Power Shift using future focus education approach to benefit lifelong

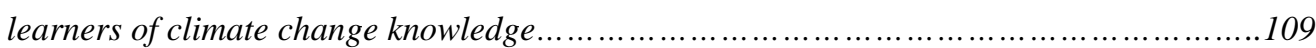

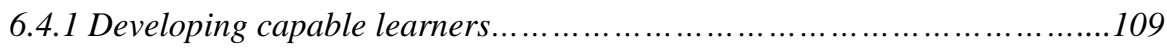

6.4.2 Providing solution-based approaches........................................111

6.4.3 Builds self-confidence in the learner.......................................112

6.4.4 Building connections between learners....................................114

6.4.5 How did the future focus education approaches used at Power Shift

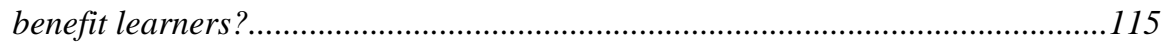

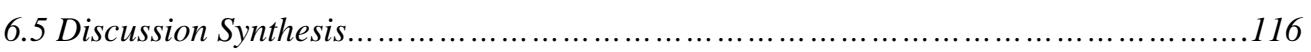

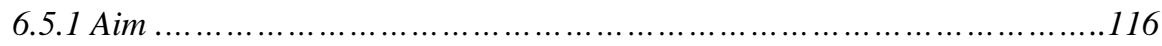

6.5 .2 Chapter overview....................................................116

Chapter 7: Conclusion...........................................118

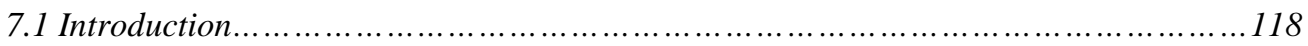

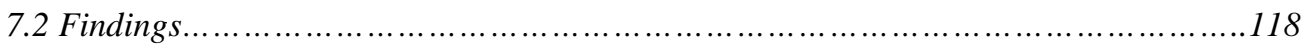

7.2.1 What does this research tell us?............................................................118

7.2.2 Why is this important?.......................................................................120

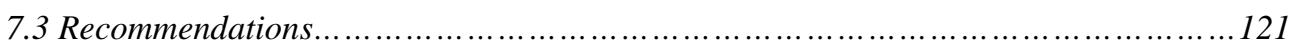


References...............................................122

Appendix A.............................................131

Appendix B..............................................132

Appendix C...........................................133

Appendix D.............................................134

Appendix E............................................135 


\section{List of Figures}

Figure 1- Thesis diagram.....................................................

Figure 2- Photo of Power Shift plenary session.................................23

Figure 3- Wicked problem characteristics...................................34

Figure 4- Future focus education characteristics..............................44

Figure 5- Revised thesis diagram..........................................46

Figure 6- Future focus education characteristics.............................48

Figure 7- Power Shift flash mob..............................................49

Figure 8 - Complexity diagram..........................................63

Figure 9- Connections diagram...........................................

Figure 10- Collaboration diagram......................................81

Figure 11- Confidence diagram.........................................88

Figure 12- Commitment diagram........................................ 95

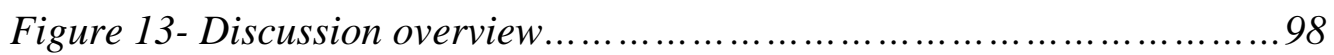




\section{Chapter 1: Introduction}

\subsection{Introduction}

\subsubsection{Context}

The concept of wicked problems has been around since the 1970's when it was first used by Rittel and Webber (1973). They found that science was unable to deal with 'wicked' social policy problems because it had been developed to deal with what they described as 'tame’ problems. Rayner (2006) developed their ideas further and suggested that many current issues are wicked problems. These include waste disposal, persistent poverty, biodiversity loss and climate change. Bolstad (2011:3) described wicked problems as 'complex challenges that cannot be addressed or solved using simple problem solving.' Climate change is an example of a wicked problem because of its complex and multitiered nature. Levin et al., (2012) described it as a new type of wicked problem, a super wicked problem, because it has even more demanding characteristics that were not an issue when the term was first created. Climate change meets all the criteria as developed by researchers such as Rayner (2006), Camillus (2008), and Levin et al., (2012). These criteria include different solutions can create or change other problems, it is persistent and insoluble, and it is never faced before. An interesting characteristic of a super wicked problem, such as climate change, is that those who cause the problem also seek to create a solution (Levin et al., 2012). This applies to researchers analysing climate change education.

\subsubsection{Chapter overview}

This chapter states the aim and objectives of this thesis, as well as highlighting the thesis structure and methodological approach. It gives personal positionality as a researcher and introduces the Power Shift conference as the thesis case study. 


\subsection{Thesis overview and structure}

\subsubsection{Research aim and objectives}

This thesis examines the research question as outlined below:

- How can future focus education enable lifelong learners ${ }^{1}$ to commit and collaborate with others in addressing the complexities of climate change?

The objectives of this thesis are:

- To engage with academic literature, pertaining to wicked problems relating to climate change, to research how framing climate change as a wicked problem enables learners to deal with the associated complexities.

- To investigate what characteristics of Power Shift made it a good example of future focus climate change education for lifelong learners.

- To analyse how Power Shift benefited lifelong learners when engaging with the complexities of climate change issues.

\subsubsection{Thesis and methodology overview}

To address wicked problems and super wicked problems, there needs to be clever solutions that take into account the intricate complexities and barriers to greater awareness among potentially interested parties.

'Some problems are so complex that you have to be highly intelligent and well informed just to be undecided about them' (Conklin, 2001:1).

This thesis used the discourse of 21st century approaches to future focussed education (from here on referred to as future focus education). The thesis was based on this discourse as a way of privileging future focused education approaches in a community education setting. The main ideas behind future focus education are how schooling (including tertiary education) will need to

${ }^{1}$ Life long learners are defined for the purposes of this thesis as people who are not necessarily involved with the formal education system, but not excluding those who are. It is usually in the form of community based or personally driven learning. 
change and adapt in the future, and how best to prepare our communities for 'future-focused issues’ (Bolstad, 2011:2). More traditional ${ }^{2}$ teaching techniques and educational resources are not specifically designed to equip people with the knowledge and abilities to solve these wicked problems. This thesis aimed to use the expanded definitions of future focus education which allow it to be useful in community education programmes, as well as academic/school-based education.

A future focussed climate change education conference was used to gain knowledge on how this approach works for complex community issues. Power Shift NZ/Pacific $2012^{3}$ was a climate change conference in Auckland that brought 700 people together for three days (December 7-9). It used a varied array of talks, performances and workshops to inform the participants about global and local climate change issues. This thesis aimed to gather knowledge that would enable community and academic based educators to be able to develop tools that increase their students' knowledge of climate change science and issues.

This increase of knowledge aims to be relatable to their lives, and possibly to their current or future careers. Many of the people who could benefit from this knowledge are studying in fields where they can make a contribution to solving wicked problems, such as climate change, on a regular basis. This climate change education knowledge will use future focus educational approaches to find ways of solving the barriers to wicked problem solutions. This means that the knowledge and future recommendations, though designed for climate change knowledge, could also be used at a theoretical basis to tackle any number of wicked problems. This thesis looks at developing ways to teach people how to approach wicked problems, not just explain to them what wicked problems are. The development of this knowledge will allow people to educate on climate change issues in a way that acknowledges and privileges the complexities of wicked problems.

\footnotetext{
${ }^{2}$ For the purpose of this thesis 'traditional' education refers to techniques or approaches that do not combine the characteristics of future focus education as central to teaching practice.

${ }^{3}$ www.powershift.org.nz
} 


\subsubsection{Personal Positionality}

Many researchers have stated the importance of acknowledging and sharing one's positionality in order for the reader to know the things that shape the author's worldview and how this affects the direction of their writing (Haraway, 1988; Hartsock, 1987; Steiner, 2007). Describing positionality also allows the researcher to reflect on their own assumptions and questions (Sundberg, 2004), which is invaluable when creating a research project such as this thesis. I am a young female participating in western academic postgraduate study. My positionality is centred in my upbringing in a rural, middle class, eurocentric community. I am New Zealand European and Pakeha, and use the terms interchangeably. I consider myself to be of English, Irish, Welsh and Scottish decent. I believe that all New Zealanders have a responsibility to privilege knowledge in such a way as to be decolonising and socially inclusive.

My educational background has been dominated by western ideologies and taught using western methods. Within these western systems/institutions I have studied Environmental Studies and Anthropology at an undergraduate level. It was through these courses that I gained an increased love for the environment and appreciation of cultural diversity, as well as an awareness of ethnocentrism. I am most interested in the always-changing world of climate change, and have a passion for educating people on why it is such an important issue facing this century. I am currently an Environmental Studies Masters student, and therefore this thesis is defined within the multidisciplinary world of Environmental Studies. This broad discipline allows its researchers to cross boundaries and move away from the traditional segmented western science/human connection. It brings together the segmented disciplines, such as Biology and Chemistry, and our unique interdisciplinary skills are needed now more than ever to work across spaces and combat wicked problems. Climate change is a manifestation of the problems of society as a whole, so every academic discipline is necessary in developing ways to approach these problems. I do not have a formal background in education studies and have relied heavily on the literature and 
informal discussions with educational professionals to build up my knowledge on this.

\subsubsection{Thesis diagram}

Future Focus Education Ideas For Approaching The Wicked Problem Of Climate Change

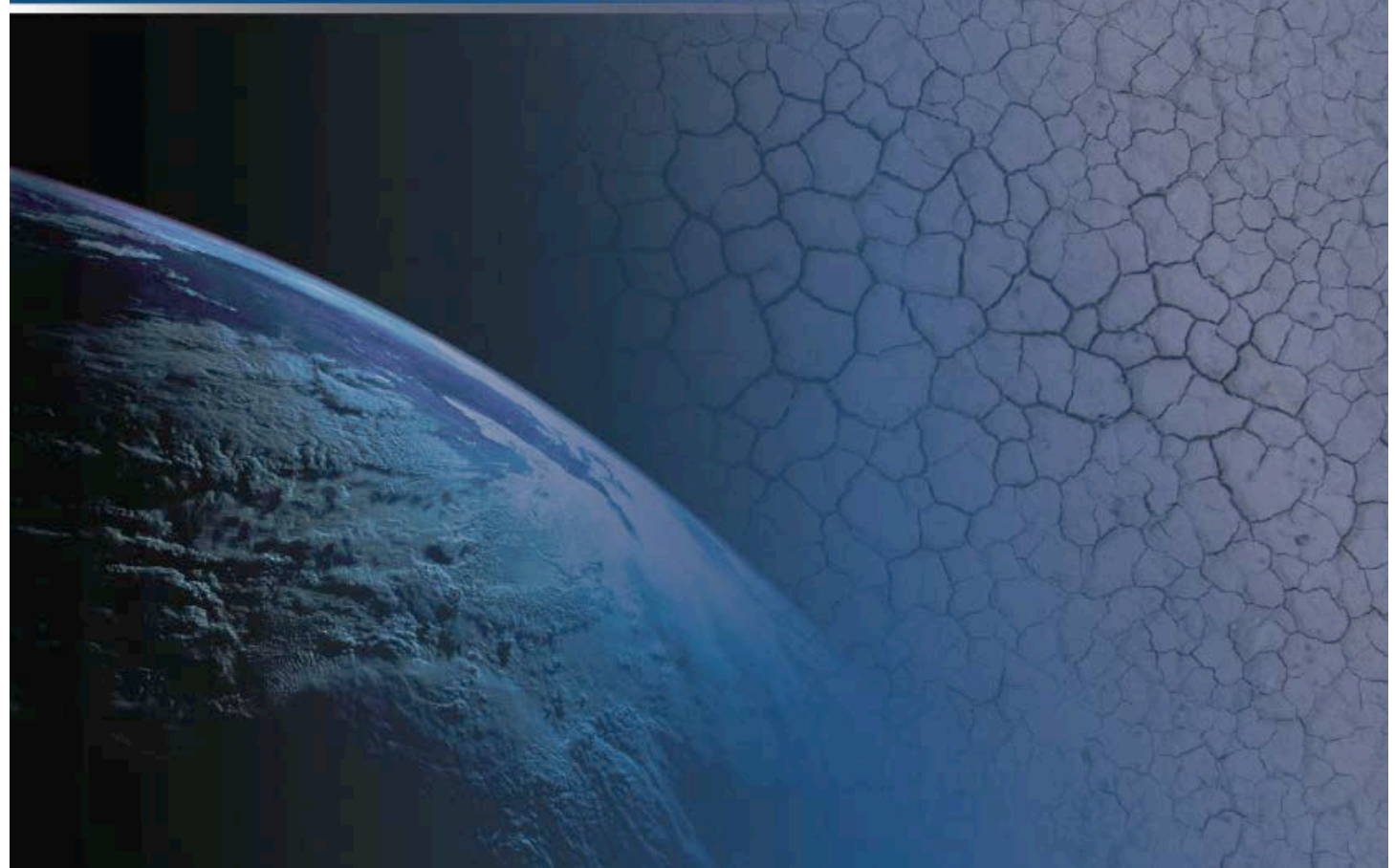

Figure 1- Thesis diagram

Figure 1, above, is a base framework from which the information gathered in this thesis will be presented. Knowledge gained from the data collection and analysis process will be added to this diagram.

\subsubsection{Synthesis and overview of thesis structure}

The structure of this thesis is broken down into seven chapters:

1. Introduction

2. Background

3. Methods

4. Literature review presentation and analysis

5. Data presentation and analysis

6. Discussion 


\section{Conclusion}

This first introduction chapter has provided an overview of the thesis. It has provided context, aim and objectives, researcher positionality, and thesis structure.

The background section grounds this thesis in some of the current knowledge surrounding the climate change debate, both globally and regionally. It also shows a range of issues associated with climate change, followed by a short summary of what the New Zealand government and community groups are doing about these issues.

In the methods chapter, the methodological approach is summarised and an outline given of the research methods used in this thesis. Data is produced through a literature review, semi-structured interviews, and a questionnaire. Transcript coding and theme analysis are used to develop key theoretical constructs. It also sets out the creation and development stages of the climate change educational diagram using these theoretical constructs.

The literature review chapter is the first section of the data presentation. It analyses the main fields of knowledge around climate change, wicked problems and future focus education. The literature review covers the basics of wicked problems and super wicked problems, and shows how climate change fits into these categories. It then explains how future focus can be used as an approach to educating for wicked problems such as climate change.

The discussion chapter is focused on the broader implications of the thesis research. It outlines the aim and objectives, and summarises information found during the study that supports these points. It answers the research question using a combination of pertinent literature and participant generated information.

The conclusion chapter outlines the findings of the thesis and outlines the broader implications of the findings. It provides further research recommendations. 


\section{Chapter 2: Background}

\subsection{Chapter overview- the reality of climate change}

The existence of global climate change has been a hotly debated issue over the past few decades. However it is now generally understood to be happening, and the cause being increased greenhouse gas (GHG) emissions. This understanding is mainly due to the work of thousands of scientists, many of which have been involved in reporting to the Intergovernmental Panel on Climate Change 4 (henceforth known as the IPCC). There are still many organisations that are not convinced of the reality of climate change, or have it in their best interests to spread distrust and misinformation about climate change science and predicted impacts. The issue that is currently still under debate in the scientific community is to what extend human interactions with the environment play a role in the amplification of these climate change processes ${ }^{5}$. The IPCC stated in their 2007 report that human influence on the climate had greatly exceeded that of processes such as volcanic eruptions and solar changes. The international community are acting to both mitigate the problem, and to adapt to the changes that are now unavoidable.

How climate change is linked to anthropogenic activities is going to be increasingly important in the way society operates, due to the many uncertainties associated with climate changes including climate sensitivity, tipping points, feedback loops and inertia. Human processes that have been used to adapting to cyclical variations, such as crop growth, may now have to get used to more extreme temperatures and rain seasons. This increase in uncertainties could leads to 'fat tail' distributions, instead of normal

\footnotetext{
${ }^{4}$ The IPCC are the world leaders in knowledge surrounding multiple aspects of climate change and its effects on the planet including sea level rise, ocean acidification, temperature rise, glacial retreat, desertification and increased storm intensity. The reports they put out are written through the use of data and theories of hundreds of different scientists from around the globe working on different aspects of climate change science from a variety of different fields. They use a ranking system to determine how sure they are that a particular outcome has a high probability of occurring. They use phrases such as 'very likely' or 'virtually certain' to suggest a very high probability, and phrases such as 'likely' and 'more likely than not' to suggest the probability is not as high, but that it is still well within the range of possibility. This allows for the fact that science as a discipline is continually morphing and adjusting to new information and discoveries.
}

${ }^{5}$ Anthropogenic climate change is caused by the increased levels of greenhouse gases (GHGs) that humans put into the atmosphere through processes such as burning stored carbon dioxide from sources such as coal and oil. 
distributions, could dramatically affect the way in which societies approach risk management. This chapter will summarise recent climate change science, risk management and social implications, as well as a close up look at current Aotearoa/New Zealand climate change action. It will explain knowledge deficit theory as it applies to climate change education, and summarises why future focus education is a solution to this knowledge deficit.

\subsubsection{Climate change science}

Climate is a statistical description of the variations of weather conditions, including averages and extremes. Climate change refers to the change in these variations over an extended period of time (Australian Academy of Sciences, 2010). Greenhouse gases (GHGs) trap heat in the Earths atmosphere and this in turn raises the Earths surface temperature. According to the Australian Academy of Sciences (2010), the changes to global temperature that have taken place in the last century do not resemble anything in the records of the last twenty centuries. The changes that result from this change in temperature are not immediately obvious, and in some cases it may take more than a century before the consequences of the warming is fully known. However, in terms of geological timeframes, it is relatively quick and may be felt more severley because of this quick timeframe (Pierrehumbert, 2006).

The main cause of anthropogenic climate change is the unsustainable way that humans are consuming fossil fuel energy. Heavy reliance on fuels such as oil, coal and natural gas has created a world economy that is both self-sustaining and self-destructive. The burning of fossil fuels emits the GHG carbon dioxide into the atmosphere that contributes to warming the planet (Pichert and Katsikopoulos, 2008). Carbon dioxide is arguably the most important gas to limit when trying to slow climate change, as described by the following quote from Le Quere et al., (2009):

'Efforts to control climate change require the stabilization of atmospheric CO2 concentrations. This can only be achieved through a drastic reduction of global CO2 emissions. Yet fossil fuel emissions increased by 29\% between 2000 and 2008, in 
conjunction with increased contributions from emerging economies, from the production and international trade of goods and services, and from the use of coal as a fuel source.' (Le Quere et al., 2009:831).

The next section outlines the issues and uncertainties surrounding climate change.

\subsubsection{Climate change issues and uncertainties}

Scientists can be very focussed on proving a question or theory to be either 'correct' or 'incorrect'. This can leave little room for the uncertainties and externalities brought about by unprecedented complex and dynamic issues such as climate change. Climate sensitivity ${ }^{6}$, inertia ${ }^{7}$ and the albedo effect ${ }^{8}$ are all examples of issues around climate change uncertainties (Huber et al, 2011; Aldred, 2009; Annan \& Hargreaves, 2011; Beerling et al., 2011; Prinn et al., 2011; Taylor et al., 2011). These issues play a major role in why it is so difficult for scientists to predict what type of habitat humans will be living in around the world by 2100 .

Varying climate models come up with different predicted ranges of GHG concentrations due to what they consider relevant to add into the model, and what is too difficult to estimate. In the Prinn et al., (2011) study they found three studies that suggest a wide range of levels of carbon dioxide by 2100 . This

\footnotetext{
${ }^{6}$ Climate sensitivity is how the climate system temperature reacts to radiative forcing from the sun and it plays a big role in the type of results that climate models produce. It is measured by modelling the temperature if the carbon dioxide levels were to double the preindustrial levels. Beerling et al (2011) conducted a study on GHGs and showed their contribution to past global warmth and the equilibrium climate sensitivity of the Earth system. Their results suggested that climate sensitivity in the Anthropocene could be amplified by chemistry-climate feedbacks. Taylor et al (2011) showed in their study how seasonality could alter the models for climate sensitivity as a result of albedo seasonality differences.

${ }^{7}$ Inertia is the types of process that slowly build up in the background without easily evident effects, such as severe tornadoes. A good example is the warming of the oceans by increase in global sea temperature. This could be linked to many other climate related problems such as methane stores under the ocean being released with warmer temperatures and to the ability of the thermohaline circulation (THC) to continue. If the THC slowed down, or even stopped working as it currently does, then it could have significant consequences for weather distributions patterns globally. For example, the United Kingdom could become dramatically colder with greater ice coverage but due to its anonymity it would be to late to stop it once it has past its tipping point (Lenton et al, 2008).

${ }^{8}$ The albedo effect is a process that focuses on the amount of light versus dark colour to radiate or absorb the suns radiation. The ocean (dark colour) absorbs the radiation, whereas, for example, the Antarctic ice sheets (white) reflect it. The more the Earth heats up and melts the ice, the less solar radiation that is being reflected and the more that it is being absorbed with growing sea levels (Lenton et al, 2008).
} 
range is between $470 \mathrm{ppm}$ and $1020 \mathrm{ppm}^{9}$ and it shows how current uncertainties will make it increasingly difficult to organise risk management for the coming decades. This is shown in the 'fat tail' distribution phenomenon, which is discussed in the next section.

\subsubsection{Social costs, risk management and economic implications}

According to Weitzman (2011) 'Fat tail' or Pareto distribution has a large amount of probability in its upper tail. In terms of climate change this can mean there is a higher probability that there will be more significant/catastrophic events. If his theory is proven correct then this could mean that risk management planners and those in the business of catastrophes such as insurance companies need to plan for a higher probability of events, with the range of outcomes being higher also. An example of this would be the ability to have once in a hundred year floods, more than twice in a decade. There would need to be significant policy changes to cope with the resulting devastation from such events, and possibly significant human impacts such as town relocations.

Climate change will effect all parts of the global human community, including the current economic system, energy resource use, food production and land use changes. The global agriculture industry will be severely challenged in the coming decades due not only to climate changes, but also to a population that is estimated to grow from 6 billion to 8.3 billion by 2030 (IPCC, 2007). This means feeding more people while facing new and changing climate variations.

\footnotetext{
'Projected future climate change, for example, is likely to require system transformations as areas and economic activities may be no longer viable in particular places over the next century' (Nelson et al, 2007:396).
}

Health impacts associated with climate change issues will be far reaching, and potentially include millions of people. Problems will include extreme climate events, the spread of disease, food and water security, and land being made

\footnotetext{
${ }^{9}$ Parts per million.
} 
unusable by sea inundation or desertification (Costello et al., 2009; IPCC,2007). These issues have been summarised in Appendix A.

Current infrastructure is not designed to cope with the proposed extremes of climate changes. The increasing range of climate variation would need to be designed for and this could increase the levels of complexity of design projects, and ultimately increase the costs (Hallegatte, 2009; Gifford, 2011). All of these examples show the complexities of the natural environment, but also the added complexities of the human dimension of climate change. This complexity within man-made cultural/economic systems adds to the problems of how well prepared the adaptive capacity of these systems is to cope with external complexities (Bosanquet et al., 2010).

People who are forced to leave their country due specifically to climate change have no status in international law as refugees. With no protection in international law, these people have no access to the aid or assistance that other refugees currently receive (UNHCR, 2009). This forced migration can lead to cultural degradation and a loss of identity. It can also impact local resources due to changing land usage, politics and population pressure (Faris, 2009; IPPC, 2007). For example, the UN has previously estimated that over 135 million people could be at risk of climate induced migration as a consequence of severe desertification during this century (Myers, 2001).

Indigenous people have contributed the least to the world's greenhouse gas emissions and they have the smallest ecological footprints on Earth. However, many of these indigenous groups are in areas of the planet that are predicted to come under the most threat from climate change. Although indigenous groups still living 'traditional' lifestyles are generally highly adaptive, climate change will be on a scale not seen by many of these groups, nor accounted for in their written or oral traditions.

With the world's sea level predicted to rise by $0.26-0.59 \mathrm{~m}$ by the end of this century, many low lying areas are at risk of forced migration and even a small sea level rise can have a massive impact (IPCC, 2007). According to the IPCC, 
climate change poses the most risk to developing countries such as Bangladesh. The people of Bangladesh are extremely vulnerable to sea level rise and extreme weather events because over half of Bangladesh lies within $5 \mathrm{~m}$ of sea level and $80 \%$ of the country is a mega-delta and extremely vulnerable to flooding (Gain \& Bari, 2007; Myers, 1993; IPCC, 2007). Many low lying islands in the South Pacific are already negatively affected by rising sea levels; including Tuvalu, Kiribati and the Carteret Atoll (Locke, 2009). The sea level rise in these countries will have a direct relation to the number of forced migratants to approach New Zealand for aid.

\subsection{Climate Change in Aotearoa/New Zealand}

The Aotearoa/New Zealand (A/NZ) government uses the United Nations Framework Convention on Climate Change (UNFCCC) definition of climate change, which separates the anthropogenic and 'natural' climate change:

'A change of climate which is attributed directly or indirectly to human activity that alters the composition of the global atmosphere and which is in addition to natural climate variability observed over comparable time periods’ (UNFCCC, 1992:3).

The government website (Ministry for the Environment, 2012) states that A/NZ temperatures will increase by one degree Celsius by 2040. It also states that climate change is already becoming evident and that it will have effects on both the environment and the economy. The website states that the main causes of anthropogenic climate change are human activities, examples of which are burning coal and driving cars.

\subsubsection{Aotearoa/New Zealand Government climate change action}

According to the Ministry for the Environment website (2012) the A/NZ governments' main policy tool to reduce emissions is an Emissions Trading 
Scheme (ETS) that puts a price on greenhouse gas emissions. The website also suggests that the governments target for the energy sector is that 90 per cent of New Zealand's electricity will be generated from renewable sources by 2025 .

There has been opposition to the governments' stance on climate change, especially from environmental groups. This is because of the contradiction with delaying the inclusion of agriculture within the ETS and increasing the levels of fossil fuel extraction in and around New Zealand. This is also the case with the A/NZ stance at last Conference of the Parties (COP) meeting in 2012 where they did not sign on to a post Kyoto agreement. They were also accused by the global meeting of getting in the way of progress and were awarded 5 'fossil of the day' awards, plus the overall title, which is embarrassing for its overall international image. These awards are given to the country that inhibits progress at the meetings the most.

\subsubsection{Community levels responses to climate change}

Community level responses to climate change issues within A/NZ include different community groups such as 350 Aotearoa, Generation Zero, Climate Camp and the Hikurangi foundation. The main aim of these groups is to address climate change knowledge deficit and promote pro-environmental action ${ }^{10}$. They use different types of action to create knowledge and interest in the climate change movement. 350 Aotearoa put on numerous climate action days aimed at providing information to the general public about climate change and how it will impact $\mathrm{A} / \mathrm{NZ}$ and how everyone can make changes to help mitigate the impacts. Examples of this include 'Moving Planet Day' and 'Connect the Dots,' both global action days. Generation Zero are a movement of young New Zealanders aimed at mobilizing youth to help solve the climate crisis. They have instigated many public displays of climate change action in the recent two years including public transport funding protests and climate change flash mob.

${ }^{10}$ Pro-environmental action for the purpose of this thesis means action that is undertaken with the purpose of helping the environment. This could taken many different forms, and because of the complex nature of ecosystems, each action could have a positive or negative effect on other aspects of that eco-system. For this reason, many environmentalists disagree on the appropriateness of particular actions. 
They were politically active leading up to the A/NZ 2011 elections. Climate camps have been successfully held in several countries overseas. Each camp event weaves four key themes: education, direct action, sustainable living, and building a movement to effectively tackle climate change by both resisting climate crimes and developing sustainable solutions. The Hikurangi Foundation provide sustainable projects with funding, knowledge and mentoring with the aim of reducing climate change impacts.

Each of these groups use different methods to address the climate change knowledge deficit (as will be described in section 2.3.1) and promote the issue of climate change within the wider A/NZ community.

\subsection{Barriers to climate change reducing behaviour}

Barriers to climate change behavior can be structural (beyond an individuals control) or psychological (within the individual). These include, but are not limited to economic, political, lack of knowledge and psychological barriers. The economic barriers to climate change mitigation are systemic, and a result of a whole series of underlying problems. The economic system has been on fossil fuel resource consumption and forest degradation, both of which are high causal factors of global climate change. Breaking down the economic barriers would require a paradigm shift. There is also the problem if inadequate political will and incentives to make the shift away from a fossil fuel economy. Vested interested and lobbying keep the environment vulnerable to political decisions, and ecosystem services are often undervalued.

Knowledge deficit of climate change information is another barrier to climate change action. This is when more knowledge is needed for a person to change their mind about an issue. It supposes that if more climate change information is given to a climate change sceptic, then they will change their view to match this new information. Psychological barriers are also a factor in stopping people from taking action on climate change issues. Gifford (2011) produced a paper 
outlying the psychological barriers to climate change action. Within this paper he broke down the 29 barriers into seven categories. These show how many different aspects of peoples' lives influence their reactions and responses to climate change.

These barriers are useful to be aware of when communicating climate change information but will not be researched further by this thesis due to the different nature of climate change communication and education. Much of the information in this thesis could be useful for climate change communication. There is a strong link between climate change education and communication, but this thesis uses an education lens due to the nature of the future focus education literature that was central to its development.

\subsubsection{Climate change knowledge deficit theory}

Knowledge deficit theory suggests that there is information missing that would influence decision-making. When applied to climate change, the knowledgedeficit theory suggests that people are climate change deniers simply because they do not know enough of the 'right' information to prove its validity. Therefore, to reduce the number of climate change deniers there needs to be an increase in the amount of correct information given to them. There is already a great deal of climate change information available to the public but, in spite of this, public concern levels have been declining in recent years (Cornforth, 2011; HSBC Climate Partnership, 2010; Jones, 2011; ShapeNZ, 2010; The World Bank, 2009). Cornforth (2011) researched into how levels of climate change knowledge are related to climate change concern. The aim of her thesis was to determine whether the knowledge-deficit theory applied to concern for climate change.

'The knowledge-deficit theory suggests that if people are not concerned about climate change, it is because there is a deficit in their knowledge of climate change' (Cornforth, 2011). 
She found that high levels of concern were found in people with high levels of actual knowledge, rather than those with high levels of perceived knowledge. She also found that older male participants displayed less concern than younger females (Cornforth, 2011).

Cornforth concluded in her study that:

'climate change communications should provide information that accurately represents the scientific consensus and explains that climate change is due to human activities and describes the consequences of climate change' and that 'because perceived efficacy is also such a strong predictor of concern, climate change communications should emphasise the different ways that people can act and the effectiveness of taking such actions... tailored to different sets of values and worldviews' (Cornforth, 2011).

This has wider implications for climate change due to the nature of the environmental education processes. Telling people that there is a problem is simply not enough to generate sufficient action. This is useful to consider when approaching climate change education in A/NZ. It would seem that, according to Cornforth's findings, it is not sufficient to tell people information about climate change, but instead there needs to be a better way of helping people use this information in a way that motivates action.

Within A/NZ, climate change education falls under the umbrella of environmental education and within this broad category there are different fields of focus for climate change depending on the organisation and its goals (PCE, 2007). Some organisations, such as New Zealand Association for Environmental Education (NZAEE) and many local councils focus more on the biophysical aspects of human-environment interactions. Others, such as the Ministry of Education and school-based programmes, focus more on sustainable development and use of the natural world (PCE, 2007). When it comes to education of climate change, knowing 'how' is often better than knowing 'what' (Hirsch, 2006). It is more important to become an expert in solving complex problems, similar to wicked problems, rather than fill heads with facts and 
figures. If someone can think critically then they have the mental tools at their disposal to learn whatever else they need to solve the problem (Hirsch, 2006). Future focus education is based around these issues, that in the coming century it will be more how you learn, rather than what you learn, that will enable people to overcome increasingly complex and varied wicked problems.

\subsubsection{Future focus education as a solution to climate change knowledge deficit}

Future focus education gives rise to a style of learning that enables students to cope with the complexities of 'wicked problems.' Traditional teaching is now seen as inadequate to deal with these problems, because it focuses on teaching a lot of information, rather than a process that the students can learn to use the information (Bolstad, 2001; Bull, 2009). According to Bull (2009:4) future focus education is focussed on 'acknowledging and dealing with complexity, uncertainty and diversity.' She sees that is it important to use systems level thinking to help teachers cope and develop teaching strategies to deal with these new ways of thinking, rather than try to mould these ideas into the current system.

\subsection{Reflexivity of background chapter}

There seems to be an obvious divide between climate change science and the issues/problems that will result from this change. Non-climate scientists need to be careful what research they privilege in their discussions and decisions. It is easy to highjack specific, out of context information or 'evidence' to promote agendas - and this can be on both the extreme environmentalist and climate change denial sides.

There possibly needs to be a distinction made when dealing with climate change. Is the problem in question about the science or the resulting issues involved? Climate change science is the facts and figures that tell climate scientists that the climate is changing due to anthropogenic influence. Climate change issues 
are the problems for the planet associated with these climate changes. This is where the social, economic, political and conservation issues associated with climate change enter the debate.

\subsection{Synthesis}

The scientific world is about as certain as it will ever be that climate change exists and that it is happening now. Uncertainties will no doubt continue to cause confusion in the face of climate change. This confusion will have a direct affect on how humans attempt to adapt to such changes, including challenges to insurance and risk analysis. The South Pacific will be one of the hardest hit areas, and this will have a direct influence on A/NZ politically, economically and socially. A/NZ currently has weak climate change mitigation strategies, and the continued diluting of the ETS has not helped this. Climate change education in $\mathrm{A} / \mathrm{NZ}$ is growing as a sub-discipline and it is now included in the national curriculum. There are a few grass-roots organisations that are providing community level education on climate change issues, including 350 Aotearoa and Generation Zero.

Chapter 3, Methods, will outline the methodological approach that this research is based in. It will describe the methods used when collecting and analysing the research data. 


\section{Chapter 3: Methods}

\subsection{Methodological approach}

This chapter outlines the methodological approach and methods used during this thesis. The research undertaken for this thesis was in compliance with the Victoria University of Wellington's Human Ethics Policy (VUW, 2007). Approval was granted by the Human Ethics Committee to conduct interviews (Appendix B) and a questionnaire (Appendix C).

\subsubsection{Qualitative research}

Quantification as a research method has historically been seen as true or real science. Qualitative research methods, however, have increased in use over the past decades with the academic acknowledgment of their value and the change in nature of what is perceived as valid science (Guba and Lincoln, 1994; Denzin and Lincoln, 1994). Qualitative research methods have evolved from a variety of different schools of thought including disciplines as diverse as education, policy studies, anthropology and medicine (Denzin and Lincoln, 1994). A qualitative research study assumes aims to understand the participants' perspectives and assumes that the reality presented is socially constructed (Tolich and Davidson, 1999).

This research study is a qualitative research study. It aims to draw out themes from information shared by the participants to create a theoretical knowledge that can be used to aid in the experience of educating others about climate change. The researcher and participants' worldviews are central to a qualitative research approach (Tolich and Davidson, 1999). This makes it important for the researcher to position themselves so that there is an acknowledgement of what types of worldviews they are bringing into the research. These worldviews will impact upon how they chose their topic, why they deem it important, who they chose to interview, where the interview will take place, what information they chose to privilege in their discussion chapter among many other things (Tolich and Davidson, 1999; Creswell, 2003). This is done initially with the personal 
positionality statement (section 1.2.3) and also in the limitations and reflexivity of method section (section 3.4).

Because there is an acknowledgement made of the personal involvement of the researcher, observations made cannot be described as impartial or objective (Tolich and Davidson, 1999). This type of research also acknowledges that science is socially constructed. Researchers provide 'appropriate and useful insights into social situations... not the one right view, but a collection of valuable ones nonetheless' (Tolich and Davidson, 1999:30).

Qualitative research acknowledges both complex findings and observations cannot be understood or solved outside of their wider context. The observations made are also complex as there cannot be observations made that are impartial. This means that the language used in qualitative research can be more personalised, compared with the neutral language used in quantitative studies.

In quantitative research, methods often take primacy over subject matter. Methods are adaptable within qualitative research so that the researcher is able to apply what method is most appropriate to gain the insight needed. It is required that the method be adapted to meet changes (Tolich and Davidson, 1999). Sometimes the audience that will read the research will define what methods people use. This is especially true in student work that will be graded, but also of higher levels of research work that will need to withstand the judgement of their peers (Creswell, 2003). This research thesis will be marked within a western academic context. This has played a role in the development of the methods and methodology as it is important that the topic be match up with what is considered an appropriate method to use.

\subsubsection{Grounded theory}

One qualitative approach to research is grounded theory, which uses general research concerns rather than research hypotheses because of the limited initial knowledge of the researcher. The research concern aims to learn about 
particular lived experiences (Auerbach and Silverstein, 2003). After developing the theory, participants are chosen based on their relevance to the research. The theory determines the relevance of the participants, rather than a requirement of randomness (Auerbach and Silverstein, 2003). Participants are chosen because they have lived through an experience and are therefore deemed experts in that area. It is acknowledged by the researcher that the participants have more knowledge of the subject than themselves. This is the opposite to the traditional methods of research in which the researcher is the 'expert' and the participants are used to prove or disprove their hypothesis. A grounded theory approach allows the researcher to ask the participants about their experiences and learn from their views.

\subsection{Method of data collection}

To increase the validity of this research there was three different types of data collected. This is using a method called triangulation, which Tolich and Davidson (1999) describe as 'the use of multiple sources of information, methods, theories, and techniques to generate a variety of data that measure the social phenomenon under investigation’ (Tolich and Davidson, 1999:34). They state this increases the validity of the findings if all three sources are giving similar results. For this research there are three different types of methods for information collected. Firstly, there is a literature review undertaken to find pertinent information that is relation to wicked problem theory, future focus education and climate change. This literature analysis is the secondary data source for the research. Secondly, there were two semi-structured interviews with wicked problem and future focus education 'experts.' ${ }^{11}$ Thirdly there were qualitative questionnaires given out at Power Shift New Zealand Pacific 2012 with a follow up reflective question for the climate change educators involved. This questionnaire and interview data make up the primary data used for the research.

\footnotetext{
${ }^{11}$ All of the research participants were considered experts in their own personal knowledge. The interview participants were considered experts due to their published work on the two relevant topics (wicked problems and future focus education).
} 
'The researcher collects open-ended data with the primary intent of developing themes from the data' (Creswell, 2003:18).

Text analysis, plus interviews and qualitative questionnaire with open ended questions all fit within the structure of qualitative research (Creswell, 2003; Tolich and Davidson, 1999; Auerbach and Silverstein, 2003).

\subsubsection{Literature review}

Literature relating to wicked problem theory, climate change as a wicked problem, and future focus education were analysed. Thematic analysis was used to develop key themes within the literature that would form the basis of the interview and questionnaire questions. The analysis of the literature review is shown in chapter 4 (section 4.0).

\subsubsection{Semi structured interviews}

Two semi-structured interviews were undertaken. The first was with Rachel Bolstad, from the New Zealand Centre for Educational Research (henceforth referred to as NZCER), Wellington, New Zealand. She had written several papers on future focus education within New Zealand (Bolstad, 2011; Bolstad et al 2009; Bolstad et al 2012). Within these papers she discussed the ability of future focus approaches to be used when dealing with wicked problems. The second interview was with Bob Frame of Landcare research, Lincoln New Zealand. He has written papers (Frame, 2008) on wicked problems and the role of planning and consultation when dealing with them.

\subsubsection{Questionnaire}

The third type of research method used was an anonymous questionnaire that surveyed the participants of the climate summit - Power Shift New Zealand/Pacific 2012 (henceforth referred to as Power Shift). Power shift was identified as a good example of future focus education approach while doing 
initial thesis research. It was identified from research into prior Power Shift events and casual conversations with organisers. Power Shift brought together over 700 people from around $\mathrm{A} / \mathrm{NZ}$ and the Pacific for a three-day conference on climate change. It was made up of a combination of workshops, plenary speeches (see figure 2 below), open space forums, performances and informal participant lead interaction. The questionnaire development came from the literature review, and from the topics discussed in interviews. Many of the questions were based around the three theoretical constructs found in the literature review. The questionnaire developed for this thesis aimed to find out what approaches used at Power Shift were liked by the participants. It also aimed to find out how the participants knowledge of climate change had developed at the conference. There were 157 questionnaires filled in and handed back on the Sunday morning when they were handed out. Three further questionnaires were sent into the 350 Aotearoa office from participants who took them home to fill out. This meant a total of 160 questionnaires were filled out and used in the data analysing process. The organisers of the Power Shift conference were able to add in questions to the questionnaire that they felt would increase their understanding for creating events in the future.

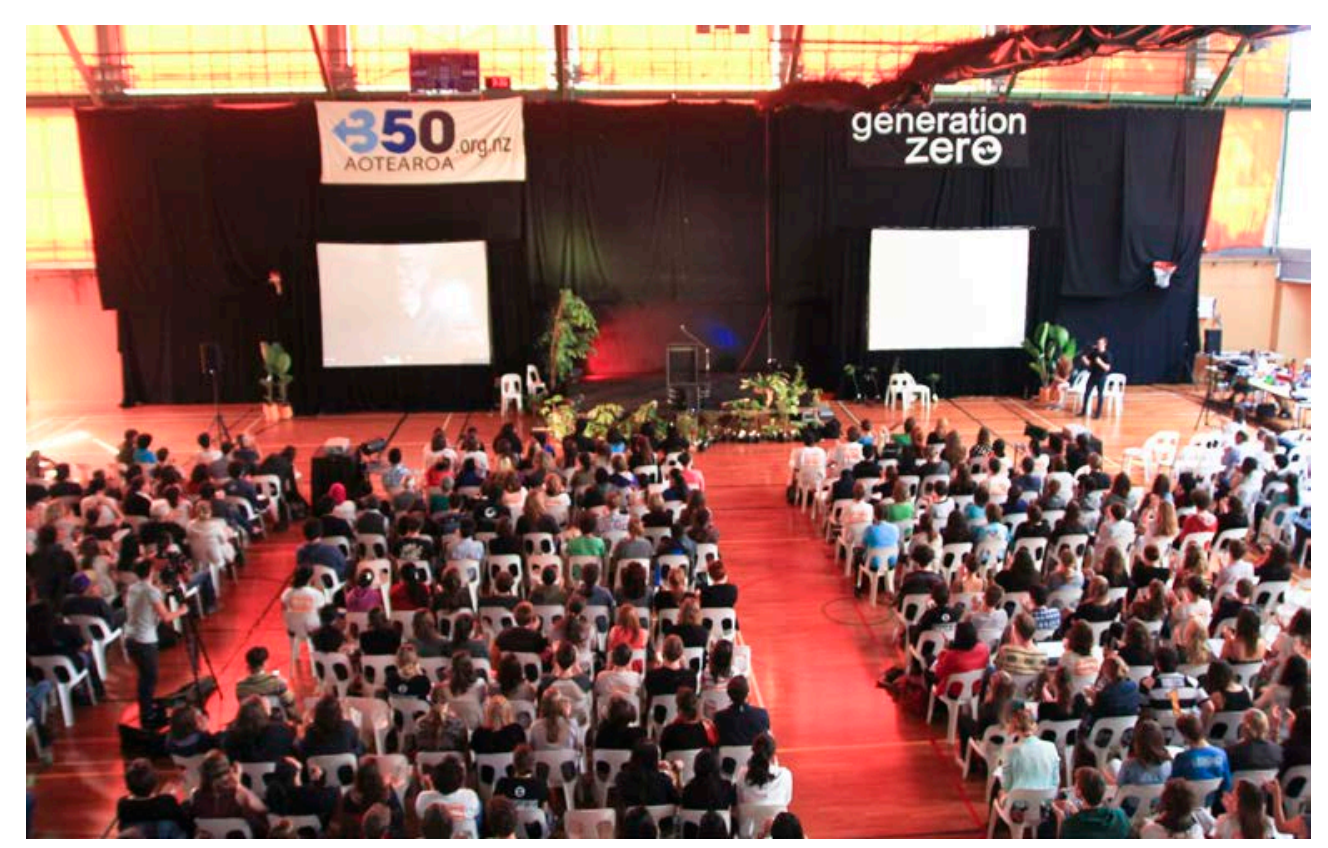

Figure 2- Photo of Power Shift plenary session 
Organisers of Power Shift were sent a follow up question aimed at getting them to be reflexive on the conference. This was to allow the organisers to critique the conference, and voice their opinions on its relevance and effectiveness, and whether or not they would use this structure again in their teachings. It also allowed them to suggest changes and decide whether it is representative of the values that they wanted to privilege. One of the organisers, Aaron Packard, gave a short semi-structured interview to answer these points, and it is recorded in Power Shift organisers reflexivity section (section 5.4.1).

\subsection{Method of data analysis}

Combining wicked problem theory and future focus education approaches is appropriate when using qualitative research methods as developing theory, not just proving/disproving theory, is central to this type of research ${ }^{12}$. This inductive logic research allows for this creation because the researcher aims to develop formal theory by generating hypothesis using coded data (Tolich and Davidson, 1999; Auerbach and Silverstein, 2003). This means that the end result of qualitative research can be quite different to that of quantitative research.

\subsubsection{Thematic analysis}

Auerbach and Silverstein (2003) suggest that thematic analysis aims to discover patterns in descriptive material. For this thesis, each interview was transcribed and the transcript was then coded to show the themes developing within it. Each questionnaire that was filled out was read and individual answers were colour coded to recognise the developing themes within it. The development of themes or categories within the data collected is important when using a grounded theory approach.

\footnotetext{
${ }^{12}$ It is appropriate to use the wicked problem/future focus education mix in a Masters thesis because this combination has already been used by researchers, such as Bolstad (2011).
} 
'This process involves using multiple stages of data collection and the refinement and interrelationship of categories of information' (Strauss and Corbin, 1990, 1998, from Creswell, 2003:14).

This data was then used to create 17 themes. The themes developed for this thesis were organised into the five theoretical constructs that were developed from the data collected. The first three were from information gathered in the literature review- Complexity, Collaboration and Commitment. The additional two were developed using data from the interviews and questionnaireConnections and Confidence. Comparing the data within and between themes enables the researcher to show the difference and similarities in the information (Creswell, 2003).

Then to present all this data, a theoretical narrative was created which summarised the researchers interpretation of the importance of each theoretical construct and underlying themes. Auerbach and Silverstein (2003) describe the narrative as:

'the culminating step that provides the bridge between the researchers' concerns and the participants' subjective experience. It tells the story of the participants' subjective experience, using their own words as much as possible. However, it also includes the researchers' theoretical framework by including the theoretical constructs and themes in parentheses throughout the narrative. Weaving together subjective experience and abstract concepts brings together the two very different worlds of researcher and participant' (Auerbach and Silverstein, 2003:40).

It is important to acknowledge when doing qualitative research narrative that the interpretation of the information by the researcher is only one of the ways that the information could be interpreted and that all such interpretations are 'right' (Auerbach and Silverstein, 2003; Tolich and Davidson, 1999). The narrative in this thesis tried to use as much of the participants answers as possible, with linking concepts in between. This was to privilege their information and roles as experts in their own experiences. How they identified themselves on the questionnaire was how they were referred to in the narrative. 
The questionnaire asked for their age, gender and ethnicity. The answers were not analysed or divided into categories according to these identifiers due to the restrictions of time of a Masters thesis. They were included after each participants answer to show the diversity among the participants that was central to many of the thesis arguments.

\subsection{Limitations and reflexivity of method}

Reflexivity is one way that a researcher can acknowledge the beliefs and underlying preferences that they bring to the research.

'Reflexive research reflects upon and questions its own assumptions. Researchers must self-consciously reflect upon what they did, why they did it, and how they did it. The values of the researchers become an explicit part of the research process' (Tolich and Davidson, 1999:39).

There was an 18month time frame, which the thesis had to be completed within. It was written for an academic audience but had to privilege a community focus. There was a 30,000 word maximum, and 25,000 word minimum requirement. This meant that a lot of great quotes from participants did not make the final draft. Being a Masters student does not pay well and it meant that there were limitations as to what I could spend money on. For example, I did my interview with Bob Frame over the phone to save me flying to Christchurch from Wellington. Climate change is a large and complex topic and this meant the thesis could have turned out in numerous ways, depending on the aspect I focussed on. It was a learning process, as personal knowledge of how to research such a big topic was missing from my skill set in the beginning, as was a prior knowledge of traditional and future focus educational systems.

I participated in the conference as well as being a quiet observer, which would have had some bearing on the narrative write up. I joined in on conversations to gain a sense of how other participants were finding the conference. In qualitative research, the researcher cannot separate themselves enough to be 
considered completely impartial while undertaking their research. I brought to this research my own assumptions and ideas that will have influenced the outcomes and interpretations of the research, and indeed the creation of the research topic itself.

I had chosen the original three themes with my supervisor after the literature review (section 4.6) so they were already featured in the questionnaire. I gave out a piece of candy for every survey handed back, which could have influenced return rates. All questionnaires were handed out on the Sunday morning before the plenary, those who did not attend this early morning plenary (9am) would have missed out on answering. I met and talked with a lot of the participants and explained my research before the Sunday when the questionnaire took place. Having a prior knowledge of climate science and policy could have meant that I understood things at the conference that a lot of the participants didn't.

The interview participants were chosen specifically for their extensive knowledge on future focus education or wicked problem theory. I had never done a telephone interview before doing one with Bob Frame. I had done an interview face to face before, but never by myself. The questionnaire participants were chosen because of their involvement with the Power Shift conference. This type of selection is warranted within a qualitative approach as it 'does not stress representativeness in selecting a sample... the researcher decides, on analytical grounds, what information to collect next and where to find it' (Tolich and Davidson, 1999:34-35).

This also makes the research location specific as the conference was held in Auckland and this meant that some people who could not attend who otherwise would have. There were also many storms in Auckland that week including deadly tornadoes. This meant that a lot of people couldn't make the conference from out of town. I almost didn't make it as had to change flights to Friday morning from Thursday night. I was only person to code the transcripts and analyse the questionnaire data. This means I may have missed things and interpreted differently than someone else might have. 


\subsection{Synthesis}

The methods chapter showed what methodological approach was being used to approach this thesis. A qualitative approach using grounded theory and thematic analysis was chosen as the most appropriate method. It showed the limitations and provided reflexive look at the method used.

Chapter 4, Literature review presentation, will summarise the findings from the literature analysis, and develop the broader knowledge of the fields of literature this thesis is grounded in. It will help to develop themes that will be used to develop questions for semi structured interviews and questionnaires. 


\section{Chapter 4: Literature Review Presentation}

\subsection{Introduction}

This chapter outlines the literature on wicked problem theory, climate change as a wicked problem, and future focus education.

\subsubsection{Post-normal science}

Kuhn (1970) developed the term 'normal science' to identify traditional scientific methods that are objective and context free. It did not allow for the inclusion of the researchers standpoint and worldviews (Haag \& Kaupenjohann, 2001). Post-normal science (PNS) was developed to contrast this concept. Complex, value laden problems needed a different approach which was when PNS is necessary. It acknowledges complexity and allows for the legitimisation of a diverse range of perspectives and ways of understanding (Frame, 2008; Funtowicz and Ravetz, 2003).

\subsection{Wicked Problems}

'Some of the most difficult policy problems of the modern era have been described as complex, intractable, open-ended and 'wicked' (Head, 2008).

The concept of wicked problems has been used since the 1970's and has been developed and widened in its meaning over the past decades. Head (2008) posed three questions that can be used to analyse wicked problems:

1) 'what are the key features of such problems?

2) are they really very different in nature from more routine problems?

3) are we developing better ways to address these wicked problems?' (Head, 2008:1) 
These three questions are answered in the three sections below.

\subsection{Part one- Key Features of Wicked Problems}

Rittel, a German physicist, coined the phrase wicked problems with an initial focus on architecture and city planning. He saw city planning as 'wicked,' as it came with built in complexities and identifying the problem was often difficult. He suggested that the solutions could show that the problem was not properly defined in the first place (Rittel and Webber, 1973). Other works on the subject were developed at around the same time, including work by Ackoff (1974) who called such complexities 'mess.' All of this research into complex social problems was a result of the need to address issues that were becoming increasingly complicated, in comparison to traditional 'tame' problems.

In 2001, Conklin summed up ‘tame’ problems as a problem which:

'has a relatively well-defined and stable problem statement, has a definite stopping point i.e. we know when the solution is reached, has our solution which can be objectively evaluated as being right or wrong, belongs to a class of similar problems which can be solved in a similar manner and has solutions which can be tried and abandoned' (Conklin, 2001:11).

In contrast to these simple issues, wicked problems have a much greater degree of uncertainty. Rayner (2006) attempted to summarise the work of Rittel. He describes wicked problems as problems that are:

- 'symptomatic of deeper problems

- unique opportunities that cannot be easily reversed

- unable to offer a clear set of alternative solutions

- characterised by contradictory certitudes

- (contain) redistributive implications for entrenched interests

- persistent and insoluble’ (summary from Frame, 2008:1118) 
Camillus, a professor at the Katz Graduate School of Business, also aimed to define what made problems wicked. He conducted a study 22 companies over a 15year period and identified five key criteria for a problem to be classed as wicked. The five criteria are if a problem:

- 'involves many stakeholders with conflicting priorities;

- if its roots are tangled;

- if it changes with every attempt to address it;

- if you've never faced it before;

- and if there's no way to evaluate whether a remedy will work' (Camillus, 2008:1).

Both these definitions show the complexities that are involved when dealing with wicked problems. It is hard to know how to solve a wicked problem and even harder to define the exact parameters of it. Jentofta and Chuenpagdeeb (2009) state that wicked problems have no solution that can be determined scientifically and that it is hard to see when the problem is solved. Weber and Khademian (2008) describe wicked problems as 'relentless' and that they are the same as dropping a stone into water, as 'the ripples spread rapidly to have an impact other issue areas' (Weber and Khademian, 2008:337). This links in with the 'unsolvable' quality mentioned by Jentofta and Chuenpagdeeb (2009), as if the problem is indeed 'solved' there are always consequences for all the connected areas. Weber and Khademian (2008) give the example of habitat restoration to explore this concept of complexity and linkages. Restoring a particular habitat would have all types of implications for surrounding development and farming, plant species and hunting practices.

One way of addressing problems is with 'clumsy' solutions where all perspectives on the problem are heard (Frame, 2008; Bolstad et al., 2012). The main issue surrounding wicked problems is the complexities that are associated with it. Wicked problems are unstructured, relentless and interrelated, with little consensus on the best way to approach or solve them. They are difficult to identify and model, and this can lead to conflict due to the lack of consensus on the problem or the best solution (Weber and Khademian, 2008; Shindler and 
Cramer, 1999). Bosanquet et al., (2010) differentiated between natural environment complexities and human complexities. There is complexity within cultural systems and these succeed when they are able to deal with external complexities. Wicked problems cross many social and political boundaries, and are viewed differently depending on the perspective of those involved. They can be both dividing and uniting in nature and require a commitment on many levels of society to tackle them. Lamberts (2006) stated that existing social and physical complexities create wicked problems in the first place. Climate change is perhaps the most interconnected wicked problem facing the $21^{\text {st }}$ century.

Weber and Khademian (2008) summarise the complexity within the very nature of wicked problems;

'The wicked problem space comprises multiple, overlapping, interconnected subsets of problems that cut across multiple policy domains and levels of government. Wicked problems, in other words, cut across hierarchy and authority structures within and between organizations and across policy domains, political and administrative jurisdictions, and political “group” interests' (Weber and Khademian, 2008:337).

Since Rittel first used the term wicked problems in the field of city planning, the concept has expanded to include numerous industries including; economics, IT, public administration, law, policy science, health, education, ecology, business administration (Batie, 2008; Yeh, 2001; Lazarus 2008).

There are many different types of wicked problems including child abuse, terrorism, fisheries, forestry, healthcare, international drug trafficking, nuclear waste, pandemic influenza, AIDS, IT software development and global climate change (Horn and Weber, 2007; Devaney and Spratt, 2009; Jentofta and Chuenpagdeeb, 2009; Wang, 2002; Yeh, 2001: Shindler and Cramer, 1999). Lazarus (2008) suggests that the nature of wicked problems means climate change will have a significant effect on the law because it will need to adapt to the new problems and complex situations that climate change produces. 
This concept has been further developed in the last several years with the introduction of the new 'super wicked problems' category, which includes climate change. Levin et al., (2010) introduced the term in 2007 at the International Studies Associated Convention in Chicago, USA. This term adds four new additional features to the list of wicked problem characteristics that Rittel and Webber created. They felt these new characteristics were necessary to describe a new class of environmental problems that were not an issue when the initial characteristics were devised.

'Most policy-relevant work on climate change in the social sciences either analyzes costs and benefits of particular policy options against important but often narrow sets of objectives or attempts to explain past successes or failures. We argue that an "applied forward reasoning" approach is better suited for social scientists seeking to address climate change' (Levin et al., 2010:3).

These new four characteristics are:

- time is running out;

- the central authority needed to address them is weak or non-existent;

- those who cause the problem also seek to create a solution;

- and hyperbolic discounting occurs that pushes responses into the future when immediate actions are required to set in train longer-term policy solutions' (Levin et al., 2010:3)

The main ten characteristics of wicked problems that will be used in this thesis are summarised in the diagram below (Figure 3). They are a combination of those characteristic complexities as stated by Rayner (2006), Camillus (2008) and Levin et al., (2012). For the purposes of this thesis not all of the criteria presented by the authors could be included so these ten were chosen to keep the project manageable. Also, for the purposes of this thesis, there will be no differentiation made between wicked problems and super wicked problems they will be referred to as wicked problems. 
The main ten characteristics of wicked problems that will be used in this thesis are summarised below.

They are a combination of those characteristic complexities as stated by Rayner (2006), Camillus (2008) and Levin et al (2012):

Different solutions can create or change other problems

Characteristic of deeper problems

- Implications for entrenched interests

- Involves stakeholders with conflicting priorities

Persistent and insoluble

- Never faced before

- Hard to evaluate

Time is running out

The central authority needed to address them is weak or nonexistent

Those who cause the problem also seek to create a solution:

Figure 3- Wicked problem characteristics 


\subsection{Part Two- Different in nature from other problems}

\subsubsection{Wicked problem difference}

Using the characteristics identified in the previous section enables a researcher to class a problem as wicked, and this change the way it should be approached. The following section relates to objective one as it aims to summarise the particular ways in which climate change is a wicked problem.

\subsubsection{Climate change as a wicked problem}

Using the 10 criteria as set out in figure 3 in the previous section, it is clear that climate change can indeed be classed as a wicked problem. Below is a summary of climate change points that link up with each of the criteria:

Wicked problems have no clear set of solutions. The complexities of climate change mean that there are no clear pathways to take in solving them. It is firstly hard to predict the outcome of climate changes. Weber and Khademian state that 'causes and effects are extremely difficult to identify and model' (Weber and Khademian, 2008:336). This makes it hard to concisely predict climate change outcomes and put trust in the various climate models that have been designed analyse the proposed changes. Different solutions can impact the outcomes in different ways and these solutions could either positively or negatively affect the current climate situation.

Wicked problems are characteristic of deeper problems. The majority of scientists believe that climate change is a real phenomenon and that human activity is a direct cause of it (Gleick, 2010). Unsustainable living, changes in land use, forest degradation and urban sprawl are all issues that will influence how ecosystems, including humans, will cope with climate change. They are also linked to GHG emissions, which as was established in the background section (section 2.1.1) are the main cause of climate change. The biggest source of carbon dioxide emissions is from the burning of fossil fuels. Reliance on these fuels is not only harmful in the way it is impacting on our atmosphere, but it is also unsustainable at current rates as they are non-renewable resources that 
will one day be depleted (Roberts, 2005; Pichert and Katsikopoulos, 2008).

Wicked problems have redistributive implications for entrenched interests. An example of this was demonstrated by Hallegate (2009) who suggested that new infrastructure will be needed to cope with the changing conditions brought about by climate changes. This will make the design of urban infrastructure more complicated and expensive, especially with the lack of climate information needed to make the design decisions. 'Uncertainty in future climate makes it impossible to directly use the output of a single climate model as an input for infrastructure design, and there are good reasons to think that the needed climate information will not be available soon’ (Hallegatte, 2009 :240). Another example of this are the significant gains and losses to be made within the insurance sector in reaction to the changes proposed by climate scientists. If climate change is human induced then are the effects of climate change now less natural than they were? A storm may still have been created, but would it have been as big? This has implications for the definition of 'natural hazards' which may have to change.

Wicked problems involve stakeholders with conflicting priorities. Within the climate change problem car manufacturers, oil, coal and gas companies, forestry companies and other GHG emitting companies all have significant invested interests in making sure the current fossil-fuel based economy continues unchallenged.

Wicked problems are persistent and insoluble. Because of the complex nature of climate change issues, there is no quick fix to solve it. This relates to the other characteristics in that one solution may cause more problems. The persistent nature of climate change may mean that current economic and social practices need to be adjusted. 'Even where risks are not quantifiable, environmental changes may be hugely significant. Projected future climate change, for example, is likely to require system transformations as areas and economic activities may be no longer viable in particular places over the next century' (Nelson et al, 2007:396). 
Wicked problems are defined as problems that have never been faced before. 'Evidence going back up to 20 centuries does not show changes in global temperature resembling those that have taken place in the last 100 years' (Australian Academy of Sciences, 2010). Climate change on this scale, caused by human activities, is previously unseen and this means there is no blueprint for how it should be stopped or the impacts reduced. Due to this uncertainty, climate change has been a highly contentious issue. There is little consensus on what the effects of climate change will be or how best to deal with it (Weber and Khademian, 2008:336). Viewed from the perspective of geological time, climate change is 'a catastrophe equal to nearly any other in our planet's history' (Pierrehumbert, 2006:1).

Wicked problems are hard to evaluate. Climate change is a 'highly non-linear, chaotic system which is inherently unpredictable' (Aldred, 2009 :448) and this means that it is also hard to tell how the effects of it will react to mitigating measures. Humans may reduce the amount of GHGs this century but a complicated set of events may have already been put in motion, including complicated feedback loops, ice melt and temperature increases.

Wicked problems are deemed to be time dependent and time is running out. This relates to climate change in the sense that as global population increases, and developing countries become more developed (and hence using more fossil fuels with increased affluence) there is a greater increase in GHG emissions. 'Efforts to control climate change require the stabilization of atmospheric CO2 concentrations. This can only be achieved through a drastic reduction of global CO2 emissions. Yet fossil fuel emissions increased by 29\% between 2000 and 2008, in conjunction with increased contributions from emerging economies, from the production and international trade of goods and services, and from the use of coal as a fuel source' (Le Quere et al., 2009:831).

One of the biggest issues with wicked problems is the central authority needed to address them is weak or non-existent. Some scientists believe that nations are making ambitious targets for reducing their GHG emissions (McKinsey \& Company, 2009). The Copenhagen Accord 2009 stated an aim of keeping 
global warming to below $2^{\circ} \mathrm{C}$ but other scientists believe that the national emissions-reduction pledges 'are insufficient to meet this objective' (Rogelj et al., 2010:1126).

The final criteria used by this thesis to describe wicked problems is that those who cause the problem also seek to create a solution. Unless someone is completely off the grid, making their own clothes from their own home grown material, growing all of their own food, and not using fossil fuel powered transport, then they are part of the problem. It could be turned around to say that those trying to solve the problem of climate change are involved in creating it, because not all those who are creating the problem are interested or have the ability to create solutions to it.

The following section shows how future focus education is useful when helping learners become capable at approaching wicked problems.

\subsection{Part Three- Addressing Wicked Problems}

'Failing to recognize the "wicked dynamics" in problems, we persist in applying inappropriate methods and tools to them' (Conklin, 2001:2-3).

Camillus (2008) suggests that although wicked problems have no correct solution, they can be tamed with the right approach. This thesis aims to show that the approaches to future focus education can be used as an effective way to approach wicked problems such as climate change. This section outlines future focus education to create a base of knowledge to enable analysis of objectives two and three.

\subsubsection{What is future focus education?}

We have always been learning for an unknown world because the world is constantly adapting and changing but a rate of change within a persons' lifetime 
is a relatively new phenomenon (Barnett, 2004). This increased rate of change, and the complexities that it brings, pose numerous complications to learning. This is summarised well by Barnett who stated 'the unknown cannot be anticipated so how can a learning take place that is adequate to the unknown, to the unanticipated?' (Barnett, 2004:247). Bolstad (2011) linked the principles surrounding future focus education with 'the notion that these concepts are bound up in "wicked problems"' (Bolstad, 2011:3). She discusses how the complexities of wicked problems may influence what is needed from future education systems.

The Partnership for $21^{\text {st }}$ Century Skills developed a 'Framework for $21^{\text {st }}$ Century Learning' (Degenhardt, L. \& Duignan, 2010:iii) which stated that:

'young people have become increasingly reliant on social networking technologies to connect, collaborate, learn, and create, and employers have begun to seek out new skills to increase their competitiveness in a global marketplace. Education, meanwhile, has changed much less. With few exceptions, schools have yet to revise their pegagogy to reflect current trends and technologies' (Degenhardt, L. \& Duignan, 2010:iii).

This means that education needs to catch up to the rest of society in the way it is educating people for these complex networks of problems, and also catch up in the way this information is taught or presented to students to better reflect the world they now live in. Bull (2009) suggests that education facilitators need to teach how to learn, not just what to learn and that knowledge needs to be seen as a tool to use rather than just memorise facts and figures. She states that thinking at a systems level is important when using future focus education principles, as is 'dealing with complexity, uncertainty and diversity' (Bull, 2009:4).

\subsubsection{Knowledge and Complexities}

One of the most important principles of future focus education is the fact that the ways in which people use knowledge needs to change, and keep up with 
developments in society. Bolstad et al., (2012:14) state in their report for the A/NZ Ministry of Education that:

'the terms "knowledge age" or "knowledge economy" refer to a reorganisation away from an Industrial Age economy, where exploitation of natural resources, primary production, mass production and bureaucratic management hierarchies were the standard model for economic development.'

There is a growing acknowledgement within the education sector that there are multiple ways of knowing. This 'signals a move away from absolute understanding and the essentialism of single positions to a more fluid and relational conceptualisation of knowledge' (Abbiss, 2009:4). This requires those who teach knowledge (teachers, community leaders, company leaders etc) to change not only what they know, but how they know (Bull, 2009).

With the changes in technology over the last few decades, knowing information is no longer enough. Instead of learning and memorizing facts and figures, which can now be accessed through websites such as Google, there is a move to focus on how information is understood and processed. 'Understanding, synthesising, processing and sifting have become essential skills”' (Kelly, 2007:2). This means there is a shift towards 'active seekers, users and creators of knowledge, not passive receivers (who are) able to think, participate and contribute, manage self, relate to others and to communicate’ (Kelly, 2007:3).

Within the school system, Degenhardt and Duignan, (2010:3) suggest that graduates need 'a deep conceptual understanding of complex concepts, and the ability to work with them creatively to generate new ideas, new theories, new products, and new knowledge.’ This works alongside the view of Bolstad et al., (2012:14) who stated that knowledge should incorporate 'knowing, doing and being.' Within $\mathrm{A} / \mathrm{NZ}$ the educational curriculum is 'designed to ensure that all young New Zealanders are equipped with the knowledge, competencies, and values they will need to be successful in the twenty-first century’ (Bull, 2009:4). However, within current educational systems both in New Zealand and globally, there is still a great emphasis placed upon quantifiable achievement. Currently, 
'the only kind of achievement that really matters is individualistic, quantifiable, and statistically comparable... such an assumption is misleading because it distracts attention from the larger cultural contexts of living, of which formal education is just a part' (Gruenewald, 2003:621).

Where the knowledge is generated and learnt is also becoming increasingly important to approaches education approaches. Place conscious education aims to provide practical, firsthand experience and learning concerning what is happening in a particular location. This is seemed to resinate more with learners as it makes broader connections to their lives. 'Experiential learning, contextbased learning, problem-posing education, outdoor education, environmental/ecological education, bioregional education, natural history, critical pedagogy, service learning, community-based education... all of these approaches to education tend to include engagement with local settings' (Gruenewald, 2003:621).

Roberts and Bolstad (2010) conducted a study on the ReGeneration $2009^{13}$ learning environment and contrasted these features with common approaches to secondary school teaching and learning. They set out a list of features that set the two types of learning environments apart:

- 'Collaborative construction of ideas, rather than students being taught the "correct" answers

- Multimodal and experiential learning, rather than learning mostly through text and talk

- $\quad$ Place-based approaches, rather than a curriculum built from universalised or decontextualised knowledge

- $\quad$ Narratives and storytelling as part of the curriculum, rather than only as social side-talk

- A strengths-based and positive approach, rather than a competitive environment and problem-based approach

- Interdisciplinary and multiple knowledge's, rather than knowledge separated into discipline

\footnotetext{
${ }^{13}$ ReGeneration brought together young adults and secondary-school-aged youth with an interest and involvement in sustainability and environmental issues within their schools, workplaces and communities. A long-term goal was to help inspire and build youth-initiated and youth-supported regenerative action in communities across New Zealand.
} 
- $\quad$ Bicultural and intergenerational learning as integrated dimensions of the learning experience' (Roberts and Bolstad, 2010:xi).

It is not just at the secondary school level where learning for the future is taking on an importance. Bosanquet et al., (2010) researched tertiary level education which showed increased emphasis on 'a future that may include any or all of the following: rapid technological advancement, globalisation, interconnected economies and communities, climate change, resource constraints, political instability, social surveillance, and the need for graduates to possess creativity and flexibility to manage these complexities’ (Bosanquet et al., 2010:2).

\subsubsection{Learning within complex systems}

Peter Senge describes 'detail' complexity as being processed using 'conventional management tools for forecasting, planning and analysis... such tools assume linear relations of cause and effect, and hence predictability of outcomes' (Senge, 1992:71). This complexity is too regulated and visible to be classed within the wicked problems concept. He also describes a far less structured type of complexity, 'dynamic' complexity, as having the following characteristics; 'relationships between cause and effect are subtle, processes put in place interact with each other, effects of interventions vary over time, and all of which means that some consequences will be "nonobvious" and hence not predictable or necessarily predicted’' (Senge, 1992:71-72; Hipkins, 2011:2).

These complexity characteristics lend themselves to being part of the wicked problems concept, especially due to the uncertainties that surround them. People who are teaching issues that involve wicked problems 'need to be familiar with the concept of big ideas and complex problems otherwise there will be little change and innovations they create will be fitted into the current system' (Bull, 2009:4). The more complex systems dynamics are kept in mind, the more likely it is that our desired outcomes would be achieved (Hipkins, 2011). 
It is important to figure out how best to work within these complex systems. Dennis Sumara and Brent Davis (2006) listed five ways that increase the desired outcomes within a complex network of learners:

- $\quad$ 'It is important to draw on diversity to access the power of collective thinking.

- While diversity of input is essential, redundancy also matters. There must be common ground where the people who are interacting can stand together and share the same vision.

- $\quad$ Control and authority must be able to be distributed across the group.

- $\quad$ Creating spaces for interaction is essential to the emergence of new insights and ideas.

- Somewhat paradoxically, setting a clear structure and boundaries around planned learning activities will make it more likely that the other four conditions can be met, but obviously this must be done in a manner that does not limit learning possibilities... enabling constraints' (Sumara and Davis, 2006, sourced from Hipkins, 2011:3).

4.5.4 List of summarised future focus education and complexity within learning approaches

Below (figure 4) is a combined list of the characteristics of learning for future issue and within complex systems. This list combines the works of Sumara and Davis 92006) and Roberts and Bolstad (2010). This list was created to make a manageable way of analysing how Power Shift was a future focus education based event. 


\section{The ten characteristics of future focus}

education and complexity within learning approaches that will be used in this thesis are summarised below.

They are a combination of Sumara and Davis (2006) and Roberts and Bolstad (2010):

- Fluid and multiple ways of knowing

- Strengths-based and positive approach

- Narratives and storytelling central to the learning experience

- Multimodal and experiential learning

- Collaborative construction of ideas

- Promote diversity (bicultural and intergenerational) for collective thinking.

-Common ground and shared vision

-Distributing power across groups

- Space and place for interaction and knowledge development

-Enabling constraints- structured for organised activities

Figure 4- Future focus education characteristics 
4.5.5 Use future focus education as a way to address the wicked problem of climate change

It is shown in the previously discussed literature that it is far more important to understand something than it is to know something. Using this theory it would be possible to use future focus education principles to design practical solutions for climate change challenges. Collaboration is mentioned many times and van Bueren et al (2003) believe that collective action is an important solution to climate change. Wicked problem analysis and solutions should also involve the 'collective judgment of stakeholders involved in a process that is experiential, interactive and deliberative' (Jentofta and Chuenpagdeeb, 2009:1). Bolstad et al., (2012:24) stated that:

'education for the 21st century needs to support learners (not to mention teachers, school leaders and families/communities) to actively develop the capabilities they need to productively engage in 21st century wicked problem solving... this is not something that our current structures and systems were designed to achieve.'

The three main themes that developed within the literature review were Complexity of climate change issues, Commitment needed to approach them and Collaboration of people needed to approach wicked problems.

\subsection{Diagram additions}

The three main ideas that were developed within this chapter were put into the thesis diagram. See figure 5 below. 


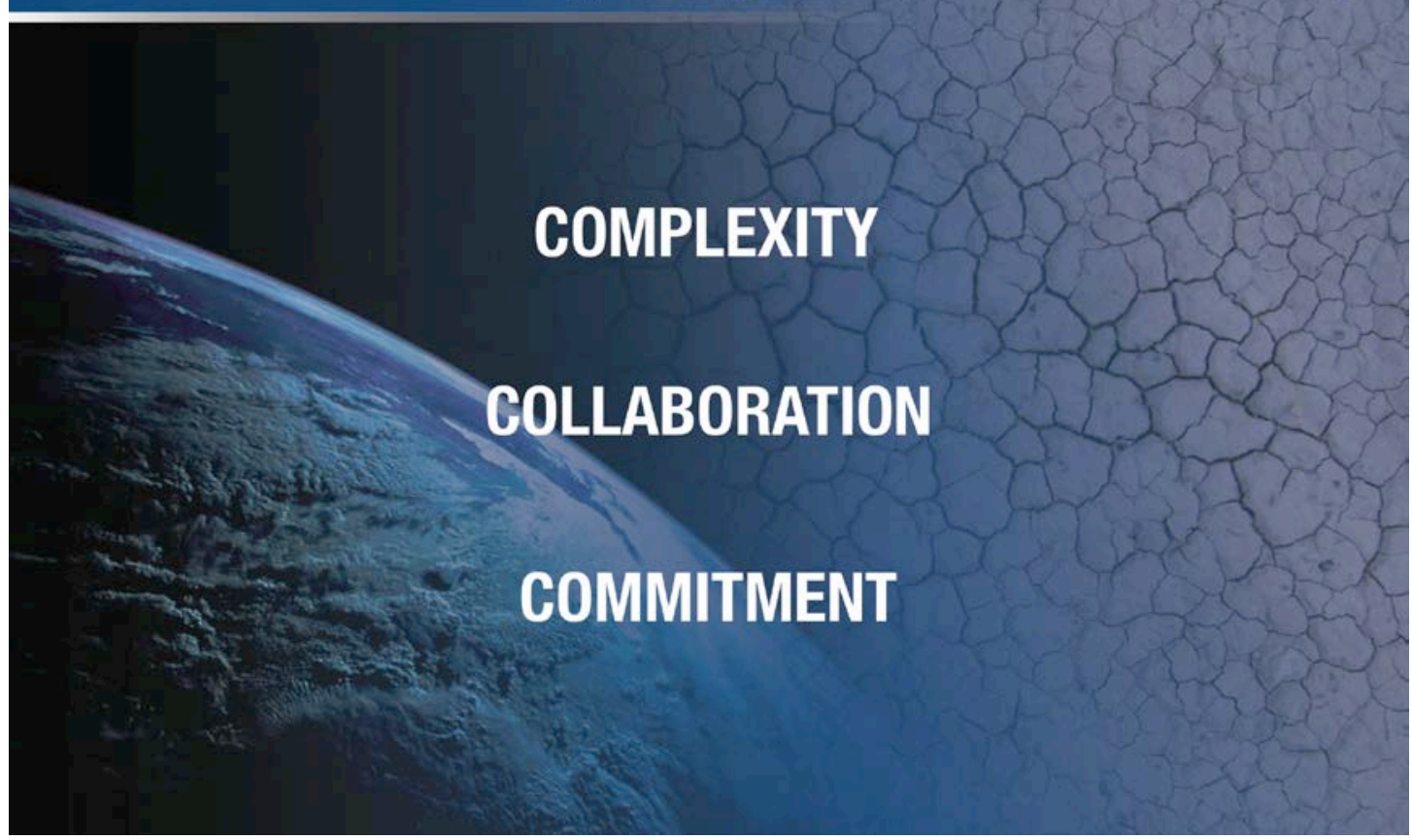

Figure 5- Revised thesis diagram

\subsection{Synthesis}

The literature review presentation chapter analysed texts, websites and journal articles that were pertinent to wicked problem theory, climate change and future focus education. It was split into three sections that aimed to answer three initial questions about wicked problems. It aimed to show the complexities of wicked problems such as climate change. It also showed how future focus education is equipped to approach these complex issues.

Chapter 6, Data analysis presentation, will summarise the findings from the interviews and questionnaires, and develop the broader implications for these findings when educating people about climate change. 


\section{Chapter 5: Data Presentation and Analysis}

\subsection{Introduction}

This chapter presents and analyses the data collected during the research process. As explained earlier in the Method of data collection section of this thesis (section 3.2), the data used for the analysis of this research came from three sources. Firstly, the literature review from the previous chapter (section 4.0) that summarised the current research findings on the subject of wicked problems and future focus education. Secondly, two semi-structured interviews were undertaken with experts in wicked problems and future focus education. Thirdly, a future focus based educational conference was attended and the participants surveyed. This chapter will analyse the questionnaire and interview data.

Power Shift was a climate change conference held in Auckland. Over 700 people from around the Pacific region attended the conference. 160 qualitative questionnaires were filled and the answers make up the majority of this research data. The questions for the questionnaires were developed using ideas gathered from both the literature review and from the semi-structured interviews. The organisers of this conference were given the opportunity to add in any questions they felt would benefit their knowledge for future events, and also were asked if they would like to make any reflexive comments on how the conference went.

\subsection{Power Shift introduction}

The following two sections show how Power Shift lines up with the future focus and learning for complexities information that was found in the literature review. Below, Figure 6, is a diagram (first shown in section 4.5.4) listing the ten characteristics of these approaches used in this thesis. To allow for analysis of objectives two and three later in the discussion chapter (section 6.0), each of the characteristics is explained in the context of the Power Shift conference. 


\section{The ten characteristics of future focus}

education and complexity within learning approaches that will be used in this thesis are summarised below.

They are a combination of Sumara and Davis (2006) and Roberts and Bolstad (2010):

- Fluid and multiple ways of knowing

- Strengths-based and positive approach

- Narratives and storytelling central to the learning experience

- Multimodal and experiential learning

- Collaborative construction of ideas

- Promote diversity (bicultural and intergenerational) for collective thinking.

- Common ground and shared vision

-Distributing power across groups

- Space and place for interaction and knowledge development

-Enabling constraints- structured for organised activities

Figure 6- Future focus education characteristics 


\subsubsection{Power Shift as an example of future focus education in New Zealand}

This section summarises the researchers interpretation of how Power Shift used a future focus education approach, as listed in Roberts and Bolstad (2010:xi).

Power Shift was based on a 'collaborative construction of ideas' (Roberts and Bolstad, 2010:xi) Open space forums were participant directed, with the participants in charge of creating dialogue with other participants about certain topics. A variety of different speakers in the plenary sessions allowed for a variety of 'correct' answers that could then be discussed and built upon by the participants at the workshops. Power Shift was a good example of 'multimodal and experiential learning' (Roberts and Bolstad, 2010:xi). Different types of learning was presented throughout the conference including 'Art Shift,' numerous performances by cultural groups and entertainers, speeches from prominent community leaders, hands on workshops, and panel debates. The flash mob (Figure 7) that was done in a central Auckland park received national news coverage and was a fun and creative way for the group to spread an educational message about climate change issues.

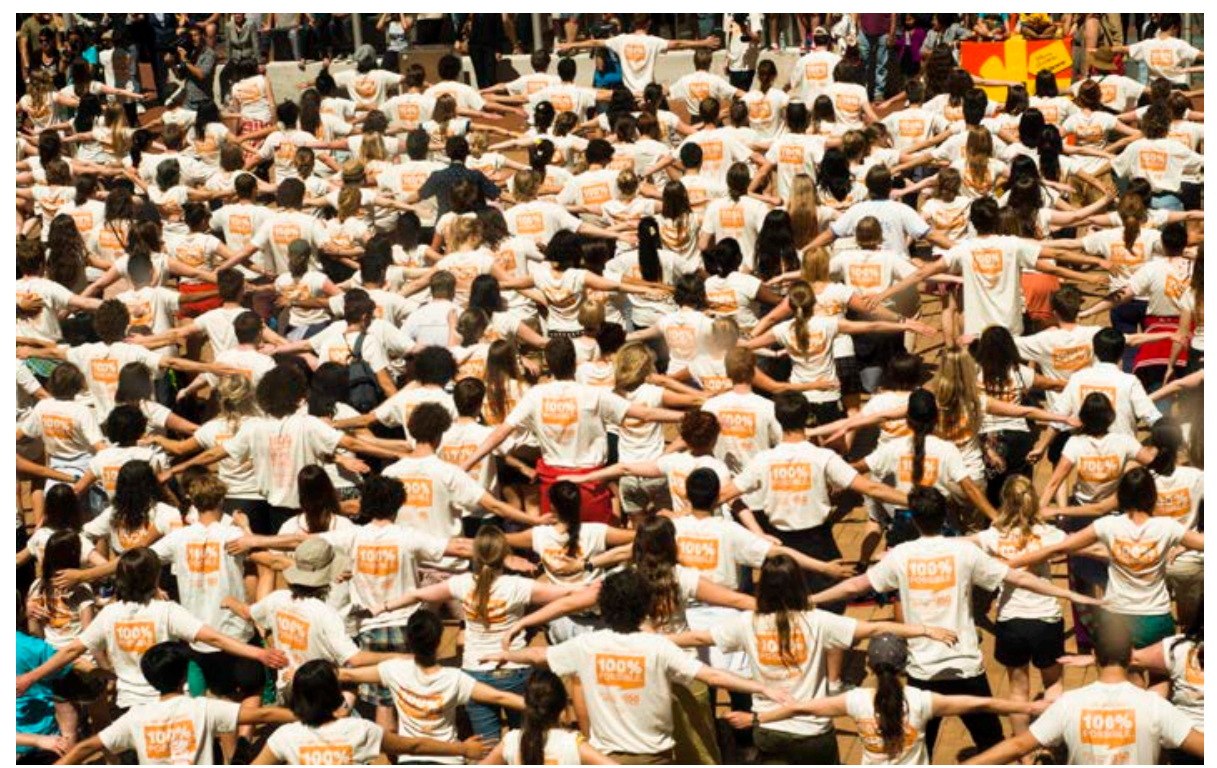

Figure 7- Power Shift flash mob 
The conference was place-based in its approach. The focus of the conference very much aimed at the South Pacific region. Localised context gave increased connectivity to the subject matter being discussed. Emotive stories from Pacific Islanders added to these connections. Regional breakout sessions connected people from the same region to plan future work together that is specific to their region. Every participant was encouraged to share their story and knowledge to add to the knowledge of the group as a whole. This made narratives and storytelling part of the conferences curriculum. Stories from the Pacific Islands that related to their homes being destroyed were taken as fact and very much central to the climate change issue, not just as an interesting side note.

The conference had a solutions based approach to learning. It focused on how people can change behaviours around climate change, not just why they should. It was a community-building event which promoted the roles of each participant as important. This made it a strengths-based rather than a competitive environment. The launch of the $100 \%$ possible campaign shows this positive solutions-based approach being put into action. The conference used multiple knowledge's and an interdisciplinary approach. It was a climate change conference and therefore had climate change central to each debate, whether it was coming from a political, economic or social standpoint. Because climate change is an interdisciplinary subject it meant that all three of those standpoints entered into each debate. It also valued multiple knowledge's from a wide variety of participants. This wide variety of participants led to multicultural and intergenerational learning. The participants came form a wide variety of different ethnic backgrounds and from different regions around the South Pacific. The conference was aimed at youth so the majority of people were under the age of 35 , yet there were some people attending who were in their 50 's.

\subsubsection{Power Shift as an example of working within complex learning systems}

This section summarises the researchers interpretation of how Power Shift lined up with the criteria of 'learning within a complex network of learners' (Sumara and Davis 2006, found in Hipkins, 2011:3). 
The conference promoted and celebrated diversity. It was said by many participants and organisers that diversity was the groups greatest strength. This allowed for a more holistic approach to problem solving by drawing on different knowledge sets and experiences. The conference had the same common goaldecrease the effects of climate change and grow a sustainable future. This was summarised in the $100 \%$ possible to move beyond fossil fuels campaign ${ }^{14}$. This common goal united the group, even though there would be differences in opinion as to which pathway for action would be the best one to realise that goal. There were over 80 volunteers involved with organising the conference, led by a core group. These volunteers ran many of the workshops, which created a wide power distribution network, though the core organising group still did a lot of work. With the open space section and regional break out sections, power was given to the participants to chose the ideas up for discussion.

The participants would not have met on such a large scale without the conference and the spaces for interaction it created. This would have meant that the ideas generated at the conference would not have come about. The connections between people would not have been created and the plans for going forward would be very different. The large Auckland University Recreation Centre was the venue for the plenary speeches, which allowed all the participants to be there at the same time. The smaller workshop spaces, held in the university lecture theatres and tutorial rooms, allowed for more intimate discussions in smaller groups. The conference was strictly structured and timekeeping was controlled so that the programme was followed exactly. There was enough free time that meant that conversations could be carried on into lunch breaks. Having the conference over a three day period meant that although it was packed full of workshops, performances and speakers, it did not seem rushed. Having time kept so exactly meant that it was more formal and meant that participants kept focus as it was not dragged out, which is the enabling constraints concept discussed by Sumara and Davis (2006).

\footnotetext{
${ }^{14}$ http://100percentpossible.org.nz
} 


\subsection{Thematic Analysis}

Thematic analysis was used to analyse the data from the interviews and the questionnaires. Using methods approaches found in Auerbach and Silverstein (2003:39), repeating ideas found in the data were grouped into themes. These themes were organised into larger umbrella concepts called theoretical constructs. The initial three themes that were found in the literature review (Complexity, Collaboration and Commitment) were turned into theoretical constructs and were joined by an additional two (Confidence and Connections). Each of the theoretical constructs had three or four themes that go with it. The next section will break down these themes.

\subsubsection{Theoretical Construct- Complexity}

Complexity as a concept makes up a significant part of the wicked problems literature. It also is prominent in the future focus education literature because of the complex problems that future issues pose to education practices. Both of the interviews mentioned complexity as being a positive thing, not necessarily a negative issue. The participants saw complexity as a hindrance or negative problem that stops action from happening to solve climate change issues. There were many aspects of this overarching complexity discussed within the questionnaires answers, and in many different questions within the questionnaire. Mostly however, the answers relating to complexity came from the question- please explain what you think are the most complicated aspects of dealing with climate change. The theoretical construct of complexity was the overarching concept developed for the following themes:

- Climate change is complicated and full of uncertainties

- Climate change is a symptom of deeper problems

- Those trying to solve the problem of climate change are also creating it

- The central authority needed to address climate change is weak or non-existent 
This next section will unpack these themes in relation to the evidence given by the questionnaire and interview participants.

\subsubsection{Theme- climate change is complicated and full of uncertainties}

The first theme in the theoretical construct of 'Complexity' is that climate change is complicated and full of uncertainties.

My interview participants, Bob Frame and Rachel Bolstad, commented more positively on the complicated aspects of wicked problems such as climate change. In contrast to some of the participant's answers, Bob Frame suggests that the reduction of the problem doesn't work for wicked problems:

"If you start to reduce that down to something that's simple, you take away that one thing that makes it different and special, and that's its complexity” (Bob Frame interview, 2012).

This can be especially true when doing scientific research. In reference to quantitative researchers or modellers Bob Frame stated that:

"They believe that if you reduce things mathematically down to some equation whereby you can model it, you get an approximation of the answer. To which point my answer is no, that's the one thing you cannot do with a wicked problem" (Bob Frame interview, 2012).

Rachel Bolstad uses this to build for complexity within a learning system using complex systems and interactions:

"Another one (principle of future focus education) would be around the kind of belief that our purpose is to actually build everybody's individual and collective capacities to learn, and engage with each other in complex ways... so there is the idea of thinking about the future as a structure for thinking about how you design learning. There's the belief in building everybody's capacities. Belief in it, and committed 
actions that support that. There's the idea of the ability to deal with complexity and uncertainty, in a way that isn’t destabilising” (Rachel Bolstad interview, 2012).

Working with complicated situations like climate change it is important to be comfortable with uncertainties, and comfortable working with uncertainties. She stated that:

"I think that the key idea I'm trying to get at here is that it's about comfort with uncertainty, because knowing that re-making and renegotiating your understanding and your decisions isn't a weakness, it's a strength. To me saying something is complex is a good thing, and it's something that I'm comfortable with, but for different other people saying something is complex is a frustrating thing to say because they are like 'no its not' it's simple, it's just this and we fix it this way. And that's the problem, you know if we have a lot of people out there thinking that everything is simple, and that it's got a simple fix, we are never going to get anywhere. But if we have people thinking that things are so complex and that there's nothing that we can be doing, and so then they disengage, that's not going to work either” (Rachel Bolsatd interview, 2012).

Because the problems are complex people need to be flexible in their approach, and they also need to be able to change their mind with the discovery of new information. Rachel Bolstad discussed this below:

“It's moving from that to a way of seeing the world where actually we don't know all the answers to the things that really matter, and that doesn't mean that we throw up our hands and kind of lose all hope, but its more about doing the best with what we have now and knowing that choices and decisions that we make individually and collectively can change, and probably need to change as we develop new knowledge and new information comes to light. So it requires comfort in that uncertainty, comfort in knowing that you can steer your course through a complex and uncertain situation, and that its not just an individual that can deal with it, it's something that requires interaction and collective abilities to do that. So it is quite an emotional thing as well” (Rachel Bolstad interview, 2012). 
Below is a range of answers from the Power Shift questionnaire. They are in response to the question -please explain what you think are the most complicated aspects of dealing with climate change. There was a diverse range of answers to this question, with the majority of the questionnaire participants framing answers in a way that suggests climate change being complex is a negative thing.

One of the main issues that the participants had with climate change being complicated was that it is hard to explain the science of climate change to other people. This included explaining the science, communicating the science and simplifying the science. An example of the challenges that are involved is noted below:

"People getting knowledge to people in a language they can understand" (female, 30, Pakeha).

This was particularly important when discussing ways of communicating that science to people in a way that will insight action. An example of this included:

"Understanding people's responses to climate change information. Learning how to best share key messages to influence change” (female, 31, Pakeha).

A small percentage of the participants identified people who deny the existence of climate change as a part of the complication. This included dealing with the spread of misinformation, as evident in the following statements:

"Probably dealing with all that eggs that think it doesn't exist" (male, 13, New Zealand).

“Ignorance, denial” (male, 24, Maori/Pakeha).

“Combating false information” (male, 20, New Zealand European). 
Another issue discussed by the participants surrounding the spread of information on climate change is the lack of media representation of the issue:

"The fact that people tend to forget about the issue after a few weeks or years. Also the fact that extreme weather events aren't really being blamed on climate change in the media - there isn't a real focus on global warming at all” (female, 16, New Zealand European/Pakeha).

A significant portion of those surveyed discussed having an impact on other people, and telling them what to do. This could be due to the nature of the conference, which was very much aimed at developing personal climate change knowledge and then spreading these messages to ones own community. Examples of complicated aspects of climate change that relate to this include gaining support from others, commitment, creating awareness and inspiration and convincing people to change their lifestyles. Talking to as many people as possible within a persons sphere of influence was prominent in the answers received, as shown in the following answer:

"Community involvement - getting other people as passionate as we are. There is such a diverse range of people, and we need them all” (male, 16, Pakeha).

This also includes making climate change issues and actions more personal to people, as evident in the following two statements:

"Trying to get more and more people on board and educating them about what climate change is and how it will affect their lives” (female, 19, Indian).

"Making people not feel useless - like they themselves make an important contribution" (female, 21, New Zealander).

As well as communicating the issues of climate change to people, the participants discussed the need to offer solutions. An example of this is: 
"I feel like getting the concrete solutions is the most complicated part. A lot of people are sensitive to climate change, but they don't know what they can do that will actually make a difference” (female, 15, New Zealand European).

Many of the participants discussed how that because the solutions themselves were complicated, it became a lot harder to persuade people to act. There were a wide variety of examples that discussed this point and two examples are listed below:

"The underlying social issue/way of thinking that caused climate change and the fact that there is no one solution, but many, which is harder to market” (female, 21, Pakeha).

"Mobilising others take action. I find articulating scientific data easy but turning that info into some tangible action in others is challenging” (male, 24, New Zealand European/Maori).

Many participants saw global action as essential to approaching climate change issues. One participant said the complicated aspect of climate change was:

"Working together as a global community... bringing together diverse cultures to develop creative ideas of ways we can bring down the fossil fuel industry” (female, 16, Pakeha).

However, it was suggested by some participants that it is hard to take global action as the problem becomes too big. This could be because worldwide actions are harder to coordinate and that knowing where to start and figuring out how to break down the issue is complex. One example of how to combat this complexity within the global approach was suggested by a participant:

"I think we really need to narrow down on one aspect instead of looking at the large picture and hammer down on that one aspect because I think society looks at climate change as one large obstacle that can't be fixed” (female, 16, European/Maori). 
The participants raised the importance of connections when dealing with complexities of climate change. This includes the need to have a diverse range of people approaching the issue, as evident by the following two statements:

“The need to bridge people and different skills together - connecting people” (male, 19, New Zealand Asian).

"Uniting everyone who cares. People of every demographic have a stake in this, and the movement can't afford to restrict itself to just youth” (male, 19, Pakeha).

The participants also discussed the impact of those spreading the climate change 'message'. This included keeping legitimacy within the movement, which is summarised by the following statement:

"Keeping the movement mainstream - risk of extremist groups trying to claim it. Ensuring the bipartisan. Complicated allows for green-washing and inaction” (male, 21, New Zealand European).

\subsubsection{Theme- climate change is a symptom of deeper problems}

The second theme in the theoretical construct of 'Complexity' is that climate change is a symptom of deeper problems. This can be seen when looking at the causes of climate change including fossil fuel use and deforestation. It can also be seen with the economic system that the world currently operates under. Bob Frame explained in his interview that many complex social problems are caused by neoliberal economics:

"There is a real tension about 'well, can we solve things like climate change, or social equity issues, whatever they happen to be, if we don't deal with that complexity?' All these problems have problems that are layered underneath them... so you and I might start a conversation on say, climate change, but what it might come back to, and in some peoples mind very quickly to it, is neoliberal economics” (Bob Frame interview, 2012). 
Many participants of the conference suggested that it was the power of the stakeholders and their underlying interests that meant the issue of climate change was more complex, as described by the following example:

"The power and conflicting interests of stakeholders. Self interest of nations; self interest of short term minded government; big business; apathy and ignorance" (female, 21, New Zealand European).

Climate change is also complicated because of the diversity of interests behind those who are trying to agree to solutions. One example of this noted by a participant is listed below:

"Getting a major emitter to take the first step without demanding the others do too" (male, 21, New Zealander).

It is also made complex by the entrenched infrastructure and the current habits of society. These would take money to rebuild/redesign and many participants thought that this adds to the complexity of the climate change issue. An example of this is:

“That the 'old' infrastructures and ways of life are still established. How do we make this crumble?” (female, 34, New Zealand).

The most widely described underlying influence of the deeper problems causing climate change was the influence of personal and cultural values, and how to balance these with climate change action priorities. Many of these centred around the consumerism culture that much of society relies on. Some participants spoke of this culture as the problem, and others spoke of the difficulty changing it being the problem. There were a wide variety of issues raised on this subject and a selection of those is listed below:

"Climate change steams from cultural values- especially consumerism and individualism” (male, 19, New Zealand/English). 
“Trying to change from what is considered to be the 'norm.' Change the general publics way of thinking” (female, 22, New Zealand European).

"Balancing personal priorities with climate change- those who are poor (suffer more immediate concerns) are not always so concerned with long term outlook. Fighting apathy and discovering 'its' causes. Convincing people to change” (female, 22, Maori/Pakeha).

“Apathy, inertia, intangibility” (male, 21, New Zealand European).

"Battling entrenched economic interests and public attitudes" (X, 39, pakeha).

\subsubsection{Theme- those trying to solve the problem of climate change are also creating it}

The third theme in the theoretical construct of 'Complexity' is the super wicked problem idea that those who are trying to solve climate change problems are also involved with creating them. This is very much related to the last section in the symptom of deeper problems theme- that the consumer driven culture is part of the problem and that each participant who attended the conference was part of this culture, even though many were dedicated to 'solving' the climate change problem.

Bob Frame described this concept when talking about wicked problems:

"That the people trying to solve them are also involved in creating them (wicked problems). Which is clearly true with climate change” (Bob Frame interview, 2012).

The participants also brought this up in the questionnaire. This was selfreflection, as they were describing how they were part of the climate change problem, as much as they were part of the solution which is evident in the following statement: 
"To recognise that we are a problem as much as a solution- young people consume a lot of energy so we need to reduce our consumption too” (female, 31, Asian).

\subsubsection{Theme- the central authority needed to address climate change is weak or non-existent}

The fourth theme in the theoretical construct of 'Complexity' is the super wicked problem idea that the central authority needed to address climate change is weak or non-existent. Many participants saw this as the fault of their government. Bob Frame suggests that this does not necessarily mean the United Nations or governments are at fault but that the current systems that are in place to work for these institutions may not be designed in a way that allows them to approach wicked problems like climate change. He stated that:

"It may be the current system is made to deal with a much simpler world. Now we need more complex processes than the existing government structure. But that's not going to happen quickly” (Bob Frame interview, 2012).

Some participants stated that a complex aspect of climate change was the ability of governments to do something to address climate change issues. Two examples include:

"Political commitment and will power because of invested interests, money and corporations, ideology and model or politics, inflexible institutions" (female, 23, tangata tiriti/Pakeha).

“Government balancing the importance of economy and environment” (male, 34, Tokelauan).

There were many participants at the conference that were dissatisfied with the current political action on climate change, as shown in the following statement:

"Our government is unreliable and New Zealand politics do not support a long term solution” (female, 18, New Zealand European). 
One approach to dealing with this dissatisfaction is to make change and influence governments to do something to address climate change issues. This was discussed by many of the participants and two examples are included below:

\footnotetext{
“Trying to influence the government and those in power to be less interested in the economy, the present and themselves and more on creating a life that is sustainable for the future” (female, 17, European/Maori).
}

"Getting government and farmers to agree to do something” (male, 23, New Zealand European).

\subsubsection{Power Shift climate change word diagram}

This diagram (appendix 6) shows the diversity of opinions of the Power Shift participants when asked to describe what words they would use to describe climate change. The larger the font of a word, the more respondents answered with that word. The smallest words had one-person answer. Whereas the largest words had multiple people use the, for example the five most answered words were -change, challenge, urgent, scary and opportunity. They were mentioned by at least 20 different individual participants per word. This has been included to show the variety of feelings and opinions associated with climate change and why it is such a complex issue.

\subsubsection{Summary diagram for theoretical construct of Complexity}

The following diagram shows is a visual representation of the theoretical construct of Complexity and its four themes. This will be added to the main thesis diagram at the end of this chapter. 


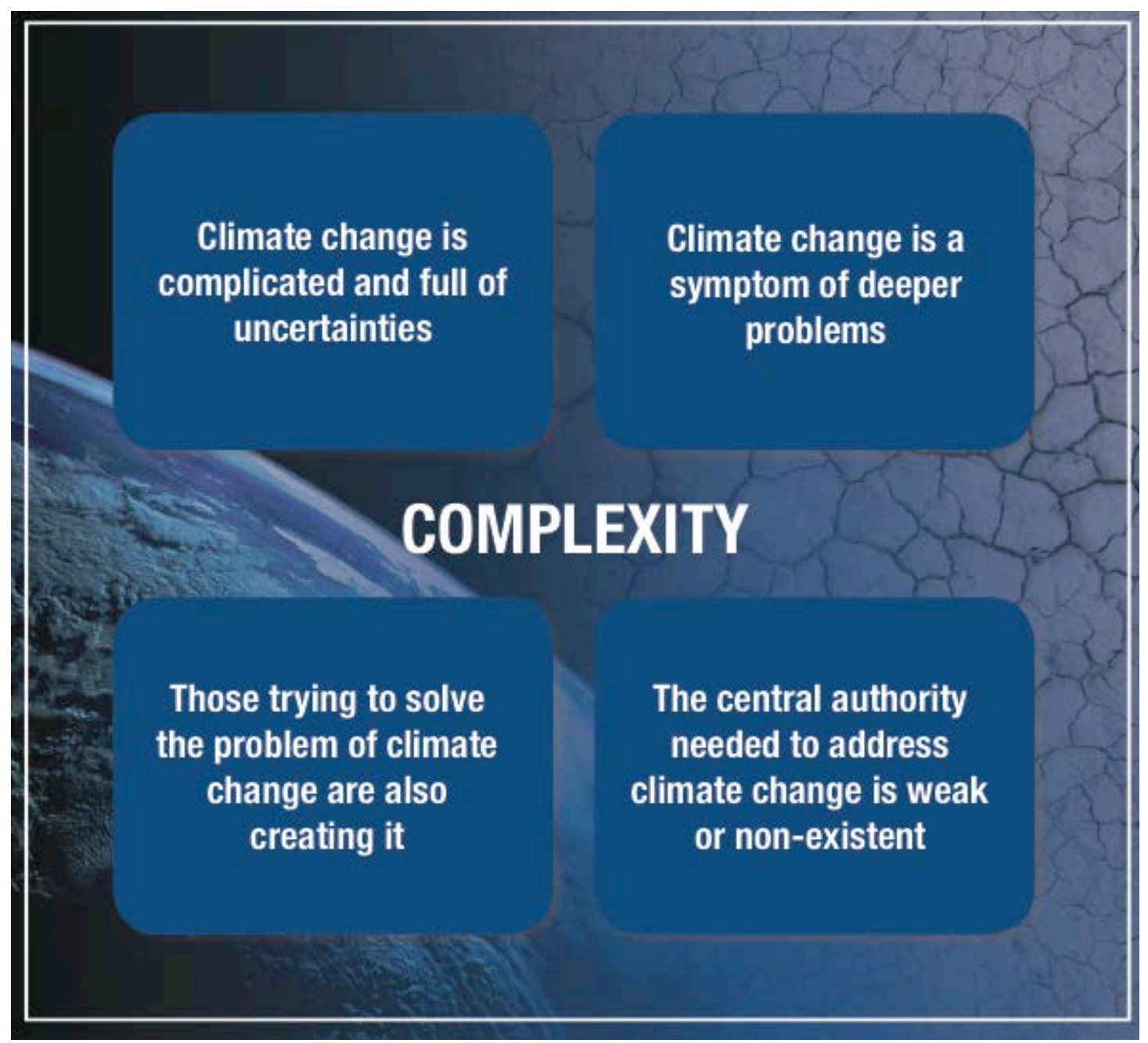

Figure 8- Complexity diagram

\subsubsection{Theoretical Construct- Connections}

Connections as a concept was first included in the initial collaborations theme in the literature review. It was then turned into its own theoretical construct when a division was noticed between meeting and networking, and then actually undertaking some sort of action or project with others. Connections came through strongly within the Power Shift questionnaires. A connection to others within the group was a highlight of Power Shift for many participants. Connections were seen a positive by all who mentioned it in the questionnaire. There were many aspects of the connections theoretical construct discussed within the questionnaires answers, and in many different questions within the 
questionnaire. The theoretical construct of connections was the overarching concept developed for the following themes:

- A sense of connection to other people who are involved in climate change issues

- A connection to the environment that learning about climate change creates or strengthens

- A connection to the issue and problems resulting from climate change, and the solutions to those problems

- A connection to space/place aids the learning process when learning about climate change issues

This next section will unpack these themes in relation to the evidence given by the questionnaire and interview participants.

\subsubsection{Theme- a sense of connection to other people who are involved in climate change issues.}

The first theme in the theoretical construct of 'Connections' is a sense of connection to other people who are involved in climate change issues. Rachel Bolstad acknowledged the importance of connections within future focus education:

"If you look at early childhood literature, it’s quite well theorised ideas around sociocultural theories of learning which sees the learner in connection and relationship with their wider contexts in teaching and learning. You're not just dealing with the individual, you're dealing with the individual in relation to them as part of a family and them as part of a community. So the sort of social-cultural learning ideas, that's not what our learning systems have been designed around. Our systems have been designed around knowledge and transfer of knowledge. It's quite a different intention. So future focus education by definition puts learners and their relationships, context and connections at the centre of learning and builds from that... its building with a view of what the bigger picture is and why it matters” (Rachel Bolstad Interview, 2012). 
Bob Frame discussed how connecting with people and communicating with them allows for a more diverse range of opinions on an issue:

"It could be that starting to have these conversations around these issues, especially if you have bigger groups than just these experts. You might start to get insight in different ways of doing it” (Bob Frame interview, 2012).

He also discussed how a lack of connecting was often present between those dealing with climate change:

“Climate change scientists don't talk to transport planners who don't talk to public health who don't talk to the education research community" (Bob Frame interview, 2012).

Power Shift allowed many participants a way of connecting with like-minded people, and also those who share the same end goal but have varying ideas of how to get there. Answers discussed by the participants suggest that connection grows a sense of community and common ground as shown in the following two examples:

"Before Power Shift I felt that because I was one individual I would not do much, but after coming to Power Shift and seeing other people passionate about the cause, I no longer feel that I have to act alone” (female, 16, Maori/European).

"I was able to gain other peoples perspective and learn the human side of climate change” (female, 22, New Zealand European).

This sense of community increased the willingness of some participants to learn as noted in the following two examples:

"With more interaction with others you feel more comfortable to get out and learn" (male, 16, African).

"Interaction was the main was I learnt- there was so much knowledge from the participants- connecting with them was incredible” (female, 19, Pakeha). 
Some participants felt that those connections also lead to a better learning environment. Two examples of this are included below:

“(Other participants) mostly were positive and friendly. This helped create an environment where it was easy to learn in as there were fewer barriers” (female, 22, New Zealand European).

"I felt their spirit and willingness to make a change in the world so I took their examples and constructed myself to be like them” (female, 14, Maori).

Connections were felt to help show the potential in other participants. This was seen by many to help learning from both other participants and organisers/speakers. This is evident in the following three examples:

"Expanding my awareness of individuals capacities and individual strengths and talents" (female, 34, Kiwi Iwi).

"I was more interested in the opinions of the experts. But the other participants presented different views/perspectives which need to be included in solutions" (male, 21, New Zealand European).

"Conversations helped to digest the talks. In workshops the participants have had almost as much to share as the facilitators. A huge part of my learning has been about the other participants and where they are at” (female, 23, Pakeha).

Connections were made to others through stories, as shown in the following statement:

"The speakers in the plenary sessions were so inspiring. Their stories and messages and experiences empowered myself to continue with what I believe in” (female, 19, Indian).

Learning was aided from the connections with a diverse range of participants. Three examples include: 
"Was great to hear from people with different backgrounds and levels of knowledgeit provided a holistic view of the issue” (male, 21, New Zealand).

"It definitely built up my confidence that others felt the same way and that there was no stereotypical background. Hearing diverse opinions was thought provoking and inspiring” (female, 21, New Zealander).

"It was always interesting to learn why others were here, to hear their ideas and views, I learnt a lot form that. I also learnt a lot about my own ideas and views from expressing them to others” (female, 19, British).

Connection allowed participants to learn from differences in opinion. People working towards the same goal do not necessarily need to have the same views on the issue, as was described in the following example:

"It was the primary focus for me (interaction with other participants); I found that it was more prevalent than I realised to have differences of opinion on the detail” (male, 18, European).

Connections were made between different generations, as noted in the following example:

"Impressed that there are so many switched on young people" (female, 30, Pakeha/New Zealander).

\subsubsection{Theme- a connection to the environment that learning about climate change creates or strengthens.}

The second theme within the theoretical construct of 'Connections' is connections to the environment were created or strengthened by learning about climate change. This section focuses on the learning of climate change issues at 
Power Shift. It made some participants want to learn more about the planet and environmental issues. For example:

"(Power Shift) inspired me to want to learn more about our planet, what is happening to it and what I can do to make a brighter future for generations to come" (female, 27, Maori).

Power Shift related to some participants own life and experiences, and their view of the environment, as noted in the following example:

"The integration between the person experiences with the effects of climate change, related to how I see the environment” (female, 27, Maori).

Consumer choice was put forward as a way to reduce harm to the environment that was discussed at Power Shift. An example of this includes:

"Consumer choices- need to think more why buying- to consume less- be a conserver, not a consumer” (female, 36, New Zealand Maori/European).

\subsubsection{Theme- a connection to the issue and problems resulting from climate} change, and the solutions to those problems.

The third theme within the theoretical construct of 'Connections' is a connection to the issue resulting from climate change, and possible approaches to those problems.

Rachel Bolstad discussed in her interview how important it is to see the connections within and between ideas:

“Being able to take what's valuable from other people's thinking, but be comfortable reengineering things to fit with the directions in which they are already developing, or use them as a way to reflect on and perhaps question or challenge the directions they 
are currently taking... that's the benefit of future focus education being this interconnected web of ideas, because in a sense you could start anywhere, with any of the big ideas, because they each connect with the other ideas. To me it's about seeing the connections, and being able to connect from where you are to "what's missing" in your thinking or practice, rather than a linear sense that we must start with this, then do this, then do this, in a stage-wise approach, which is still $20^{\text {th }}$ century thinking” (Rachel Bolstad interview, 2012).

Power Shift influenced a connection to climate change issues among participants, which is shown by the following statement:

"It educated me in how my everyday living and decisions can make a difference and empowered me to spread our message to everyone!” (female, 27, Maori).

Power Shift discussed climate change issues with a New Zealand focus, as evident from the example below:

"By focusing on NZ issues, especially in some of the workshops and regional breakouts. I felt like I was more connected to the issue and affected by it” (female, 16, New Zealand European/Pakeha).

Connections were made to the actions associated with solving climate change issues. An example of this includes:

"Challenged me to act on my knowledge about climate change through my consumer decisions and all my actions” (female, 23, New Zealand European).

Participants included personal examples of this connection in their answers. Two examples are stated below:

"My neighbour is quite wasteful” (female, 14, European/Pakeha).

“I come from a right wing family who isn’t too phased by climate change. It was cool to learn how to change that ignorance” (female, 21 New Zealander). 
Power Shift created a sense of responsibility for action on climate change issues:

“It made me more aware of my own responsibility” (Male, 39, Maori).

\subsubsection{Theme- a connection to space/place aids the learning process when learning about climate change issues.}

The fourth theme within the theoretical construct of 'Connections' is a connection to space/place aids the learning process when learning about climate change issues. This can include the country/region, the city, the people creating a sense of place, the buildings and grounds.

Some participants noted that regional break-up groups at Power Shift were a connecting factor for many participants, as evident in the following example:

"When we broke into regional groups it meant we could talk about climate change issues that were specific to our region” (female, 15, New Zealand European).

The conference being held in Auckland changed the dynamics of people who attended. It restricted accessibility to some that would have wanted to attend. For example:

“Almost didn't come because of the distance, other wise an appropriate venue" (female, 22, New Zealand European).

The space and place of Power Shift influenced learning, as one participant explained:

"Having access to experts enthusiastic and like minded people- it was the people that made the difference, not necessarily the space” (female, 19, Pakeha). 
The space and place helped one participant connect with the issues of climate change, as shown in the following answer:

"Auckland brought me back to the reality of the unsustainability of big cities. It can be made more sustainable” (female, 21, Pakeha).

The conference being held in Auckland University meant different things to different participants. One noted that it was a good place to hold such an event:

"I think a university was the perfect place for such a summit because there was plenty of room and it feels like a place of learning; good atmosphere” (female, 15, Pakeha).

The venue being at a university validated the authenticity of Power Shift for many participants, as is discussed in the two following examples:

“Holding it at a uni gives it credibility” (male, 21, New Zealand).

“University setting- more ‘official’” (male, 25, New Zealand/Pakeha).

\subsubsection{Summary diagram for theoretical construct of Connections}

The following diagram shows is a visual representation of the theoretical construct of Connections and its four themes. This will be added to the main thesis diagram at the end of this chapter. 


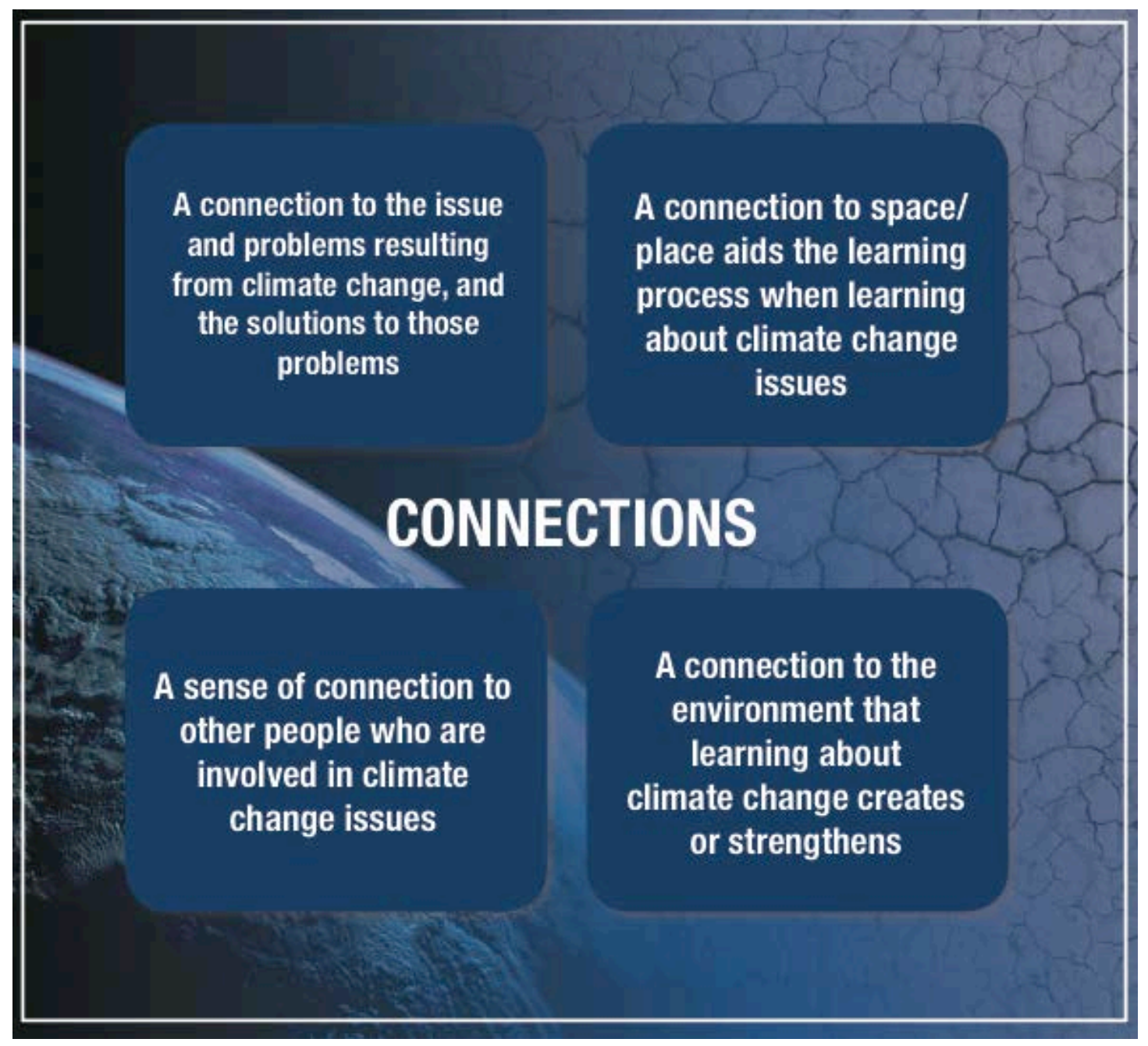

Figure 9- Connections diagram

\subsubsection{Theoretical Construct- Collaboration}

Collaboration as a concept was seen as necessary by many participants, especially due to the social nature of climate change issues. Participants recognised the need to understand and communicate with each other to better approach the issues. There were many aspects collaboration discussed within the questionnaires answers, and in many different questions within the questionnaire. Mostly however, the answers relating to collaboration came from the question- how do you feel collaboration between people helps combat climate change? The theoretical construct of collaboration was the overarching concept developed for the following themes: 
- A diverse range of people needed to approach the climate change issueincluding different backgrounds, knowledge sets, and ages

- A diverse range of learning styles needs to be catered to when educating on climate change issues

- Need to create pathways for climate change action using common goals

This next section will unpack these themes in relation to the evidence given by the questionnaire and interview participants.

\subsubsection{Theme- a diverse range of people needed to approach the climate change issue- including different backgrounds, knowledge sets, and ages.}

The first theme within the theoretical construct of 'Collaboration' is there is a diverse range of people needed to approach the climate change issue- including different backgrounds, knowledge sets, and ages.

Bob Frame suggested in his interview that multiple viewpoints should be heard, but also that it is hard for all those viewpoints to be included in a unified solution:

\footnotetext{
“Climate change- some people said it's going to get warmer, so we will have better productivity on the land, or something like that. And so some of that solutions..., well your solutions, my solutions might take us in completely different directions because of the different value sets. And its only by recognising the multiple sets of values, and say well if we do go down path A it really is going to make a mess of the things that you wanted in your one. So that's a solution from the other person's perspective. So it's really how do you hold those irreconcilable differences" (Bob Frame interview, 2012).
}

Rachel Bolstad also mentioned this in her interview in reference to Bob Frames ideas around multiple perspectives and collaboration on solutions: 
"Bobs ideas around post normal sustainability technologies I think are quite interesting... his ideas say that decision making around sustainability is going to have to draw on a much broader range of perspectives, and is going to give your ordinary layperson citizen a position from which to be involved in those decisions... basically the demands of citizenship need to shift. Citizenship is more than just being responsible and voting, and obeying the law... we need to be more actively engaged as citizens and be able to be wicked problem solvers" (Rachel Bolstad interview, 2012).

Within the Power Shift participants, collaboration of a diverse group of people is needed in approaching climate change.People approach problems differently, but this is seen as a strength rather than a weakness. Two examples include:

“Approach same problem with unique ideas/backgrounds” (male, 26, white).

"It allows you to use a diverse number of tools to combat a complex problem" (female, 21, New Zealander).

Some stated that each person has something different to offer when creating solutions, as shown by the following example:

"Everyone has something different to offer in combating climate change, every contribution of skills helps” (female, 21, New Zealander).

Power Shift gave exposure to a variety of different knowledge's, as evident in the following three statements:

"Loved the diversity of participants- allowed me to think about the potential of different age groups, school groups, cultural groups etc" (female, 23, Pakeha/New Zealand European).

"I see climate change essentially as a failure in human cooperation. So better cooperation is a huge part of the solution” (female, 23, Pakeha).

“Climate change needs to move beyond the middle class” (male, 39, Pakeha/Tongan). 
This collaboration of knowledge was stated as helping to combat climate change issues. One example includes:

"By strengthened relationships and wider knowledge networks” (female, 31, Pakeha).

Collaboration was said by some participants to create confidence, for example:

“It helps in boosting confidence and giving each other strength” (male, 20, Filipino).

A diverse range of collaboration could mean more resources to share, as evident in the following three statements:

"Sharing of resources and information allows for stronger campaigns and more grass roots interconnecting” (male, 19, New Zealand Asian).

"By drawing from a diverse pool of strengths and experience, planning events and ideas can be more comprehensive, innovative and successful” (female, 21, Maori).

"The more people you have, the more resources you can access, the more it can grow" (female, 19, New Zealand European).

Age was also shown to not be a barrier. Many young participants saw their age an asset to collaboration. One example includes:

“It had made me realise that being young isn’t a barrier” (male, 13, New Zealand).

Strength in numbers was identified by participants as a positive result of collaboration, as shown in the following three statements:

"I am really confident. We in New Zealand are over 700 people strong. We have a community of willing people ready to make a difference” (female, 16, Pakeha).

"The more people, the louder the voice. As a group I think we are more likely to be heard and listened to" (female, 15, New Zealand). 
"It creates a sense of community, and that community is vital in catalysing change. It also means action is more powerful” (female, 16, Pakeha).

\subsubsection{Theme- a diverse range of learning styles needs to be catered to when educating on climate change issues.}

The second theme within the theoretical construct of 'Collaboration' is a diverse range of learning styles needs to be catered to when educating on climate change issues.

Rachel Bolstad raised compelling questions related to this issue:

"How might climate change context provide a mechanism to be much more engaged with their communities, and shaping learning experiences for learners that draw on the resources of the wider community? Or how might climate change as a context... help people to develop deeper views of diversity and the strengths that can come from having diversity in your community or learning environment? How can it help us to have a more rich understanding of different worldview $s$ or perspectives on a problem? How could it help us to develop more ways of creating space for dialogue across multiple perspectives?” (Rachel Bolstad interview, 2012).

She went onto discuss the importance of positive community building:

“Things like power shift and 350, Gen Zero and other communities that are really thinking about the positive community building, and the emotional support needs that have to go along side the shift. If you're always feeling negative, and scared and afraid it's not a very enabling position to take action” (Rachel Bolstad interview, 2012).

Bob Frame provided an example of this when discussing interventions into knife violence in Scotland: 
"There was a thing in Scotland that was about knife death/gang death. Glasgow, where I come from, has a very high level of knife violence and they wanted to reduce that. And they did all three. They got the police to absolutely hammer anyone that was caught with a knife. Used the regulation very strongly. They created jobs, if people handed in their knives and went clean, so they used the market. And participatory, where they had the mothers of predominantly young men, but not specifically, who had lost their sons or daughters come forward and talk to gang members and say 'you know, the way you guys behaved you actually killed my son' etc, and so they had a participatory approach. And they actually managed to halve the death rate. (Lisa: Wow, so you're hitting it at a social, economic and political level.) You got it. They did all three. They absolutely hammered it. Huge resources involved... it went for a year” (Bob Frame interview, 2012).

Power Shift was a good example of this as it had a wide variety of ways to connect people to the issue of climate change. There were multiple ways of learning identified as educational or inspiring and this diversity of methods was noted by many participants. This showed the importance of diverse ways of educating. For example:

"I think its necessary as it is such a huge challenge (climate change). The more advice, discussions and support from different fields like science, art, activism, politics etc" (female, 24, Maori).

There was a great variety within the answers to the question - what parts of the Power Shift conference did you find the most educational? Several examples are listed below:

“Performances- Antonio was great” (male, 21, New Zealand European).

"It has enlightened me in an economic sense" (male, 17, Chinese).

“Artshift” (female, 24, Maori).

“Combination of theory, speakers and practical action” (female, 21, New Zealand European). 
"I found the open space on Saturday really valuable because they were in smaller groups” (female, 13, Pakeha).

A section of Power Shift that was mentioned the most as being educational was the workshops. For example:

"The format of the workshops allowed more detailed discussions" (30, F, Pakeha New Zealand).

Two high school aged participants found learning in Power Shift environment a positive experience, as shown by their answers below:

"It was an introduction to what it may be like at uni so I kind of acted like a grown up, hence I listened and focused more? Lol” (female, 14, Maori).

"It was a good and friendly environment and I think I learnt better in it" (male, 13, New Zealand).

Also within the topic of multiple ways of knowing was the issue that some participants preferred information in traditional forms, as opposed to other forms such as story telling. For example:

“The 'hype' during the plenary sessions made me sceptical. I'd get more out of having more content (maybe I'm too old to appreciate it...!)” (female, 30, Pakeha/New Zealand).

\subsubsection{Theme- need to create pathways for climate change action using common goals.}

The third theme within the theoretical construct of 'Collaboration' is the need to create pathways for climate change action using common goals. 
Having a common goal is important to create a unifying action, as evident from the following example:

"A consensus of opinion is needed to create change and raise awareness" (male, 21, New Zealand).

Power Shift made the common goal of fighting climate change causing activities and provided A/NZ based ideas. An example of this includes:

“(Power Shift) took a global problem and addressed it at local tangible levels" (female, 16, Pakeha).

This includes having solutions to the climate change issue, as shown by the following answer:

"The workshops for me provided a lot of insight into the reality of climate change and the possible solutions to make a change” (female, 27, Maori).

It also includes the importance of having definite pathways to reach the solutions. An example of this was stated by one participant:

“One person as an individual can’t do much but if they talk to other people then they can start a movement. It means people will all focus their energies in the same direction” (female, 15, New Zealand European).

Power Shift provided connections and ways of developing pathways for climate change action, as evident in the following two statements:

"Sharing ideas and opinions helps to build a purpose, a goal, as well as a way of achieving said goal” (female, 17, Maori/European/American).

"Good to hear different ways and paths to reach the same ultimate goal” (female, 21, Pakeha).

Specific examples of common issues are: 
“That we all fight a common problem in the pacific” (male, 34, Tokelauan).

"Its important aspect to encourage politicians but more important is collaboration between professionals who have the ability to design for sustainability” (male, 21, new Zealand European).

\subsubsection{Open space topics}

There was a section at Power Shift that enabled participants to run their own workshops for an hour to discuss things they were passionate about with others. Below is a list of some of the topics that participants chose to discuss. These topics were diverse and varied, but all with the similar aims of reducing climate change impacts. They are good examples of diverse ways of approaching common goals.

- Encouraging mobile shift in urban transportation- how can we make transport sustainable in our cities?

- Collaborative electronic learning- power to make change has a foundation in education and collaborative learning in communities

- UNICEF- children's rights \& sustainability

- Climate and TPPA- the TPPA is a US trade deal that threatens to stop us making the policy about climate that we want

- Agricultural emissions dialogue- brainstorming solutions and actions from a grassroots perspective

- Healthy and sustainable housing- pooling ideas about healthy and sustainable living

- Being a climate citizen- meaningful engagement of politicians/how can we influence decision-makers and up-skill our climate knowledge at the same time?

- Solutions focused local campaigns- how can we run effective campaigns which shift regions towards climate solutions

- All politics are local- how to change your school/university for the better

- What are the possibilities for carbon neutral campuses in New Zealand?

- Substantiating the vision for reducing emissions

- Young people running for local body government in 2013 
- Environmental activism in China- how do we best work with authority, what are the opportunities and challenges?

- Art with environmental focus- creative open space= ARTSHIFT

- Cross sector dialogues on water-introduction to new organisation that builds relationships and facilitates dialogue in water management

\subsubsection{Summary diagram for theoretical construct of Collaboration}

The following diagram shows is a visual representation of the theoretical construct of Collaboration and its three themes. This will be added to the main thesis diagram at the end of this chapter.

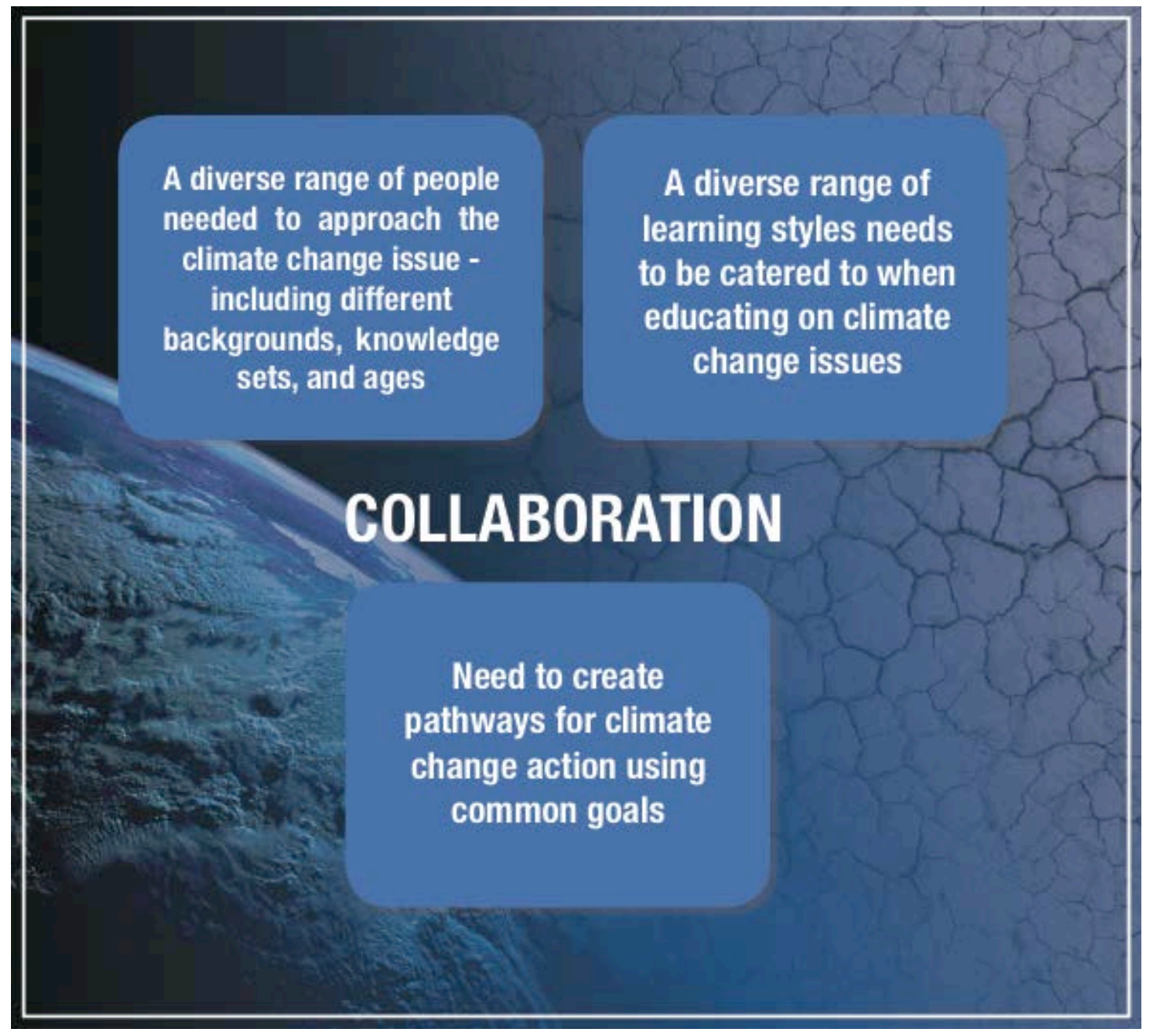

Figure 10- Collaboration diagram 


\subsubsection{Theoretical Construct- Confidence}

Confidence as a concept is directly related to objective three of this thesis (how Power Shift benefits participants). So far in this analysis the complexities of climate change have been acknowledged, and the importance of connecting with others has led to collaboration with others. Many participants of Power Shift stated that their confidence had grown as a result of the previous three theoretical constructs and that they felt that they had the skills needed to approach climate change issues.

There were many aspects confidence discussed within the questionnaires answers, and in many different questions within the questionnaire. Mostly, however, the answers relating to confidence came from the question- how has Power Shift changed your sense of empowerment towards climate change? The theoretical construct of confidence was the overarching concept developed for the following themes:

- The participants gaining confidence in themselves from the learning process and the feeling of empowerment they take from it

- Having confidence in the science and knowledge surrounding climate change - Arming learners with the right skills and tools to use while approaching climate change issues

This next section will unpack these themes in relation to the evidence given by the questionnaire and interview participants.

\subsubsection{Theme- the participants gaining confidence in themselves from the learning process and the feeling of empowerment they take from it.}

The first theme within the theoretical construct of 'Confidence' is that of the participants gaining confidence in themselves from the learning process and the feeling of empowerment they take from it.

Rachel Bolstad discussed the above concepts in her interview: 
"I think what is good about some of the 350/Gen Zero movements is that they are trying to shift it into a more empowering, positive, building, experiencing, success sort of culture, and do believe that things that are driven from a place of positivity and empowerment can only be good for the people, and can only be good for the people that they impact” (Rachel Bolstad interview, 2012).

Below are two answers that refer to the question - how has Power Shift changed your sense of empowerment towards climate change? They show how participants increase in confidence due to Power Shift:

"Strengthened my belief in my individual power” (male, 24, Maori/Pakeha).

"I learned so much about the wide effects of climate change. I have honestly had a life changing experience and I know that from here on I will think/act/apply myself differently” (male, 25, New Zealand European).

Power Shift gave some participants hope that climate change issues can be tackled successfully, as evident in the following example:

“I used to think about what needs to be done but how it's nearly impossible. But now I feel that it can be done” (female, 15, New Zealand).

Some participants were not feeling as confident after Power Shift. One example is noted below:

“Made me feel inspired yet anxious and cynical” (female, 19, Chinese/New Zealand).

Some participants noted that Power Shift has given them the resources and/or knowledge to have the confidence to take action against climate change. Two examples include:

"It made me feel that I can take effective action. It also introduced a local Pacific focus that I haven’t heard before” (female, 24, Pakeha). 
“To know I have all these resources and people standing with me gives me strength and the help I need” (female, 17, New Zealand European).

Two specific examples of this include:

"I feel more motivated now to go home in fight even harder for my island" (female, 14, Samoan).

"I am confident enough to try and make my school carbon neutral” (male, 16, white).

Many participants noted that they had been inspired by Power Shift. One example is noted below:

"I feel replenished as my energy was depleting. I am ready to continue the struggle to save my people and wheua (land). I will stand up against fracking by the 'Joint Venture' (Tag oil and Apache). Mangatu lands will NOT be taken and used for random strangers who know nothing about us. We will not stop the FIGHT!" (female, 39, Maori, Nga Ariki Kaiputahi te iwi).

Some participants noted that they wished to use this newly found confidence to inspire others, as evident in the following two statements:

"I have been inspired by all the people only a few years older than me. I am not too young to make a change" (female, 13, Pakeha).

"I'm going to the flash mob, where before I would have gone home. I am happy to talk to mostly anyone now, because we need everyone” (male, 16, Pakeha).

\subsubsection{Theme- having confidence in the science and knowledge surrounding climate change.}

The second theme within the theoretical construct 'Confidence' is having confidence in the science and knowledge surrounding climate change. An important aspect of climate change education is having the right science to teach. 
Rachel Bolstad suggests that it is not just the science that people need confidence in; it's the surrounding issues as well:

"In the past it would have been a particularly science knowledge approach. Things have changed. I think people acknowledge and understand that cc is probably as much or even more a social political and economic issue, as a science one... that's broadened the scope of what we would think the knowledge to learn there" (Rachel Bolstad interview, 2012).

This increase in climate change knowledge gave confidence to the participants, as evident from the following two examples:

"More knowledgeable thanks to the workshops - empowered by knowledge" (female, 17, Pakeha).

"I've been inspired by that action stories I've heard - I feel now that progress is possible” (female, 22, Pakeha).

Some of the participants were then more confident in sharing the knowledge. Examples of this include the two answers listed below:

“I feel I've been given arguments in understanding to inform others" (female, 22, Pakeha).

“Because I now have more knowledge, I am sure I can educate others” (female, 19, Indian).

There were some participants however that stated that knowing the science wasn't enough, and that they needed other skills to be confident enough to share the knowledge on climate change issues:

“Because I’m more informed, I feel more confident. However, I still need to work on my public speaking skills” (female, 19, Filipino). 


\subsubsection{Theme-arming learners with the right skills and tools to use while approaching climate change issues.}

The third theme in the theoretical construct 'Confidence' is arming learners with the right skills and tools to use while approaching climate change issues. The word arming insinuates that there is a fight or battle being fought, and this is exactly how many participants view the climate change debate- a war between major polluters and those trying to reduce its effects. For this reason the word 'arming' has been included.

Rachel Bolstad discusses in the following paragraphs the importance of giving learners the ability to approach complicated issues and develop their own personal capabilities:

"It comes back to that idea again about personalising learning, and that learning is building learners, building developing, supporting, engaging, connecting, nourishing, all those holistic words, and it's building them to become independent. And again it's that idea around sharing power and responsibility, but in a responsible way. I think learners benefit from future focus approaches because they are becoming more aware, more self-aware, of their own connection, their knowledge, their relationships, and their power to affect the world... Learners ultimately become capable, confident, able to think about their personal futures, as well as community local regional global futures and their role in relation to these.

And it's not just that they are being told they need to do this, which is kind of what things are like now, but they would actually be enabled and supported to develop those capabilities through their learning. That would become the core purpose of learning... And then learners that have had these much more deep transformative experiences where they have been working on a real project for example, doing something in their communities and have had to manage this complex thing and work with other people, in those cases usually they have no trouble talking about what they have learned and how it has changed them. They develop so much more understanding of themselves and of the people they work with, and how to manage relationships and that things don't always go to plan and you have to be able to adapt and change. So that's why I am really committed to the view that doing in these ways 
benefits learners, because that's where we see the difference - talking to the learners who have experienced that kind of learning, and it benefits teachers as well” (Rachel Bolstad interview, 2012).

Participants noted that Power Shift gave them the tools and skills needed to approach climate change issues. Two examples include:

"Workshops were very in depth. Regardless if you were very new to this whole climate change idea or that you already had many experiences, you could see everyone gained new skills” (male, 16, Taiwanese).

"Communication strategies to talk to people about it. Not to worry about climate denialists as such a small percentage of total population” (female, 23, New Zealand European).

Power Shift gave skills and tools to the participants to spread through their communities, as noted in the following two examples:

"Provided me with tools to share amongst my community" (female, 22, Maori).

"I fell I now have the knowledge and the skills to make a positive change in my community” (male, 16, Pakeha).

A specific example of this is:

"I'm from the East Coast and therefore are against fracking. Power Shift gave me new tools to use against protecting my local environment from fracking” (female, 16, Maori).

Power Shift gave skills to create and execute solutions for climate change issues, as shown by the two following examples:

"I still feel that I need to look up the facts again, but I am confident in talking about solutions” (female, 22 Europe). 
"I feel like I have the tools, skills, and support to actually do something in my area" (female, 15, New Zealand European).

\subsubsection{Summary diagram for theoretical construct of Confidence}

The following diagram shows is a visual representation of the theoretical construct of Confidence and its three themes. This will be added to the main thesis diagram at the end of this chapter.

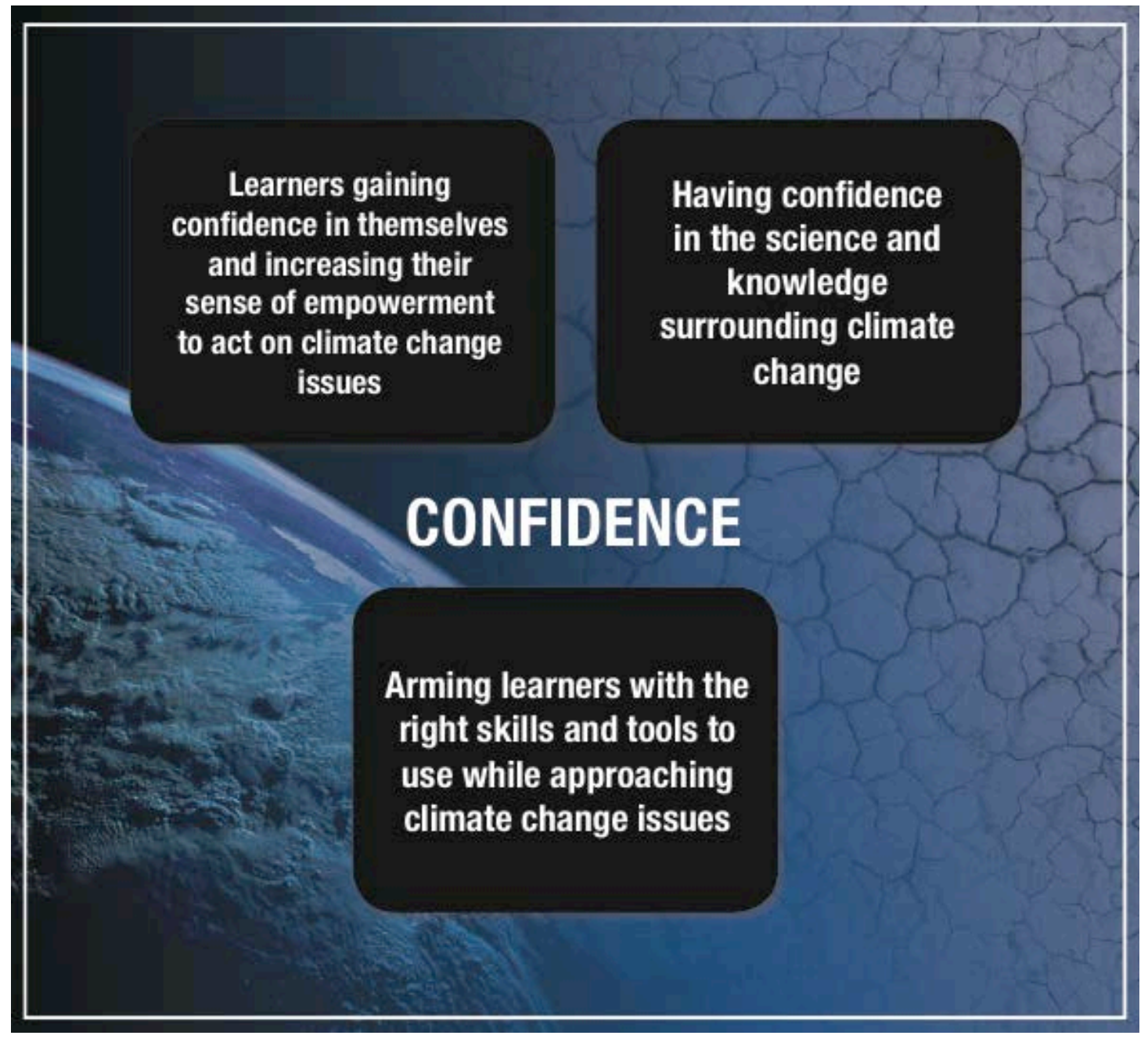

Figure 11- Confidence diagram 


\subsubsection{Theoretical Construct- Commitment}

Commitment as a concept was seen as an outcome of the learning process involved in the first four theoretical concepts. Once someone has learned about the issues, gained connections and people to collaborate with, and in the process developed appropriate confidence, they can then commit to approaching solutions to the issues associated with climate change. This is not a general rule, there are many people that could learn all the information and make the connections but not commit to any action. However, this section looks at what participants thought people should do, and some mention what they personally should or want to do.

There were many aspects of this overarching commitment discussed within the questionnaires answers, and in many different questions within the questionnaire. Mostly however, the answers relating to commitment came from the question- what type of commitment do you think is necessary for people to make in regards to climate change? The theoretical construct of commitment was the overarching concept developed for the following themes:

- A personal commitment to addressing the issues of climate change

- Commitment within our communities towards action on climate change issues

- A commitment to change at the government level in regards to climate change.

This next section will unpack these themes in relation to the evidence given by the questionnaire and interview participants.

\subsubsection{Theme- a personal commitment to addressing the issues of climate change}

The first theme within the theoretical construct of 'Commitment' is making a personal commitment to climate change issues. There were many varying ideas as to what type of commitment should be made. 
There were many people who thought that a small commitment was all that should be expected from people in regards to climate change. An example includes:

"I think people need to be educated and inspired to make their own change and commit themselves to doing what they feel they can” (female, 13, Pakeha).

However, there were also many people that believed that people should be making a full and unwavering commitment to climate change issues. An example of this is:

“ $100 \%$ commitment, not only to make a difference themselves, but set an example for others. They need to do everything possible, but not so much that in the long term it will be too hard” (female, 18, New Zealand European).

Some participants had ideas for specific commitments that need to be made in response to climate change. Three examples of this are noted below:

"Change habits and mindsets that limit us to fossil fuels. For example: instead of driving, try public transport” (female, 17, Chinese).

"A commitment to energy saving and positive reinforcement of change” (male, 24, Kiwi as).

"Minor lifestyle changes eg walk more, shorter shower, environmental conscious buying” (male, 20, New Zealand European).

One participant suggested that commitment to actions was the most effective type of climate change commitment, as evident in the following statement:

“'Commitment to change' is too broad. Committing to actions or campaigns would be more effective” (female, 22, New Zealand European). 
There were many answers that highlighted the co-benefits of climate change action. One example of this includes:

"I think people should be prepared for minor lifestyle changes, but I think that through efficient design this shouldn't decrease (but raise) their quality of life” (male, 21, New Zealand European).

There were a few participants that filled out the questionnaire that believed that those in a privileged position should do more towards climate change. Two such examples of these answers are:

"It's cliché but just all do as much as possible- especially those in a position of privileged” (female, 23, New Zealand European/Pakeha).

“A substantial commitment from a smaller group of us, a lesser but still substantial commitment is required from the masses” (male, 25, New Zealand European).

It was also mentioned by some participants that commitment is needed from different levels of society. Two examples are included below:

"Commitment to doing things differently on many levels: politics, personal habits, physical infrastructure, social expectations" (male, 25, New Zealand European/Pakeha).

"We need action from both the top-down and the bottom-up" (female, 24, Pakeha).

\subsubsection{Theme- commitment within our communities towards action on climate change issues}

The second theme within the theoretical construct of 'Commitment' is that commitment is needed within our communities for action on climate change

Rachel Bolstad suggested that a commitment from educators would be a way of increasing the learners capacity: 
"Our purpose is to actually build everybody's individual and collective capacities to learn, and engage with each other in complex ways. So its an actual genuine commitment to that idea, rather than, in education it is easy to pay lip service to the idea that we believe that everyone has potential to be developed, but actually practices are underpinned by different motivation, and its around sorting people into winners and losers... checking people against a system that has been constructed, assembly line model” (Rachel Bolstad interview, 2012).

Many participants talked about influencing their own communities as being an important part of committing to climate change issues. Two examples include:

"Be a leader and take the responsibility to raise awareness in their community" (female, 17, Cook Island Maori).

"Start locally and within own community to provide awareness amongst our neighbours” (female, 22, Maori).

One participant stated that it is important to use these connections to apply support for larger change for climate change action, as noted below:

"I think if everyone tries to make many small changes in their own spheres of influence and gives their support to the larger changes we will achieve what we need to" (female, 17, European/Kiwi).

An important aspect of commitment mentioned by participants is the need for change in societal views and priorities. Two examples of this include:

"The commitment to changing the view of climate change throughout society through implementing sustainable and renewable practices throughout the home and workplace” (female, 18, Australian).

"Commitment from the public, businesses, governments (everyone) is essential - we need to commit to changing our priorities, the economy and lifestyles in order to be successful” (female, 19, British). 
Some participants gave answers that related climate change commitment to their own lives and how they would influence their communities. A specific personal example of this is included below:

"My gymnastics clubs choices $\mathrm{n}$ clothing and my methods of transport to get to university” (female, 18, New Zealand European).

A specific workplace example of this is:

"When I go back to work tomorrow (arrggghhh!) I am going to educate my colleagues all about climate change and recycling all the organisations plastic, glass and paper" (female, 39, Maori, Nga ariki Kaiputahi te iwi).

Two specific school based examples are:

"I am inspired and prepared to raise awareness at my school and I wish to make a new group at school” (male, 16, Taiwanese).

"When I go home I am going to visit primary schools and teach them what I've learnt here at Power Shift” (female, 14, Samoan).

\subsubsection{Theme- a commitment to change at the government level in regards to climate change.}

The third theme within the theoretical construct of 'Commitment' is a commitment to climate change action at the government level.

Bob Frame referred to literature in his interview that suggests that climate change commitment by governments is not easy because of the way the legal system is set up: 
"(super wicked problem theory suggests that) because the systems that are set up that should tackle it, aren't set up in the right way... the legal system that we all use is made to privilege the present over the future. Climate change needs us to privilege the future over the present” (Bob Frame interview, 2012).

The main way that was mentioned by Power Shift participants to bring about this change was voting and pressuring politics. Two examples of this include:

"They should be prepared to VOTE in policies/governments committed to making change” (male, 21, New Zealand).

"Some kind of action. Supporting political action, lobbying, helping local body campaign pressure next year” (male, 24, New Zealand European/Maori).

Citizens voting with their wallets to change government policies was also mentioned, as noted by the example below:

"We all need to vote with our wallets to support businesses who are making the necessary changes. We need to create the society we want and governments and regulations and cooperations will have to follow-build a mandate for CHANGE" (female, 23, New Zealand European).

The aim of this action could be to get the right policies. An example of this is:

"Once we have the right policies, it will solve itself. It is "just” a matter of fighting for those” (male, 18, European).

And it was not only central government that was suggested to be a good place to commit to change, as evident in the following statement:

"Local government and the need for youth in the councils to drive change" (female, 35, New Zealand European/Maori). 


\subsubsection{Summary diagram for theoretical construct of Commitment}

The following diagram shows is a visual representation of the theoretical construct of Commitment and its three themes. This will be added to the main thesis diagram at the end of this chapter.

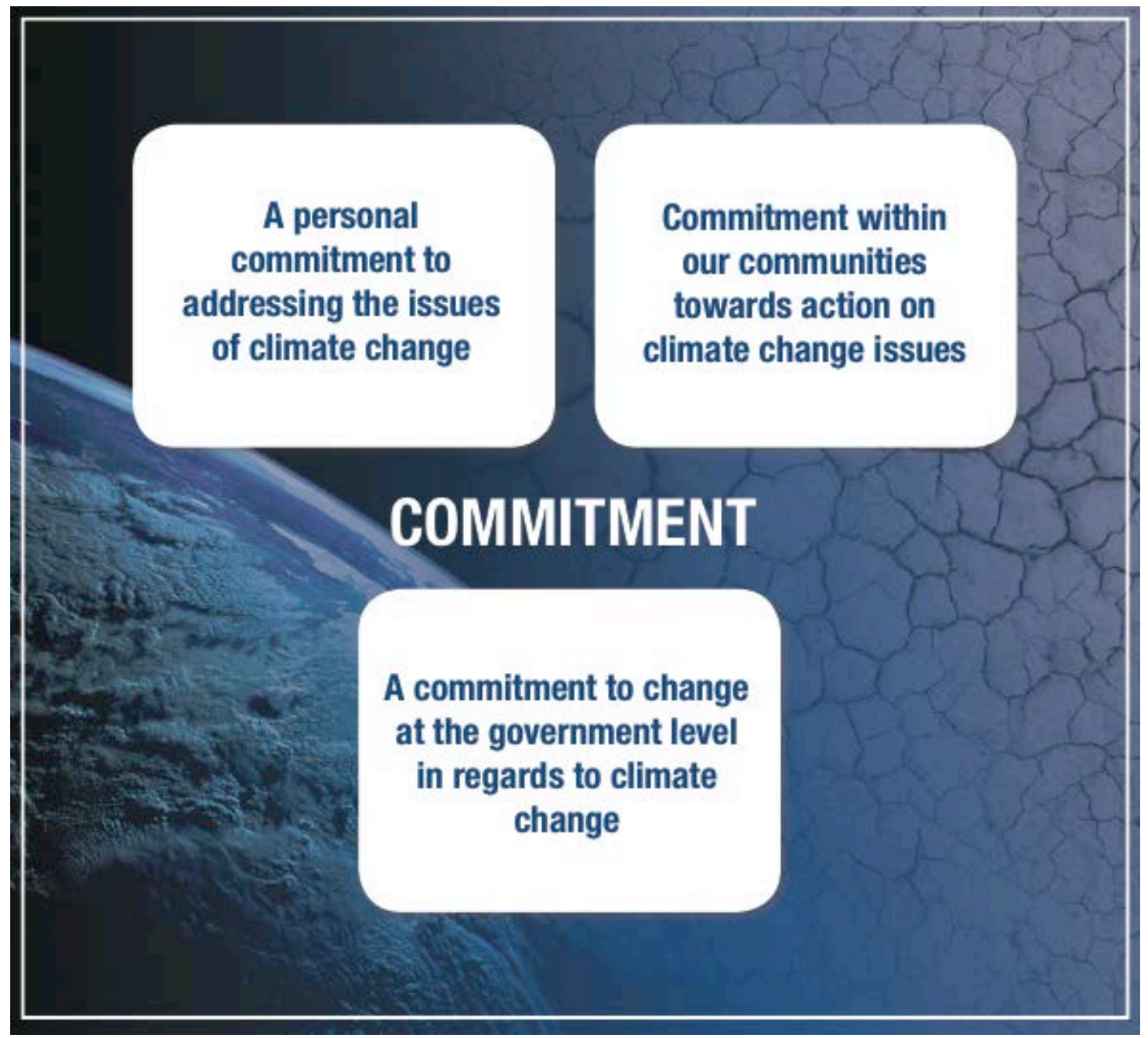

Figure 12- Commitment diagram 


\subsection{Power Shift organisers reflections}

'Reflection that just lets a person see what already is-without new lenses through which to view new possibilities, question old assumptions, and so on-is unlikely to lead to new actions. Reflection that does not simply notice what is but begins to unpack what is (to question assumptions, use new lenses, new perspectives etc.) is by definition transformational’ Bull, 2009:5)

The organisers were asked if they would like to put anything in the thesis that allowed them to reflect on how they thought the conference went. Aaron Packard from 350 Aotearoa gave a short interview on his thoughts on Power Shift.

\subsubsection{Aaron Packard interview}

"Overall, Power Shift when better than I had hoped. Things I'd changed would probably be less time in plenary... Some of them were quite long, and I felt like, as an MC that was what I was aware of- the challenge of holding everyone's attention. The longest was 2 hours which is pretty long to be seated. We engaged different people early on. We left it a bit open sourced, but that's why we went for workshops rather than just lots of speakers up the front. And that's also why we used lots of performances. Some of the performances were spur of the moment as well. 1 just because we realised that what we need right now was not someone up the front speaking, but instead need something to liven things up, and provide a space for people to reflect and for people to relax.

(Climate change being taught by non climate scientists)

I can kind of relate to that in some ways as it's really complicated. I personally have a background in science and have done some studies in climate stuff. And working in the NGO sector I do see how climate science is misrepresented quite a lot, or over simplified. I feel that it is a fine line, and it is important to have people who have a solid grounding in it. But I think often climate scientists are not particularity good at communicating it. At Power Shift we kind of avoided climate science in a lot of ways, because it's much more about the vision that we are working towards, and in that 
context climate change is the major driver for it. But yea I see climate science misrepresented in the pacific islands quite a lot.

I heard from several people who had gotten a bit cynical about whether we could achieve anything on climate, and who were a bit sceptical about what we were trying to achieve. By the end of Power Shift they were fully excited and re-energised.”

\subsection{Diagram of theoretical constructs/themes}

Appendix 7 is the combination of the individual theoretical construct and themes diagrams. This diagram could be useful for educators who are looking to enable their students/learners to approach wicked problems.

\subsection{Synthesis}

The analysis chapter showed how Power Shift used a future focus approach to educating the conference participants about climate change. It drew out themes from the semi structured interviews with Bolstad and Frame, and from the Power Shift questionnaire. 17 themes were developed that fit within 5 theoretical constructs.

Chapter 6, Discussion, will summarise the findings from the analysis chapter, and develop the broader implications for these findings when educating people about climate change. 


\section{Chapter 6: Discussion}

\subsection{Introduction}

\subsubsection{Chapter Overview}

This chapter discusses the thesis objectives in relation to the information discovered in the literature review, as well as data collected in the semistructured interviews and Power Shift questionnaire. Figure 13 (Discussion overview) shows the objectives and aim of this thesis, which are summarised in this section. The following three sections answer each objective separately, and then in the final section the aim is addressed.

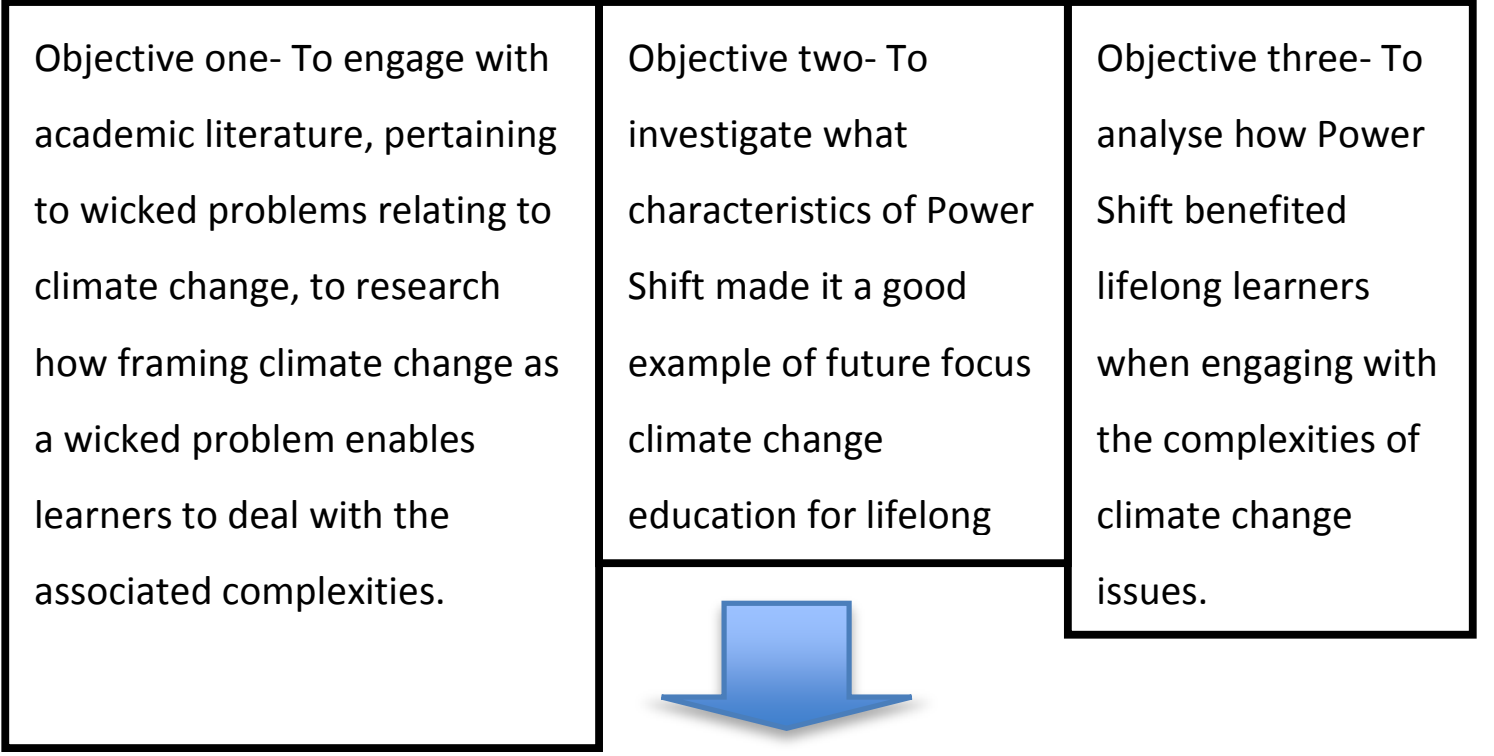

How can future focus education enable lifelong learners to commit and collaborate with others in addressing the complexities of climate change?

Figure 13- Discussion overview 


\subsubsection{Objective one}

To engage with academic literature, pertaining to wicked problems relating to climate change, to research how framing climate change as a wicked problem enables learners to deal with the associated complexities.

This objective is discussed in relation to the literature review research. Chapter four, Literature review, analysed literature pertaining to wicked problem and climate change. Section 4.3 outlined what a wicked problem is, and how climate change fits within this framework. Section 6.2 analyses how framing a problem as wicked allows learners to work with the complexities of climate change.

\subsubsection{Objective two}

To investigate what characteristics of Power Shift made it a good example of future focus climate change education for lifelong learners.

This objective is discussed in relation to the fieldwork data collected. Chapter five, Data Analysis, analysed the semi-structured interviews and questionnaire responses. Section 6.3 takes this data and shows how Power Shift worked as a future focus based educational event.

\subsubsection{Objective three}

To analyse how Power Shift benefited lifelong learners when engaging with the complexities of climate change issues.

This objective is discussed in relation to the field-work data collected. Chapter five, Data Analysis, analysed the semi-structured interviews and questionnaire responses. Section 6.4 uses this data to show the benefits of future focus educational approaches to learners. It shows how future focus education builds capable learners and solutions based approaches. It also creates confidence in learners and connections between them. 


\subsubsection{Aim}

The final section of the discussion chapter will examines the research question as outlined below:

How can future focus education enable lifelong learners to commit and collaborate with others in addressing the complexities of climate change?

Findings will be synthesised to show how future focus education benefits the learner in developing ways of addressing climate change. A summary will be provided of these findings in relation to the literature review material, as well as interview and questionnaire data.

\subsection{Objective one-climate change as wicked problem}

\subsubsection{Wicked problem framing of climate change}

Post-normal science is the base for wicked problem theory. It allows for multiple perspectives to be heard and for these perspectives to be taken into consideration when planning approaches to issues. Post-normal science provides validation for the methods of events such as Power Shift. This is because it recognises the concept of having different ways of understanding the same issues. Post normal science:

\footnotetext{
'draws attention to aspects of uncertainty and values that are often downplayed (or ignored) in traditional research... It takes the concepts of stakeholder input and democratic participation beyond notions of an integrated, single and internally consistent framework to one which allows for the coexistence of a diversity of perspectives and ways of understanding' (Frame, 2008:1115).
} 
It allows for scientific analysis of complex issues with values attached to them. The values that are associated with complex issues, such as climate change, are not always shared by each stakeholder. There can be multiple values attached to an issue from a variety of different stakeholders. This is one of the main criteria for a problem to be deemed wicked. Wicked problems have many other criteria associated with them. Climate change has been analysed against these 10 criteria in the literature review (section 4.4.2). Wicked problems allows for uncertainties, which is a valuable tool when approaching complex issues, such as those that lie under the umbrella topic of climate change.

Wicked problems fit into multiple spaces and are the responsibility of multiple actors. Weber and Khademian (2008) summarise the complexity within the very nature of wicked problems:

'The wicked problem space comprises multiple, overlapping, interconnected subsets of problems that cut across multiple policy domains and levels of government. Wicked problems, in other words, cut across hierarchy and authority structures within and between organizations and across policy domains, political and administrative jurisdictions, and political “group” interests’ (Weber and Khademian, 2008:337).

Because of the nature of wicked problems, climate change issues need approaches that can work within all types of societal structures. This explains why such a diverse range of people can congregate at Power Shift and rationally discuss solutions for climate change issues. It needs to be approached socially, politically, economically and culturally. One participant summed this up when discussing what commitment is needed when approaching climate change issues:

"Commitment to doing things differently on many levels: politics, personal habits, physical infrastructure, social expectations” (male, 25, New Zealand European/Pakeha). 
Because the problems associated with climate change issues are complex, people need to be flexible in their approach. They also need to be able to change their mind with the discovery of new information. Rachel Bolstad discussed this in her interview:

“So its moving from that to a way of seeing the world where actually we don't know all the answers to the things that really matter, and that doesn't mean that we throw up our hands and kind of lose all hope, but its more about doing the best with what we have now and knowing that choices and decisions that we make individually and collectively can change, and probably need to change, as we develop new knowledge and new information comes to light. So it requires comfort in that uncertainty, comfort in knowing that you can steer your course through a complex and uncertain situation, and that its not just an individual that can deal with it, its something that requires interaction and collective abilities to do that. So it is quite an emotional thing as well” (Rachel Bolstad interview, 2012).

Framing a climate change as wicked allows learners to include their personal involvement in the issues of climate change. The consumer driven culture is part of the problem and each participant who attended Power Shift was part of this culture. This is at odds with the fact that most of the participants were dedicated to 'solving' climate change issues. Bob Frame described this concept when talking about wicked problems. He stated "the people trying to solve them are also involved in creating them, which is clearly true with climate change” (Bob Frame interview, 2012). This presents a problem when trying to get people involved with climate change action.

The complex nature of climate change means that there has to be numerous ways of dealing with the issues. One participant answered the question - what do you think are the most complicated aspects of climate change - with:

"The underlying social issue/way of thinking that caused climate change and the fact that there is no one solution, but many, which is harder to market” (female, 21, Pakeha). 
The 'harder to market' part is an interesting concept. It is harder to persuade people to take action on climate change issues if there isn't a clear action for them to take. There needs to be a balance between multiple pathways for action and not having a clear sense of direction for this action. One example of how to combat this complexity within the global approach was suggested by a participant:

"I think we really need to narrow down on one aspect instead of looking at the large picture and hammer down on that one aspect because I think society looks at climate change as one large obstacle that can't be fixed” (female, 16, European/Maori).

Bob Frame suggested that system complexity may be too much for the current governing systems:

"It may be the current system is made to deal with a much simpler world. Now we need more complex processes than the existing government structure. But that's not going to happen quickly” (Bob Frame interview, 2012).

He also acknowledged that one of the biggest problems with climate change is the underlying problems that cause it:

“All these problems have problems that are layered underneath them. You know, so you and I might start a conversation on say climate change, but it might some back to, and in some peoples minds very quickly to it, is neoliberal economics. And of course one reason people analysing climate change don't go there is because, if climate change is hard, then trying to change the neoliberal system is really hard... and no individual can pull that off” (Bob Frame interview, 2012).

This concept of underlying complexities is shown by the word diagram (appendix D) made from the answers of the question - what words do you use to describe climate change? This diagram, first seen in section 5.3.1.5, represents what the participants of Power Shift think about of climate change. The bigger the font of the text, the more people that answered with that particular word. The variety of answers in this diagram show just how diverse the topic climate change is. 
6.2.3 Why is wicked problem theory a good way to frame climate change issues?

Wicked problem theory enables learners to approach the issue of knowledge deficit (as previously explained in section 2.3.1) and deal with the underlying issues associated with the complexities of climate change.

“There is a real tension about 'well, can we solve things like climate change, or social equity issues, whatever they happen to be, if we don't deal with that complexity?' All these problems have problems that are layered underneath them... so you and I might start a conversation on say, climate change, but what it might come back to, and in some peoples mind very quickly to it, is neoliberal economics” (Bob Frame interview, 2012).

When working with complicated situations like climate change it is important to be comfortable with uncertainties, and comfortable working with uncertainties. Rachel Bolstad discussed being comfortable working with uncertainties in her interview. She stated that:

"Knowing that re-making and renegotiating your understanding and your decisions isn’t a weakness, it’s a strength” (Rachel Bolstad interview, 2012).

There can be multiple view points on the same issue and Bob Frame discussed this concept in reference to climate change:

“Some people said it's going to get warmer, so we will have better productivity on the land, or something like that. And so some of that solutions... well your solutions, my solutions might take us in completely different directions because of the different value sets. And its only by recognising the multiple sets of values, and say well if we do go down path A it really is going to make a mess of the things that you wanted in your one. So that's a solution from the other person's perspective. So it's really how to you hold those irreconcilable differences” (Bob Frame interview, 2012). 
Wicked problem 'solving' requires multiple inputs. This encourages communication between representative parties. This is true for climate change information, which is often misrepresented by stakeholder groups for selfinterest. Information needs to be spread more to create a more unified scientific and policy front. This is one of the problems that Bob Frame discussed when talking about wicked problems:

“Climate change scientists don’t talk to transport planners who don't talk to public health who don't talk to the education research community” (Bob Frame interview, 2012).

Bob Frame discussed the concept of 'interventions.' These are things that make someone change their habits. They can be soft interventions, for example peer pressure. Or hard interventions, such as policy changes. He suggested that there are three types of interventions. The first being hierarchical- either policy based or voluntary. The second type of intervention is market based. And the third type is participatory approaches such as formal or informal meetings. Bob Frame gave an example of interventions in his interview. He discussed an initiative in Glasgow, Scotland, to counteract growing knife violence in the region. He expressed that those in charge of reducing knife violence took a three-prong approach:

"They got the police to absolutely hammer anyone that was caught with a knife. Used the regulation very strongly. They created jobs, if people handed in their knives and went clean, so they used the market. And participatory, where they had the mothers of predominantly young men, but not specifically, who had lost their sons or daughters come forward and talk to gang members and say 'you know, the way you guys behaved you actually killed my son' etc, and so they had a participatory approach. And they actually managed to halve the death rate” (Bob Frame interview, 2012).

Power Shift took a similar approach to climate change education. It looked at changing political, economic and social norms and approaches to climate 
change action. According to Rachel Bolstad, this social science approach to climate change is becoming increasingly common:

"In the past it would have been a particularly science knowledge approach. Things have changed. I think people acknowledge and understand that cc is probably as much or even more a social political and economic issue, as a science one. So first of all that's broadened the scope of what we would think the knowledge to learn there" (Rachel Bolstad interview, 2012).

\subsection{Objective two- Power Shift good example of future focus approach to climate change education}

\subsubsection{Future focus education approach}

A future focus educational approach creates engaged thinkers and participators, when compared to traditional educational approaches. Rachel Bolstad talked at length about the positive aspects of future orientated learning when interviewed for this thesis:

"I think learners benefit from future focus approach because they are becoming more aware, more self-aware, of their own connection, their knowledge, their relationships, and their power to affect the world... It comes back to that idea again about personalising learning, and that learning is building learners, building developing, supporting, engaging, connecting, nourishing, all those holistic words, and it's building them to become independent. And again it's that idea around sharing power and responsibility, but in a responsible way... create that environment that supports and enables... Learners ultimately become capable, confident, able to think about their personal futures, as well as community local regional global futures and their role in relation to these” (Rachel Bolstad interview, 2012).

She gives an example of this capacity building, describing it as being started from a very young age. It links into the different approaches to schooling using 
future focus education and how this can be applied in community based education.

"Where three and four year old children are designing fences in their centre or are building something with a engineer.... they are experiencing being an actor on the environment, and having an influence and seeing their ideas come to fruition. And if every learner could be experiencing that from their early childhood and that still continues in their schooling and their post schooling, how amazing that would be" (Rachel Bolstad interview, 2012).

6.3.2 Why is Power Shift is a good example of a future focus education approach?

Using future focus education principles requires dealing with 'complexity, uncertainty and diversity' (Bull, 2009:4). This often requires thinking about solutions that do not fit into the current models for doing things. This can be related to climate change action as the current systems and ways of approaching problems are often the causes of those problems. 'The more we keep complex systems dynamics in mind the more likely it is that our desired outcomes would be achieved' (Hipkins, 2011:2). This is why Power Shift is a good example of an education programme that embraced complexities and did not let them get in the way of creating positive and effective solutions to climate change issues.

'Qualitative research is particularly well suited to the study of diversity because it does not assume that there is one universal truth to be discovered, but rather focuses on listening to the subject of experience and stories of the people being studied' (Auerbach and Silverstein, 2003:26)

The Power Shift organsing group did not specifically use future focus literature when designing the conference. However, the similarities between the future focus education approaches, and those that were used at the Power Shift conference has already been seen in section 5.2. This direct correlation between the future focus education approaches and the approaches used at Power Shift 
was the reason why this thesis critiqued the conference for its effectiveness using this criteria.

It created space and place for interaction and creating connections. The conference was held in Auckland University. Some participants noted that they liked this venue:

"I think a university was the perfect place for such a summit because there was plenty of room and it feels like a place of learning; good atmosphere” (female, 15, Pakeha).

Power Shift also provided a sense of place by discussing climate change issues with a New Zealand focus. It also provided space for regional break out groups so that participants could plan localised events and meet others from their region:

"By focusing on NZ issues, especially in some of the workshops and regional breakouts. I felt like I was more connected to the issue and affected by it” (female, 16, New Zealand European/Pakeha).

A space/place educational event with localised examples provides the opportunities to plan real events. It's a practical, tangible event, which is more effective for learning than reading about climate change in a book. Rachel Bolstad discussed this practical learning aspect in her interview:

"Learners that have had these much more deep transformative experiences where they have been working on a real project for example, doing something in their communities and have had to manage this complex thing and work with other people, in those cases usually they have no trouble talking about what they have learned and how it has changed them. They develop so much more understanding of themselves and of the people they work with, and how to manage relationships and that things don't always go to plan and you have to be able to adapt and change. So that's why I am really committed to the view that doing in these ways benefits learners, because that's where we see the difference - talking to the learners who have experienced that kind of learning, and it benefits teachers as well” (Rachel Bolstad interview, 2012). 
There were multiple ways of learning identified as educational or inspiring. Many participants noted this diversity of methods. It shows the importance of Power Shift catering for diverse ways of learning:

"I think its necessary as it is such a huge challenge (climate change). The more advice, discussions and support from different fields like science, art, activism, politics etc" (female, 24, Maori).

Positive community building can be a result of future focus education approaches. This seems to be a much healthier way of approaching complex problems as it is enabling rather than disheartening. Rachel Bolstad stated that:

"Things like power shift and 350, Gen Zero and other communities are really thinking about the positive community building, and the emotional support needs that have to go along side the shift... if you're always feeling negative, and scared and afraid its not a very enabling position to take action” (Rachel Bolstad interview, 2012).

\subsection{Objective three- Power Shift using future focus education approach to benefit lifelong learners of climate change knowledge}

\subsubsection{Developing capable learners}

Rachel Bolstad stated that the approaches of future focus education are designed to build capable learners.

“Our purpose is to actually build everybody's individual and collective capacities to learn, and engage with each other in complex ways” (Rachel Bolstad interview, 2012). 
Building capable learners can then be used to approach wicked problems. Bolstad et al., (2012:24) stated that 'education for the 21st century needs to support learners (not to mention teachers, school leaders and families/communities) to actively develop the capabilities they need to productively engage in 21st century wicked problem solving... this is not something that our current structures and systems were designed to achieve.'

One of the ways that future focus education builds capable learners is by making the knowledge content applicable to the lives of learners. This gives the information context and allows for localised solutions to problems to be developed. Future focus education:

"puts learners and their relationships, context and connections at the centre of learning and builds from that... its building with a view of what the bigger picture is and why it matters” (Rachel Bolstad Interview, 2012).

Power Shift did this by using a South Pacific focus to the information discussed:

"(Power Shift) took a global problem and addressed it at local tangible levels" (female, 16, Pakeha).

High school aged participants found learning in Power Shift environment a positive experience. This could mean that they have learnt ways to learn that are more effective than methods they have currently been exposed to:

"It was an introduction to what it may be like at uni so I kind of acted like a grown up, hence I listened and focused more? Lol” (female, 14, Maori).

Traditional learning systems focus on the transfer of knowledge. It is more focussed on remembering this knowledge, not necessarily learning how to use it. Power Shift aimed at giving knowledge to participants with the direct aim of that knowledge being used to take action on climate change issues: 
"I feel like I have the tools, skills, and support to actually do something in my area" (female, 15, New Zealand European).

\subsubsection{Providing solution-based approaches}

Power Shift made climate change issues and actions more personal to people. This gave participants a sense of ownership over the possible solutions and inspired them to take action themselves:

"Making people not feel useless - like they themselves make an important contribution” (female, 21, New Zealander).

Power Shift gave the resources/knowledge to the participants to have the confidence to take action against climate change. Having solutions to climate change issues:

"I have been passionate about climate change for a while and so having the chance to express my opinions that I'd formed over the years was brilliant. Also, Power Shift has given me valuable information to take action and turn ideas into real plans" (female, 19, British).

Power Shift showed how each person has something different to offer when creating solutions:

"It allows you to use a diverse number of tools to combat a complex problem" (female, 21, New Zealander).

There were many examples of solutions based approaches used during Power Shift. It made a common goal seem attainable through the implementation of a series of action plans. This lead to many participants developing ideas of how best to tackle climate change issues. One such example of a solution is citizens voting with their wallets to change government policies: 
"We all need to vote with our wallets to support businesses who are making the necessary changes. We need to create the society we want and governments and regulations and co-operations will have to follow-build a mandate for CHANGE" (female, 23, New Zealand European).

\subsubsection{Builds self-confidence in the learner}

One of the most important outcomes of Power Shift was the increase in selfconfidence that many participants experienced. This increase in self-confidence allowed more easier learning opportunities and participation in the conference. It also allowed participants to feel inspired to take their new knowledge back to their own communities to engage with others on topics of climate change issues. Rachel Bolstad discussed the relationship between confidence of the teacher and learning in her interview:

“That's one of the ideas that we've looked at quite a lot is the idea of what does it mean to be an independent learner, because it doesn't mean someone that is off on their own unsupported, so its about how do you engender people's sense of ability and agency in themselves, but not leaving them to it... in a way teachers have to be a lot more knowledgeable and a lot more self-aware and confident and reflective" (Rachel Bolstad Interview, 2012).

Power Shift built confidence and then gave the participants ways to explore solutions. An example of this solution is the $100 \%$ possible campaign. One participant stated that Power Shift:

\footnotetext{
“Strengthened my belief in my individual power” (male, 24, Maori/Pakeha).
}

Rachel Bolstad talked in her interview about how society wants a new generation of wicked problem solvers but currently it waits for children to become 'real' citizens before starting to empower them with the skills to do so. She suggests that education for complex problems needs to start young instead of waiting for the 'right' time. This means that age is not a barrier to feeling empowered and involved. 
"How can what they are doing right now be done in a way that they are actually engaged, participating, contributing, active, having influence in their own spheres of influence, and at developmentally appropriate levels” (Rachel Bolstad Interview, 2012).

Age was not considered a barrier at Power Shift. Many young participants saw their age an asset to collaboration with other participants and also with their school peers in their home region.

“It had made me realise that being young isn’t a barrier” (male, 13, New Zealand).

Power Shift inspired further personal learning. This means that participants were keen to seek out information on their own after Power Shift.

"(Power Shift) inspired me to want to learn more about our planet, what is happening to it and what I can do to make a brighter future for generations to come” (female, 27, Maori).

Some of the participants were more confident in sharing their newly acquired knowledge. This meant they were able to feel more confident about connecting with other people on climate change issues.

“Because I now have more knowledge, I am sure I can educate others” (female, 19, Indian).

These connections made at Power Shift meant that participants had the confidence to take action on climate change solutions.

"Before Power Shift I felt that because I was one individual I would not do much, but after coming to Power Shift and seeing other people passionate about the cause, I no longer feel that I have to act alone” (female, 16, Maori/European).

Power Shift increased personal confidence through a sense of community. This sense of community is fostered by common goals: 
"It creates a sense of community, and that community is vital in catalysing change. It also means action is more powerful” (female, 16, Pakeha).

\subsubsection{Building connections between learners}

Learners were benefited by this approach as it allowed for more connections to be developed between the participants. This helped boost self-confidence, as seen previously in section 5.3.4. It also had an effect on the learning environment created at Power Shift. Some participants stated that their learning was made easier because of the interactions fostered by Power Shift:

"With more interaction with others you feel more comfortable to get out and learn" (male, 16, African).

This ability to create a comfortable environment where participants want to learn, and want to interact with others is really important in the learning process. This helps to break down barriers that might otherwise prevent participants from learning. Providing a safe environment with a positive atmosphere is important when asking participants to move out of their comfort zone and interact in a way that they may not be used to:

“(Other participants) mostly were positive and friendly. This helped create an environment where it was easy to learn in as there were fewer barriers" (female, 22, New Zealand European).

This connection with a variety of different people meant that a more diverse range of knowledge's was used to create solutions to climate change issues. The diversity of connections was needed to keep a broad view on the issue:

"Was great to hear from people with different backgrounds and levels of knowledgeit provided a holistic view of the issue” (male, 21, New Zealand). 
This interaction with other participants was important when collaboratively constructing ideas. These ideas were participant led and this meant using the diverse skills that the group as a whole had to offer. By connecting with other participants it was easier to tap into their strengths and skills when creating these ideas:

"Expanding my awareness of individuals capacities and individual strengths and talents” (female, 34, Kiwi Iwi).

Connections to others post Power Shift would mean connecting to a participants own community. One participant stated that it is important to use these connections to apply support for larger change for climate change action:

"I think if everyone tries to make many small changes in their own spheres of influence and gives their support to the larger changes we will achieve what we need to" (female, 17, European/Kiwi).

Rachel Bolstad discussed how connecting to ones community through climate change context can provide benefits for both the learner and the community involved:

\footnotetext{
"How might climate change context provide a mechanism to be much more engaged with their communities, and shaping learning experiences for learners that draw on the resources of the wider community? Or how might climate change as a context help people to develop deeper views of diversity and the strengths that can come from having diversity in your community or learning environment? How can it help us to have a more rich understanding of different worldview $s$ or perspectives on a problem? How could it help us to develop more ways of creating space for dialogue across multiple perspectives?” (Rachel Bolstad interview, 2012).
}

6.4.5 How did the future focus education approaches used at Power Shift benefit learners?

Learners benefited from Power Shifts future focus approach to climate change education in four interconnected ways. Firstly, it provided educational processes 
that could lead to the development of more capable learners. Learners who were able to approach the wicked problem of climate change at localised levels. Secondly, it provided solutions-based approaches to working towards climate change actions. Thirdly, it increased self-confidence within some participants. And lastly, it created connections between participants that developed into a climate change action community.

\subsection{Discussion Synthesis}

\subsubsection{Aim}

How can future focus education enable lifelong learners to commit and collaborate with others in addressing the complexities of climate change?

The Power Shift case study showed the future focus approaches were successful when applied to climate change education. These approaches may even be more appropriate than traditional educational techniques due to the complex nature of climate change issues. Future focus education is aimed at dealing with wicked problem type complexities so the two theories work together effectively. Future focus approaches to climate change education were seen to benefit learners in numerous ways. These include increasing their confidence and connections with other learners, as well as building their ability to learn for complexities and providing pathways for action through solutions based approaches. These approaches enable learners to commit to climate change action.

\subsubsection{Chapter overview}

This chapter discussed the three objectives of the thesis with the purpose of answering the research question. It used research from the literature review, and the interview and questionnaire data, to synthesise relevant information to analyse these objectives. Section two presented information that showed how wicked problem theory can be a good way to present climate change issues. 
Section three provided evidence of how Power Shift was a good example of a future focus approach to climate change education. Section four summarised the benefits to learners of this future focus approach at Power Shift.

The final section sought to answer the research question; how can future focus education enable lifelong learners to commit and collaborate with others in addressing the complexities of climate change? This was done by synthesising the information from the previous three sections and other relevant literature.

Chapter 7, Conclusion, will summarise the findings of this thesis, and include recommendations for future research. 


\section{Chapter 7: Conclusion}

\subsection{Introduction}

This chapter will summarise and conclude the findings of this thesis. It will present a case for why the research is important, and also any future research recommendations.

This thesis aimed to answer the question: How can future focus education enable lifelong learners to commit and collaborate with others in addressing the complexities of climate change? It used wicked problem theory to frame climate change and to show the complexities of addressing such issues. It used future focus education as a way to approach such complex issues because of its use of dynamic and diverse learning styles. The Power Shift conference was used as a case study to show how effective these approaches were to educating lifelong learners about climate change issues and actions. This is separate to teaching them purely about the science of climate change and this is an important distinction to make, even though the complex nature of the issues means that they are interconnected. The analysis of the Power Shift questionnaire, as well as two semi-structured interviews, created 5 main theoretical constructs, and 17 themes (Appendix E). They were developed with a combination of wicked problem theory and future focus education approaches.

\subsection{Findings}

\subsubsection{What does this research tell us?}

This thesis used three objectives to answer the main research question. 
The first objective looked at how framing a problem as wicked enables learners to deal with the complexities, with a focus on the issue of climate change. The literature showed that framing an issue as wicked allows the learner to be comfortable with uncertainties and allows multiple viewpoints to be heard. This is important as climate change problems are social and need multiple inputs from stakeholders and affected communities.

The second objective looked at what characteristics of Power Shift made it a good example of future focus climate change education for lifelong learners. Power Shift used a learning style that encompassed many characteristics of future focus education and therefore was a good example to study for this thesis. The data collected from the questionnaires showed that Power Shift embraced and promoted complexities of climate change, rather than letting them be a barrier to creating solutions. It distributed power across its many tiers of organisers and volunteers, as well as the participants. It created a space for interaction and a sense of place by giving it an A/NZ and Pacific community focus. It used multiple ways of learning including workshops, plenary speeches, performances and participant led open space sessions.

The third objective looked at how Power Shift benefited lifelong learners when engaging with the complexities of climate change issues. The literature research on future focus education approaches show that they are aimed at building capable learners that were equipped to deal with complex problems. Learners benefited from Power Shifts future focus approach to climate change education in four interconnected ways. Firstly, it provided educational processes that could lead to the development of more capable learners, including learners who were able to approach the wicked problem of climate change at localised levels. Secondly, it provided solutions-based approaches to working towards climate change actions. Thirdly, it increased self-confidence within some participants. And lastly, it created connections between participants that developed into a climate change action community. 


\subsubsection{Why is this important?}

This information generated in this study would be useful when considering how to create climate change educational material/tools/events. It has been shown by the literature review on future focus education (section 4.5.1) to be essential to provide information in such a way that learners are fully able to engage with it. This is important when trying to combat the knowledge deficit theory (section 2.3.1). When applied to climate change, the knowledge-deficit theory suggests that people are climate change deniers simply because they do not know enough of the 'right' information to prove its validity. Therefore, to reduce the number of climate change deniers there needs to be an increase in the amount of correct information given to them. This can also be applied to giving people the ability to create pro-climate change action (as discussed in section 2.2.2). Allowing people access to the right information in the right ways means that their ability to act on issues they are passionate about increases. This is linked to the theoretical constructs of confidence and commitment. There seemed to be a trend within the data that participants seemed to feel more confident about climate change information and many felt they could be more committed to proenvironmental behaviours, especially climate change actions.

The same theoretical constructs could be used when looking at how to deal with other complex problems. The literature review focussing on wicked problems (section 4.3) showed that there are many types of wicked problems, not just climate change. These include child abuse, terrorism, fisheries, forestry, healthcare, international drug trafficking, nuclear waste, pandemic influenza, AIDS, IT software development and global climate change (Horn and Weber, 2007; Devaney and Spratt, 2009; Jentofta and Chuenpagdeeb, 2009; Wang, 2002; Yeh, 2001: Shindler and Cramer, 1999). Approaching any of these problems would complicated, just as approaching climate change is. The theoretical constructs and themes could be used to help people such as regional planners, health professionals, community workers and policy makers to approach their particular wicked problem of interest. 


\subsection{Recommendations}

\subsubsection{Future research recommendations}

An interesting future research topic could expand on this research with a comparison between this research and future studies of Power Shift conferences. Two conferences that could be used in comparison are Melbourne, Australia (2013) and the Global Power Shift conference, Turkey (2013).

It would be interesting to look at the responsibility of such NGO groups, such as 350 Aotearoa or Generation Zero, that are educating the public on climate change issues to see where they are getting their information from and what they are basing their actions on. This would show the responsibility involved with 'correctly' educating on climate change issues and the importance of showing all viewpoints.

It would also be interesting to study how the theoretical constructs and subsequent themes work when approaching other wicked problems such as aids, child trafficking or drugs (as discussed in section 7.2.2). 


\section{References:}

Abbiss, J. (2009). Curriculum, twenty-first century discourse and teacher education: Position paper. Teaching and Learning Research Initiative (TLRI). Accessed from http://wiki.canterbury.ac.nz/download/attachments/5801107/TLRI+position+paper+J A.pdf?version $=1$

Ackoff, R. L. (1974). Redesigning the future. J. Wiley.

Aldred, J. (2009). Ethics and Climate Change Cost-Benefit Analysis: Stern and After. New Political Economy. 14(4), 469 - 488

Annan, J. \& Hargreaves. J. (2011). On the generation and interpretation of probabilistic estimates of climate sensitivity. Climatic Change. 104(3-4), 423

Auerbach, C., \& Silverstein, L. B. (2003). Qualitative data: An introduction to coding and analysis. NYU press.

Australian Academy of Sciences. (2010). The Science of Climate Change: Questions and Answers. Canberra: Australian Academy of Sciences http://www.science.org.au/reports/climatechange2010.pdf. Viewed on 14.03.12

Barnett, R. (2004). Learning for an unknown future. Higher Education Research \& Development. 23(3)

Batie, S. (2008). Wicked Problems and Applied Economics. American Journal of Agricultural Economics. 90(5), 1176-1191

Beerling, D., Fox, A., Stevenson, D., \& Valdes, P. (2011). Enhanced chemistry-climate feedbacks in past greenhouse worlds. Proceedings of the National Academy of Sciences of the United States of America. Washington: 108(24), 9770

Berger, J. G. (2006). Adult development theory and executive coaching practice. Chapter three in Evidence based coaching handbook: Putting best practices to work for your clients, 77-102. 
Bolstad, R. (2011). Taking a "future focus" in education-what does it mean? An NZCER working paper from the Future-Focussed Issues in Education (FFI) project Wellington: New Zealand Council for Educational Research.

Bolstad, R., Roberts, J. \& McDowall, S. (2009). Education and enterprise: Learning at the interface. Final report from the Regional Education for Enterprise Clusters Evaluation. Report prepared for the Ministry of Education, New Zealand Trade and Enterprise and the Tindall Foundation. New Zealand Council for Educational Research

Bolstad, R., Gilbert, J., McDowall, S., Bull, A., Boyd, S., \& Hipkins, R. (2012). Supporting future-oriented learning \& teaching —a New Zealand perspective.

Report to the Ministry of Education. 1-85 Accessed from http://www.educationcounts.govt.nz/publications/schooling/109306

Bray, D. (2010). The scientific consensus of climate change revisited. Environmental Science \& Policy, 13(5), 340-350.

Bosanquet, A., Winchester-Seeto, T. \& Rowe, A. (2010). Changing perceptions underpinning graduate attributes: A pilot study. In M. Devlin, J. Nagy and A. Lichtenberg (Eds.) Research and Development in Higher Education: Reshaping Higher Education. 33, 105-117

Bull, A. (2009). Thinking together to become 21st century teachers: Teachers' work: Working paper \#1. New Zealand Council for Educational Research. Accessed from www.nzcer.org.nz/pdfs/21st-century-teachers-200906.pdf

Camillus, J. C. (2008). Strategy as a Wicked Problem. Harvard Business Review. 86(5), 98-106

Conklin, J. (2001). “Wicked Problems and Social Complexity.” Unpublished working paper. CogNexus Institute. Accessed from http://cognexus.org/wpf/wickedproblems.pdf

Cornforth, A. (2011). Does knowledge about climate change predict concern?

Concern for climate change and the knowledge-deficit theory. Thesis- Master of Environmental Studies. School of Geography, Environment and Earth Sciences. Victoria University of Wellington 
Costello, A., \& others. (2009). 'Managing the Health Effects of Climate Change. The Lancet. 373

Creswell, J. J. (2003). Research Design Qualitative, Quantitative, and Mixed Methods Approaches. Handbook of mixed methods in social \& behavioral research. 209-240.

Crompton, T. (2010). Common Cause: The Case for Working with our Cultural Values. Godalming, Surrey:

WWF-UK http://assets.wwf.org.uk/downloads/common_cause_report.pdf. Viewed on 25.02.12

Davis, B., \& Sumara, D. (2010). “If things were simple ...”: Complexity in education. Journal of Evaluation of Clinical Practice, 16, 856-860.

Degenhardt, L. \& Duignan, P. (2010). Dancing on a Shifting Carpet: Reinventing traditional schooling for the 21st century. ACER Press, NY

Denzin, N. K., \& Lincoln, Y. S. (1994). Handbook of qualitative research. Sage Publications, Inc.

Devaney, J., \&, Spratt, T. (2009). Child abuse as a complex and wicked problem: Reflecting on policy developments in the United Kingdom in working with children and families with multiple problems. Children and Youth Services Review. 31(6), 635641

Edwards, P. \& Schneider, S. (2001). 'Self-governance and peer-review in science-forpolicy: the case of the IPCC Second Assessment Report', in C. A. Miller \& P. N. Edwards (eds.), 219-46.

Faris, S. (2009). Forecast: The Surprising- and Immediate- Consequences of Climate Change. Holt, New York

Frame, B. (2008). 'Wicked', 'messy', and 'clumsy': Long-term frameworks for sustainability. Environment and Planning C: Government and Policy. 26, 1113-1128. 
Funtowicz, S., \& Ravetz, J. (2003). Post-normal science. International Society for Ecological Economics (ed.), Online Encyclopedia of Ecological Economics. Accessed from $\underline{\text { http://www.ecoeco.org/publica/encyc.htm }}$

Gifford, R. (2011). The Dragons of Inaction: Psychological Barriers That Limit Climate Change Mitigation. American Psychologist. 66(4), 290-302

Gleick, P. H., Adams, R. M., Amasino, R. M., Anders, E., Anderson, D. J., \& Anderson, W. W. (2010). Climate Change and the Integrity of Science. Science. 328, $689-690$

Glesne, C., \& Peshkin, A. (1992). Becoming Qualitiative Researchers: An Introduction, Longman, London

Gruenewald, D.A. (2003). Foundations of Place: A Multidisciplinary Framework for Place-Conscious Education. American Educational Research Journal. 40(3) 619-654.

Grundmann, R. (2007). Climate change and knowledge politics. Environmental Politics. 16(3), $414-432$

Guba, E. G., \& Lincoln, Y. S. (1994). Competing paradigms in qualitative research. In Denzin, N. K., \& Lincoln, Y. S. Handbook of qualitative research. 163-194.

Hallegatte, S. (2009). Strategies to adapt to an uncertain climate change. Global Environmental Change. 19(2), 240-247

Haraway, D. (1988). Situated Knowledges: The Science Question in Feminism and the rivilige of Partial Perspective. Feminist Studies, vol 14, no. 3., pp575-599

Hartsock, N. (1987). The Feminist Standpoint. In S. Harding (Ed.) Feminism and methodology (pp157-180) Milton Keynes: Open University Press

Haag, D., \& Kaupenjohann, M. (2001). Parameters, prediction, post-normal science and the precautionary principle-a roadmap for modelling for decision-making. Ecological modelling, 144(1), 45-60.

Head, B.W. (2008). Wicked Problems in Public Policy. Public Policy. 3(2), 101-118 
Hipkins, R. (2011) Learning to reinvent the school curriculum; Research Report. New Zealand Council for Educational Research. Accessed from www.nzcer.org.nz/research/all-publications

Horn, R.E., \& Weber, R.P., (2007). New Tools for Resolving Wicked Problems: Mess Mapping and Resolution Mapping Processes. White paper accessed from http://www.strategykinetics.com//New_Tools_For_Resolving_Wicked_Problems.pdf

HSBC Climate Partnership. (2010). Climate confidence monitor 2010 (pp. 1-8). HSBC Holdings plc. Accessed from http://www.hsbc.com/1/2/sustainability/ccm-2010

Huber, M., Mahlstein, I., Wild, M., Fasullo, J., \& Knutti. R. (2011). Constraints on Climate Sensitivity from Radiation Patterns in Climate Models. Journal of Climate. 24(4), 1034

IPCC (2007). Contribution of Working Group I to the Fourth Assessment Report of the Intergovernmental Panel on Climate Change. Intergovernmental Panel on Climate Change Solomon, S., D. Qin, M. Manning, Z. Chen, M. Marquis, K.B. Averyt, M. Tignor and H.L. Miller (eds.) Cambridge University Press, Cambridge, United Kingdom and New York, NY, USA.

IPCC. (2007). Climate Change 2007: Synthesis Report Summary for Policymakers. IPCC

Jentofta, S., \&, Chuenpagdeeb, R. (2009). Fisheries and coastal governance as a wickedproblem. Marine Policy. 33(4), 553-560

Kelly, P. (2007). What changes can secondary schools make to meet the demands for personalised learning? Sabbatical report- Sabbatical Term 22007

Lamberts, S.W.J. (2006). Adaptive Networks: The Governance for Sustainable Development. Eburon Academic Publishers. The Netherlands

Lazarus, R.J. (2008). Super Wicked Problems and Climate Change: Restraining the Present to Liberate the Future. 94 Cornell L. Rev. 1153 
Lenton, T., Held, H., Kriegler, E., Hall, J., Lucht, W., Rahmstorf, S., Schellnhubert, H. (2008). Tipping elements in the Earth’s climate system. PNAS. 105(6), 1786-1793

Le Quéré, C., Raupach, M. R., Canadell, J. G., \& Marland, G. (2009). Trends in the sources and sinks of carbon dioxide. Nature Geoscience, 2(12), 831-836.

Levin, K., Cashore, B., Bernstein, S., \& Auld, G. (2012). Overcoming the tragedy of super wicked problems: constraining our future selves to ameliorate global climate change. Policy Sciences. 45(2), 123-152

Levin, K., Cashore, B., Bernstein, S., \& Auld, G. (2010). Playing it Forward:

Path Dependency, Progressive Incrementalism, and the "Super Wicked" Problem of Global Climate Change. Accessed from: http://environment.research.yale.edu/documents/downloads/09/2010_super_wicked_levin_cashore_bernstein_auld.pdf Viewed in 06.11.12

Lieserowitz, A. (2006). Climate change risk perception and policy preferences: the role of affect, imagery and values. Climatic Change. 77, 45-72

Locke, J. T. (2009). Climate change- induced migration in the Pacific Region: sudden crisis and long- term developments1. The Geographical Journal, 175(3), 171-180.

Mana Party. (2012). Environment and Energy Policy. http://mana.net.nz/policy/ Viewed on 23.08.12

McKinsey \& Company.(2009). Pathways to a low-carbon economy: version 2 of the global greenhouse gas abatement cost curve. New York: McKinsey \& Company, https://solutions.mckinsey.com/ClimateDesk/default.aspx.

Ministry for the Environment. (2011). Emissions Trading Scheme Review 2011: Issues statement and call for written submissions. Wellington: Ministry for the Environment http://www.climatechange.govt.nz/emissions-trading-scheme/ets-review2011/statement-for-consultation.html. Viewed on 08.09.12

Ministry for the Environment. (2012). Climate change science- New Zealand Climate change information. http://www.climatechange.govt.nz/science/ Viewed on 25.02.12 
Myers, N. (1993). Environmental refugees in a globally warmed world. Bioscience, 752-761.

Nelson, D. R., Adger, W. N., \& Brown, K. (2007). Adaptation to Environmental Change: Contributions of a Resilience Framework. Annual Review of Environment and Resources. 32(1), 395-419

Oreskes, N. (2004). The scientific consensus on climate change. Science. 306, 1686 http://www.sciencemag.org/cgi/content/full/306/5702/1686

Pichert, D., \& Katsikopoulos, K.V., (2008). Green defaults: Information presentation and pro-environmental behaviour. Journal of Environmental Psychology, 28(1), 63-73

Pierrehumbert, R. (2006). Climate Change: A Catastrophe in Slow Motion. Chicago Journal of International Law. 6(2), 1-24

Prinn, R., Paltsev, S., Sokolov, A., Sarofim, M., Reilly, J., \& Jacoby, H. (2009). Scenarios with MIT integrated global systems model: significant global warming regardless of different approaches. Climatic Change 104, 515-537

Rayner, S. (2006). Wicked problems: Clumsy solutions—diagnoses and prescriptions for environmental ills. Jack Beale Memorial Lecture on Global Environment, University of New South Wales, Sydney.

Rittel, H.W.J., \& Webber, M.M. (1973). 'Dilemmas in a General Theory of Planning.' Policy Sciences. 4 (2), 155-169.

Roberts, J., \& Bolstad, R. (2010). Organising for Emergence: An exploratory study of the ReGeneration network. Final report prepared for Enviroschools. New Zealand Council for Educational Research. Accessed from http://www.nzcer.org.nz/pdfs/organising-for-emergence-final-report.pdf

Rogelj, J., Meinshausen, M., \& colleagues. (2010). Copenhagen Accord pledges are paltry. Nature. $464,1126-1128$ 
Senge, P. (1992). The fifth discipline: The art and practice of the learning organization. Milsons Point, NSW: Random House, Australia.

ShapeNZ. (2010). ShapeNZ environmental issues survey 2010: A national survey of 1066 New Zealanders on environmental issues. Auckland, New Zealand: New Zealand Business Council of Sustainable Development.

Shindler, B., \& Cramer, L.A. (1999). Shifting Public Values for Forest Management: Making Sense of Wicked Problems. Western Journal of Applied Forestry. 14(1), 28-34

Smil, V. (2008). Long-range energy forecasts are no more than fairy tales. Nature. 453(7192), 154-154. http://dx.doi.org/10.1038/453154a

Steiner, K. (2007). Doing Interviews (Ed.) Flick, U. Sage: Los Angeles

Sundberg. J. (2004). Masculinist epistemologies and the politics of fieldwork in Latin Americanist geography. Professional Geographer. 55(2), 180-190.

Taylor, P., Ellingson, R., \& Cai, M. (2011). Seasonal Variations of Climate Feedbacks in the NCAR CCSM3. Journal of Climate. 24(13), 3433

The World Bank. (2009). Public attitudes toward climate change: Findings from a multi-country poll (World Development Report). The World Bank.

Tolich, M., \& Davidson, C. (1999). Starting fieldwork: An introduction to qualitative research in New Zealand. Oxford University Press.

UNFCCC. (2012). Article 1- Definitions. United Nations Framework Convention on Climate Change. http://unfccc.int/resource/docs/convkp/conveng.pdf. Viewed on 08.03.12

van Bueren, E.M., Klijn, E-H. \& Koppenjan, J.F.M. (2003). Dealing with Wicked Problems in Networks: Analyzing an Environmental Debate from a Network Perspective. Journal of Public Administration Research and Theory. 13(2), 193-212

VUW. (2007). Human Ethics Policy. www.victoria.ac.nz Viewed on 01.08 .12 
Wang, S. (2002). Wicked problems and metaforestry: Is the era of management over? The Forestry Chronicle, 78(4), 505-510

Weber, E. P., \& Khademian, A. M. (2008). Wicked problems, knowledge challenges, and collaborative capacity builders in network settings. Public Administration Review, 68(2), 334-349.

Weitzman, M. (2011). Fat-Tailed Uncertainty in the Economics of Catastrophic Climate Change. Harvard University.

Yeh, R.T. (1991). System development as a wicked problem. International Journal of Software Engineering and Knowledge. 1(2), 117-130

Zimmer, C. (2010). A Looming Oxygen Crisis and Its Impact on World's Oceans: Yale University.

http://e360.yale.edu/feature/a_looming_oxygen_crisis_and_its_impact_on_worlds_oce ans/2301/Viewed on 14.03.12 


\section{Appendix A}

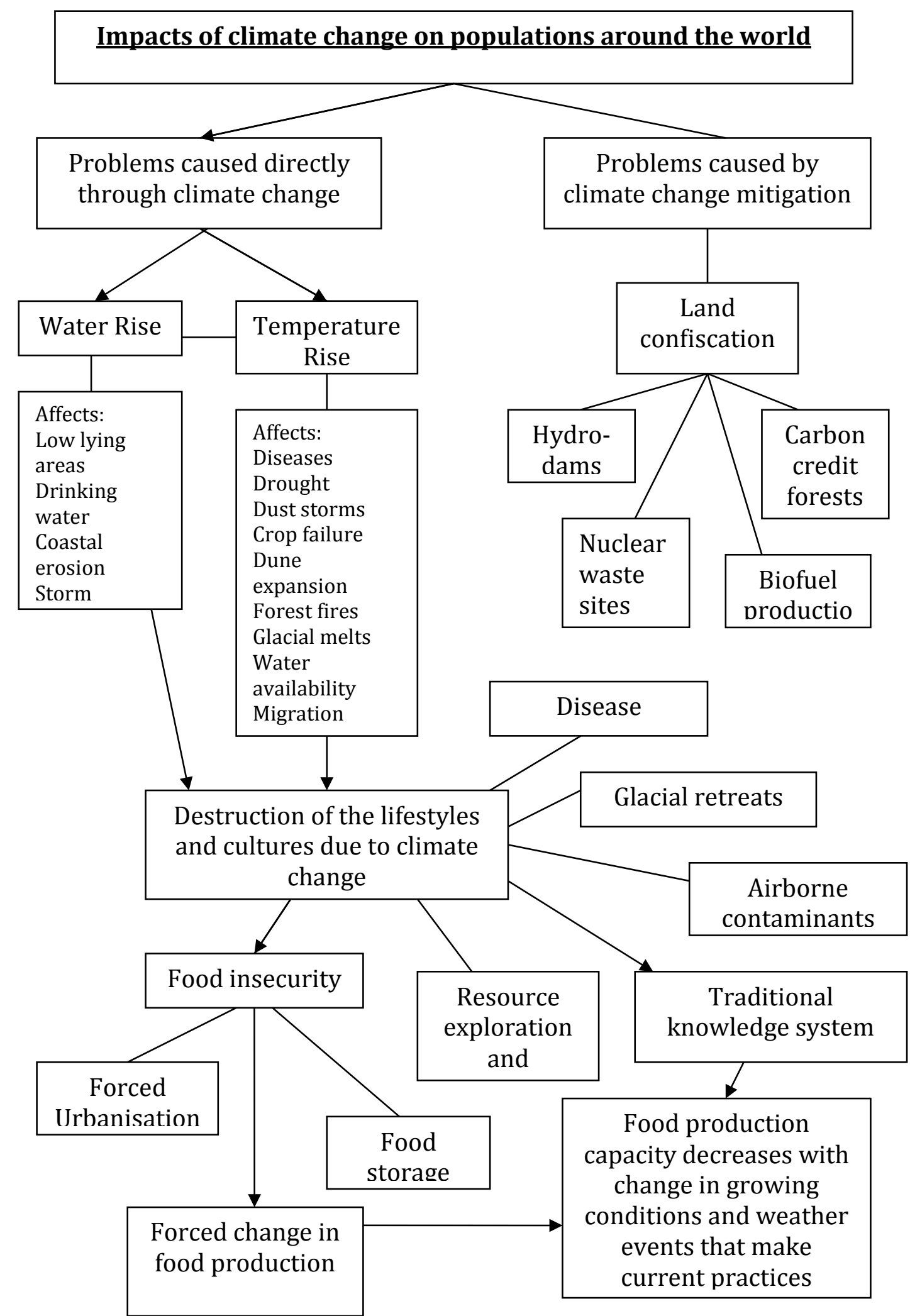

(McLaren, 2008) 


\title{
Appendix B
}

\author{
Phone 0-4-4635676 \\ Fax 0-4-4635209 \\ Email_Allison.kirkman@vuw.ac.nz
}

on to this approval.

Best wishes with the research.

Allison Kirkman

Human Ethics Committee 
Appendix C

Phone $\quad 0-4-4635676$

Fax 0-4-4635209

Email_Allison.kirkman@vuw.ac.nz

ittee 


\section{Appendix D}

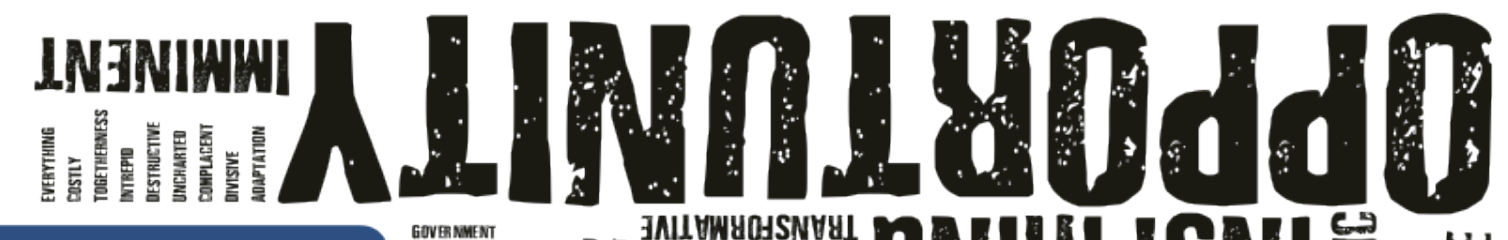

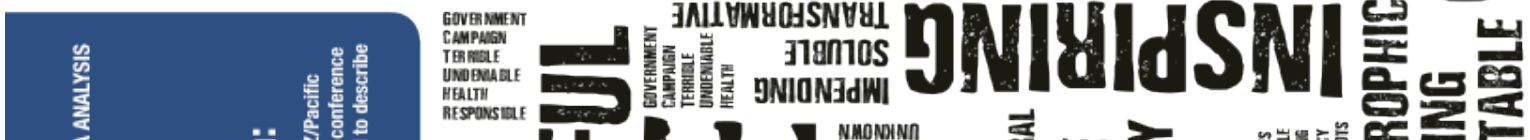

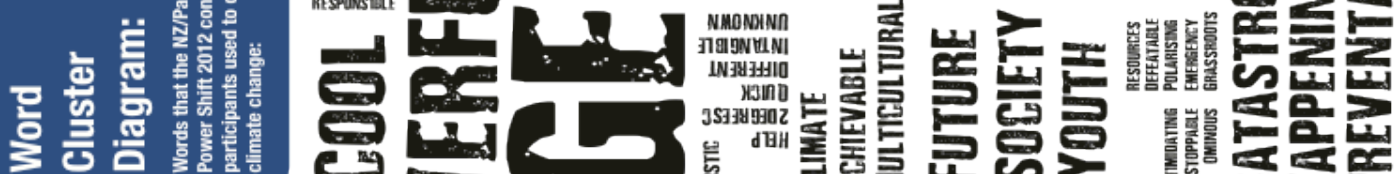

产

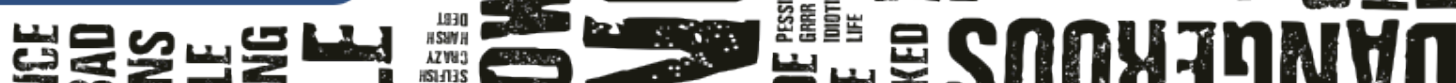

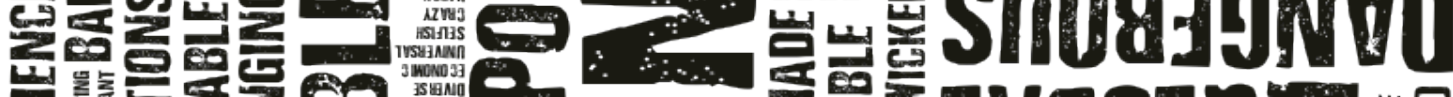
든

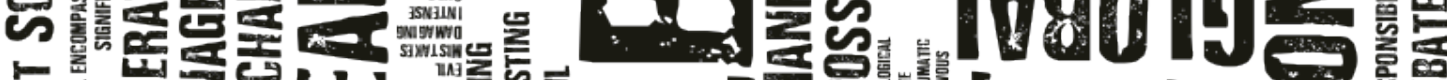

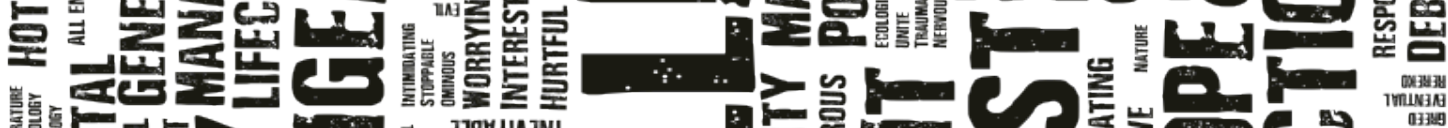

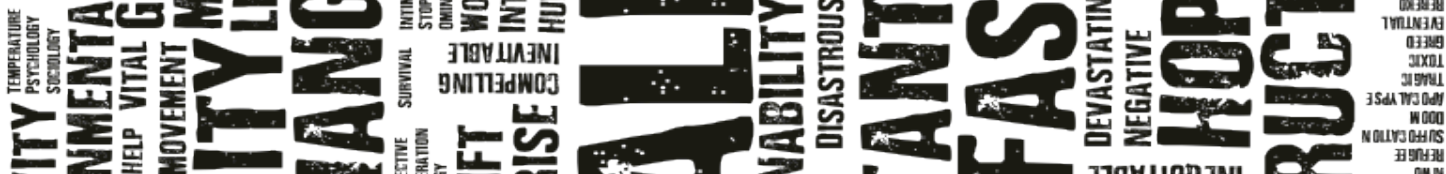

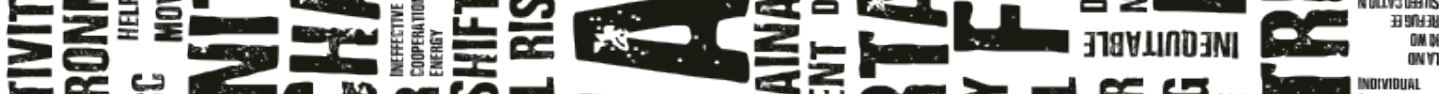
통

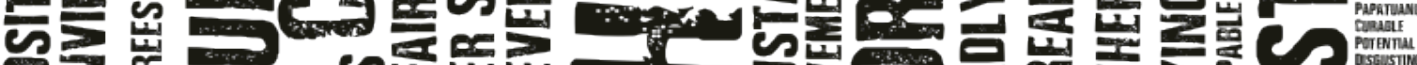

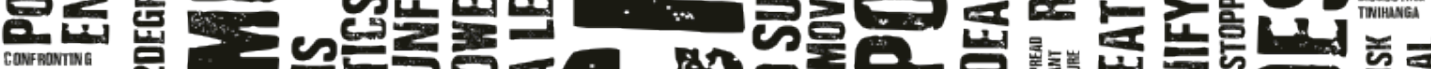

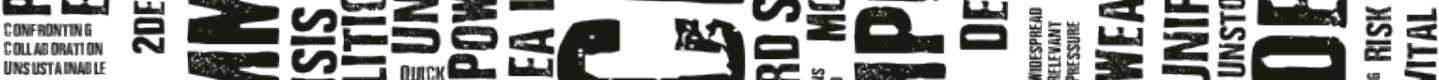

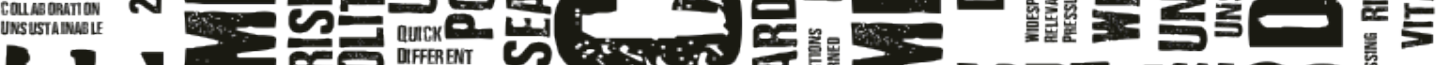

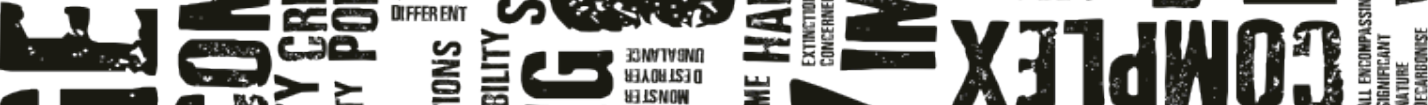

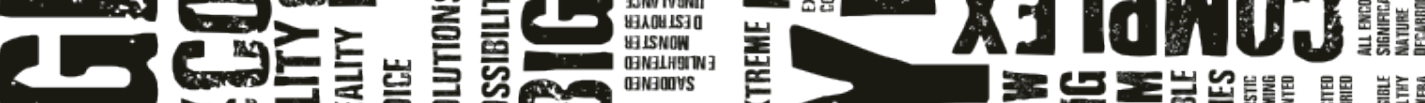

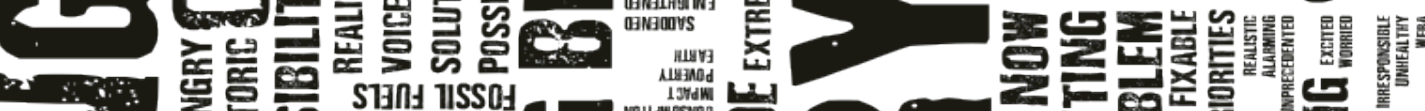

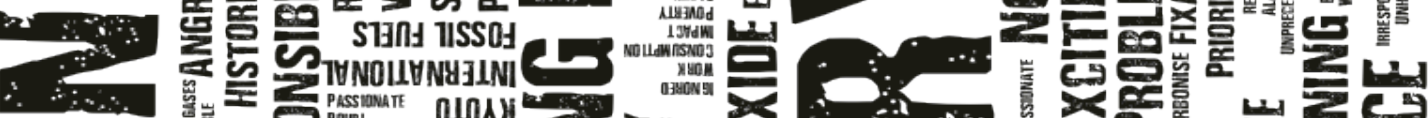

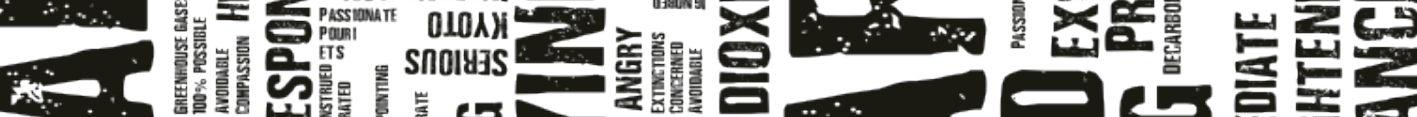

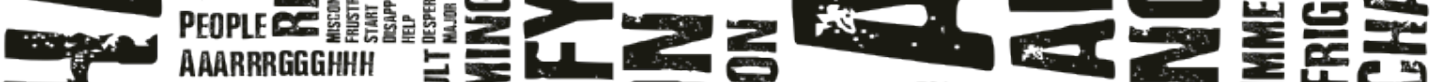
MONEY

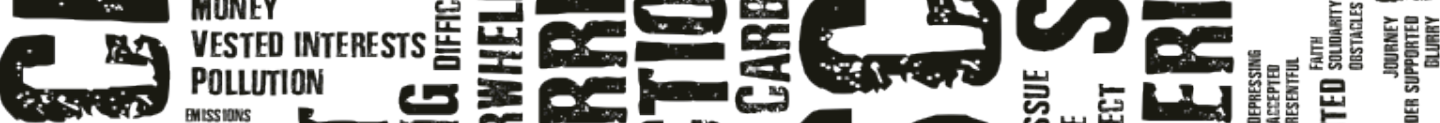

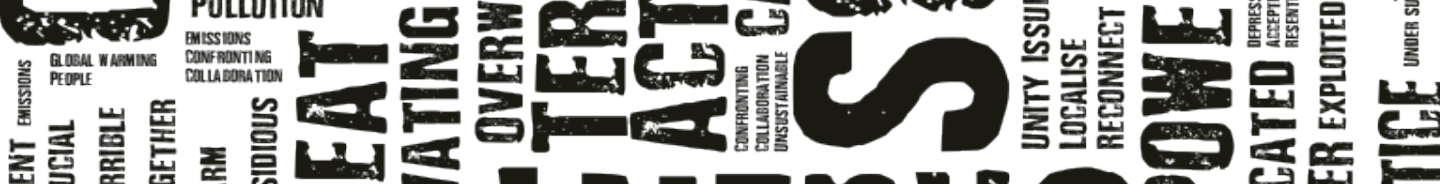

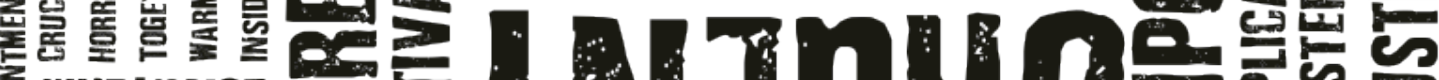

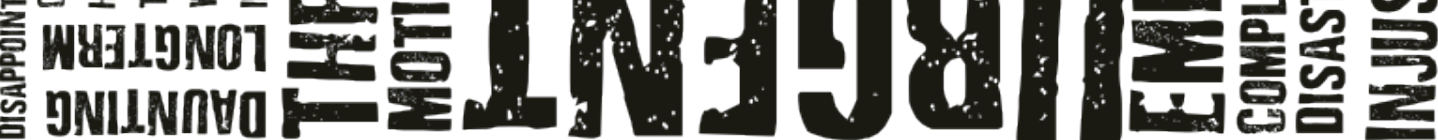




\section{Appendix E}

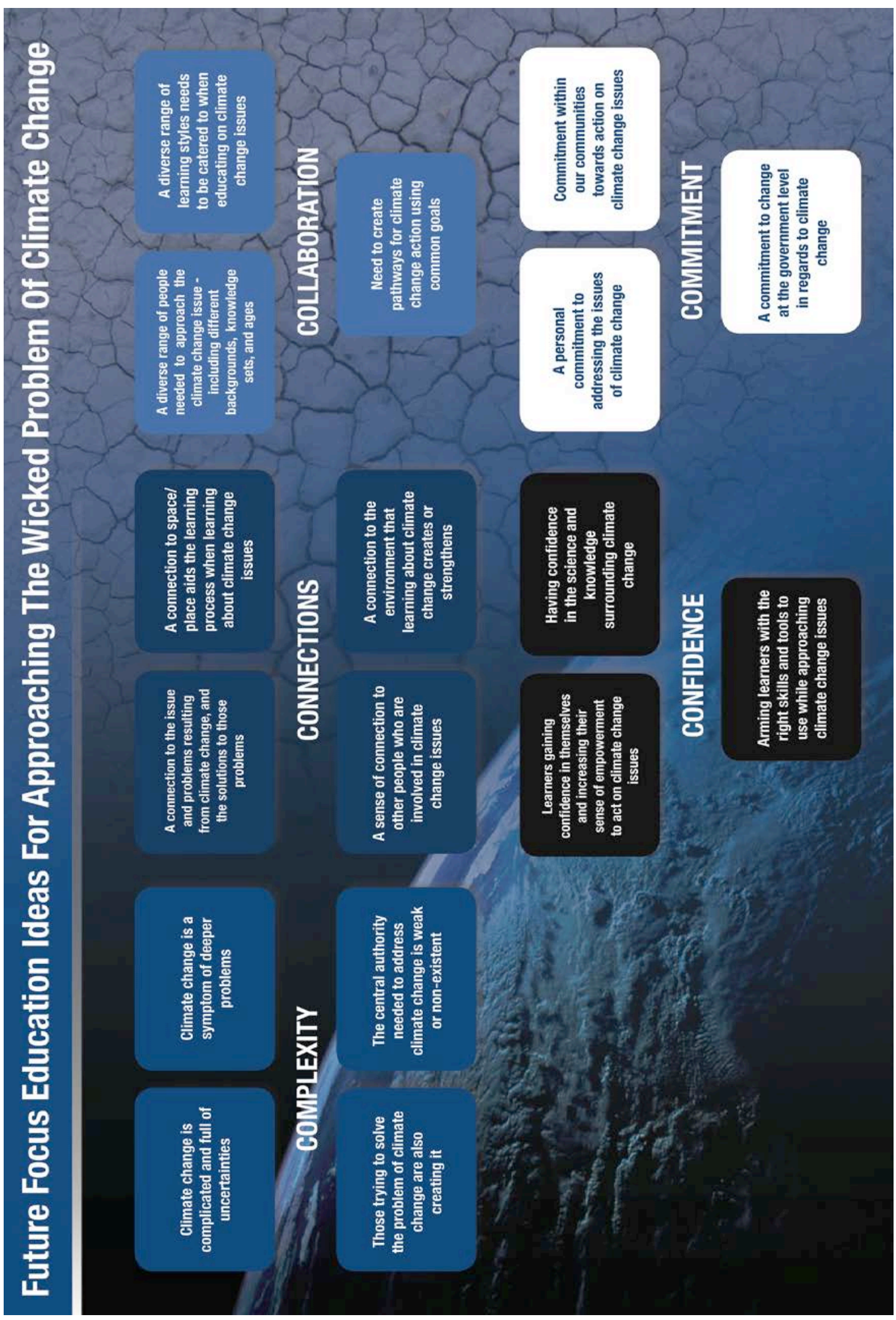

